\title{
Fall 2018
}




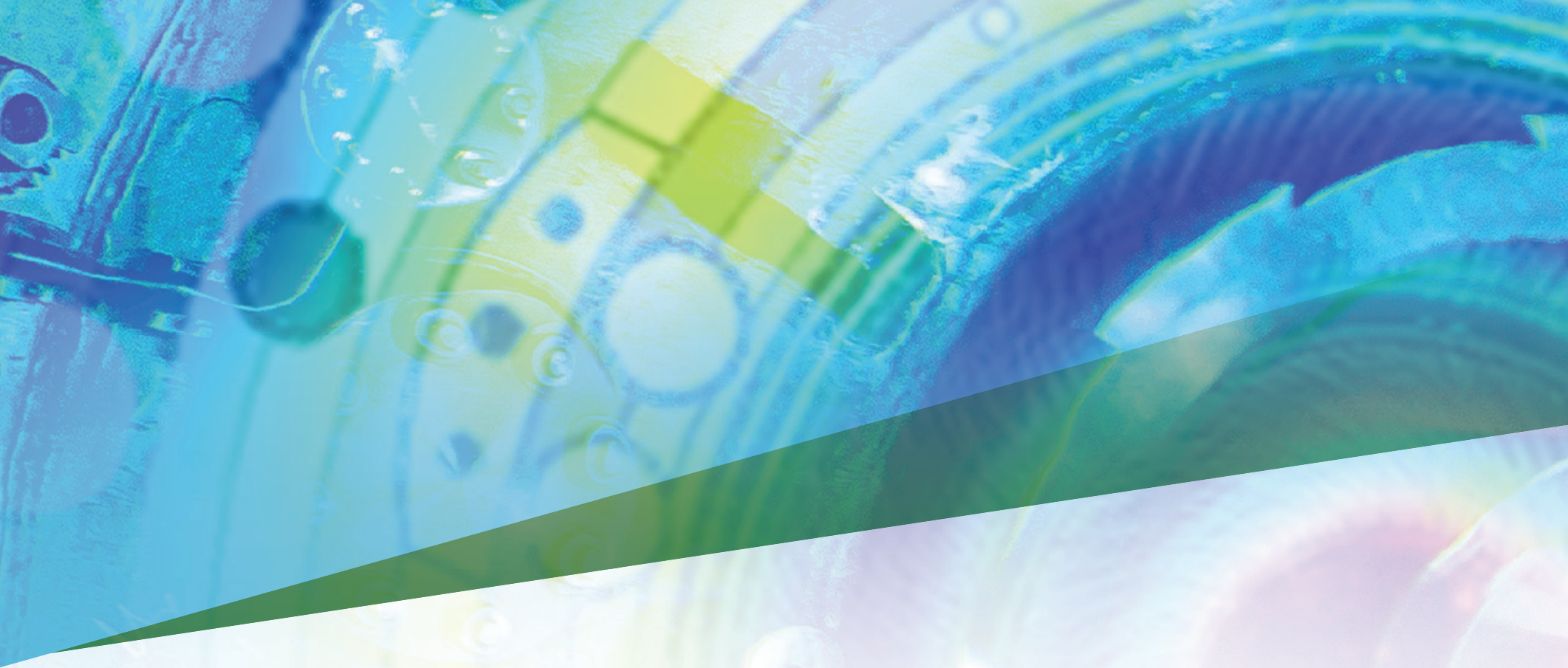

\section{WELCOME}

\section{ORNL NUCLEAR RESOURCES - ANALYSIS AND MODELING PORTFOLIO (ONRAMP)}

Oak Ridge National Laboratory (ORNL) is a global leader in the development and application of practical modeling and simulation tools for quality design and licensing of nuclear systems and is driving the next generation of analysis approaches. We have extensive expertise in fission energy systems, including the design, safety analysis, and operation of nuclear facilities, thermal hydraulic loops, laboratory critical experiments, irradiation testing in research reactors, and post irradiation examination. Our expertise also extends to isotope production, fusion energy systems, accelerators, and nuclear security applications. In support of these and other initiatives, we have created a wide range of custom developed tools that provide uniquely integrated capabilities and unmatched performance. ORNL is a global leader in computing, operating commodity clusters for production analysis and providing leading high-performance computing (HPC) systems in use today and designed for the future.

\section{Did you know that the resources in the ORNL portfolio are also available to the larger community?}

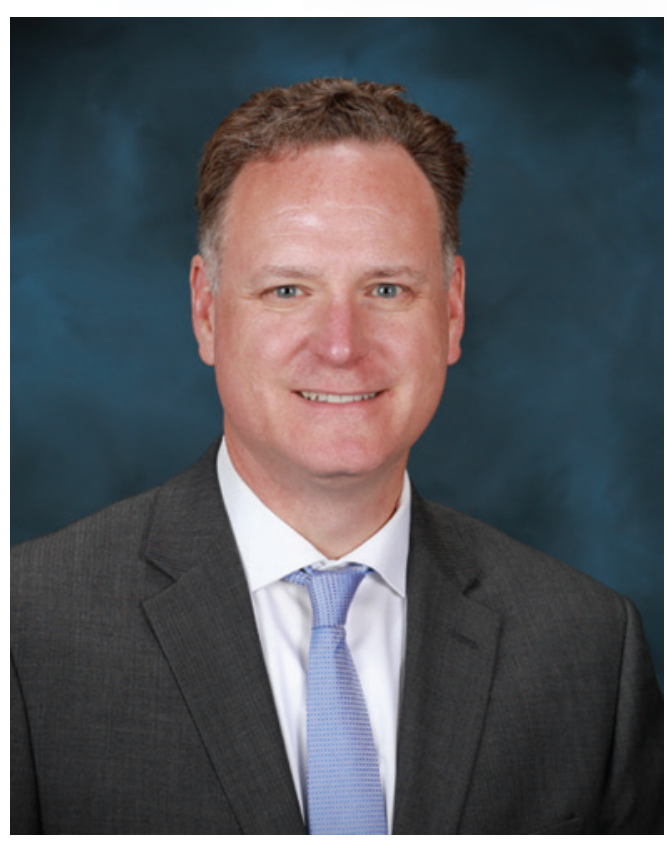

Bradley T. Rearden

Leader, Modeling and Simulation Integration

Many teams from US and international organizations, government, industry, research organizations, and academic institutions have established near-term technical exchanges and long-term partnerships with ORNL, realizing previously unforeseen innovations and efficiencies. Through ONRAMP, we invite you to learn more about the rich resources available at ORNL that can enhance your current approaches. Learn what is possible using customized, advanced techniques. 


\section{OPPORTUNITIES FOR PARTNERS}

Inform: $\quad$ Participate in workshops and symposia to present current approaches and find out what is possible using ORNL's advanced techniques and computing. Tour ORNL facilities to observe state-of-the-art practices in facility operation and experimentation.

Educate: Choose from a wide array of training courses to gain hands-on experience using advanced tools.

Analyze: $\quad$ Partner with ORNL for specialized analysis of your systems, working in our collaboration space, and accessing world class computing resources.

Enhance: $\quad$ Establish partnerships to develop enhanced computational methods and data to better meet specialized needs and to realize the possibilities of HPC.

Validate: Quantify your validation basis by applying advanced approaches to assess available experiments and then enhance understanding through the design and operation of new benchmark quality experiments for licensing.

Deploy: $\quad$ Reap the benefits of quality assurance and archival analysis for licensing and deployment.

Commercialize: In certain cases, commercial licensing opportunities are available. These agreements may be on an exclusive or non-exclusive basis if they are limited to a specific field of use. Said licenses may be for technologies that are bound by export control obligations.

The nine primary areas of the ONRAMP portfolio are highlighted below. I look forward to discussing how we can help your organization find innovative solutions to complex problems.

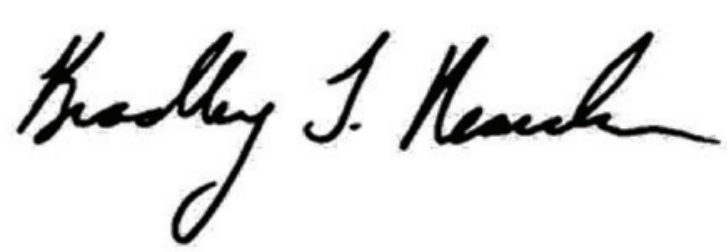

For more information: onramp@ornl.gov

Bradley T. Rearden, Ph.D. 


\section{TABLE OF CONTENTS}

Welcome

Opportunities for partners

Table of contents

Figures

vi

Tables

1.0 Production tools

1.1 SCALE code system

1.2 CASL VERA

$1.3 \mathrm{CTF}$

1.4 ADVANTG

1.5 AMPX

1.6 SAMMY

2.0 Custom-developed tools and data

2.1 UNF-ST\&DARDS

2.2 NEAMS Workbench

2.3 TRANSFORM

2.4 SCALE and VERA enhancements for advanced nuclear energy systems

2.5 Fusion plasma physics

2.6 Nuclear security

2.7 EXASCALE Computing Project

Q 3.0 Analysis expertise

3.1 Collaboration Space

3.2 Nuclear data

3.3 Radiation shielding and criticality safety

3.4 Reactor neutronics

3.5 Thermal hydraulics

3.6 Nuclear materials

3.7 Thermomechanics

3.8 Reactor core analysis 
3.9 Accident analysis

3.10 Fusion plasma physics and fusion neutronics

3.11 Nuclear safeguards and security

3.12 Fuel cycle analysis

3.13 Nuclear transportation and storage analysis

3.14 Probabilist risk assessment

3.15 High-performance computing

4.1 Workshops

4.2 Training

5.1 Commodity clusters for production calculations

5.2 Secure cloud computing

\subsection{CADES}

7.0 Experiment design and operation

7.1 Irradiation experiments

7.2 Thermal hydraulics experiments

7.3 Nuclear data measurements

7.4 Nuclear criticality experiments

7.5 Fusion experimental capabilities

9.1 Opportunities for partners 


\section{FIGURES}

Figure 1. SCALE 6.2 capabilities with features and interdependencies of the user interface (top left), modular computational sequences and modules (bottom left), and data libraries (right).

Figure 2. SCALE 6.2 Fulcrum integrated user interface displaying input generation, nuclear data plots, and geometric and results visualization.

Figure 3. CASL's Virtual Environment for Reactor Applications (VERA).

Figure 4. Capabilities jointly developed with SCALE and CASL.

Figure 5. CTF models fluids and solids at pin-level resolution.

Figure 6. ADVANTG high-fidelity simulations of pressure vessel fluence performed for the NRC.

Figure 7. Thermal neutron scattering data (left) and AMPX user interface (right).

Figure 8. SAMMY neutron transmission of ${ }^{232} \mathrm{Th}$ for varying target thickness by Derrien.

Figure 9. UNF-ST\&DARDS integrated capabilities, ranging from engineering data to licensing results.

Figure 10. NEAMS Workbench concept for integrated multiphysics workflows with multiple levels of fidelity. 10

Figure 11. Transform analysis of a sequential pump trips in a molten salt reactor (MSR).

Figure 12. Detailed SCALE/Shift model of Experimental Breeder Reactor (EBR)-II reactor.

Figure 13. TRISO kernel placement with Shift random geometry generator demonstrating a test case of loading multiple types of TRISOs in a single pebble.

Figure 14. SCALE 6.3 calculation of delayed neutron precursor

Figure 15. VERA-MSR 3D time-dependent, integrated, multiphysics calculation of a reactivity insertion for the ORNL Molten Salt Reactor Experiment.

Figure 16. Total neutron interaction rate in an SMR core using Shift in the ExaSMR project.

Figure 17. ORNL team collaborating.

Figure 18. Nuclear data life cycle from identification of needs through validation and application analysis.

Figure 19. Thermal-hydraulics model of a fluoride high-temperature demonstration reactor.

Figure 20. COMSOL fuel performance model to support production of ${ }^{238} \mathrm{Pu}$ in HFIR.

Figure 21. COMSOL thermo-mechanics model to support irradiation of ruthenium selenide in HFIR.

Figure 22. SCALE analysis of Fukushima Daiichi Unit 4 with plant model (left), assembly-specific radioactive source term quantification for spent fuel pool (center), dose rate from spent fuel (left).

Figure 23. AORSA model of ITER.

Figure 24. Fuel cycle analysis with ORION and SCALE.

Figure 25. SCALE and UNF-ST\&DARDS model of Waste Control Specialists consolidated interim storage facility with 467 used fuel cannisters on a concrete pad with dimensions of $250 \mathrm{~m}$ $\times 100 \mathrm{~m}$ (top), detailed geometry for horizontal and vertical packages where assembly-byassembly radioactive source terms are provided (left), and dose rate to the site boundary with overall dimensions of $2.7 \mathrm{~km} \times 2.5 \mathrm{~km}$ and a height of nearly $1 \mathrm{~km}$.

Figure 26. Dynamic PRA analysis of a component in an NHES (red circle), the calculated reliability data (red box), and its representation in the SPN subsystem model. 
Figure 27. MSR Workshop in the ORNL Conference Center.

Figure 28. SCALE training course in the ORNL VOCC facility.

Figure 29. ORNL commodity computing cluster Apollo.

Figure 30. CADES computing condo.

Figure 31. Validation of SCALE reactor depletion isotopics results using the multi-cycle depletion and PIE data from the Calvert Cliffs Unit 1 PWR data available from SFCOMPO.

Figure 32. VERA validation with in-core flux map data from Watt's Bar Unit 1.

Figure 33. ORNL provides comprehensive support for evaluation and optimization of material performance in irradiation environments.

Figure 34. Computational model of an irradiation experiment capsule.

Figure 35. Temperature profile of ORNL's

Figure 36. Flow visualization and application of PIV and PLIF to measure velocity distributions inside an SNS target

Figure 37. VISION vibrational spectrometer instrument at the ORNL's SNS. 37

Figure 38. Nuclear criticality experiment at SPR/CS. 38

Figure 39. ORNL staff examining a full-size replica of the HFIR core and target rods. 40

Figure 40. ORNL's Spallation Neutron Source complex. 41

$\begin{array}{lll}\text { Figure 41. ORNL's HFIR complex } & 41\end{array}$

$\begin{array}{ll}\text { Figure 42. SNS mercury target. } & 41\end{array}$

Figure 43. Reactor core replacement at ORNL's HFIR.

\section{TABLES}

Table 1. Software tools expertly applied for nuclear analysis

Table 2. $\quad$ ORNL irradiation experiment facilities and capabilities

Table 3. ORNL thermal hydraulics experiment facilities and capabilities

Table 4. Nuclear data facilities and capabilities utilized by ORNL teams

Table 5. Nuclear criticality safety experiment facilities supported by ORNL teams 


\subsection{PRODUCTION TOOLS}

Oak Ridge National Laboratory (ORNL) develops, applies and deploys modeling and simulation tools to solve challenging nuclear engineering problems across a wide range of applications, with tool development focused on deployment and use. We invite you to apply our production tools to your design, analysis, and licensing processes and to partner with us for expert assistance and custom-developed enhancements to meet your needs. As the developers of these tools, we can provide support and insights that are otherwise unobtainable, and through these partnerships, we can provide the same level of excellence to your team that we provide to the US Nuclear Regulatory Commission (NRC), the US Department of Energy (DOE), the National Nuclear Security Administration (NNSA), and other major sponsors.

Our teams implement a software lifecycle that is the state of the practice. Our custom tools and data are initially developed to solve specific challenging problems to address a compelling need. Over time, these tools and techniques are collected from the many application areas and leveraged to be included in tool sets that can be used in myriad applications, including many not yet conceived. As the tool suites mature, they are refined into production tools that are widely deployed with appropriate quality assurance, configuration management, training, and user support to ensure success. Using this model, ORNL has continuously shaped the state of the practice for many nuclear applications areas.

This section introduces the production tools available under exportcontrolled license from the Radiation Safety Information Computational Center (RSICC). RSICC maintains international agreements with the Data Bank of the Organisation for Economic Cooperation and Development (OECD) Nuclear Energy Agency (NEA) in France and the Research Organization for Information Science and Technology (RIST) of Japan. These agreements allow NEA and RIST to distribute the software under the same single-user license and export control agreements.

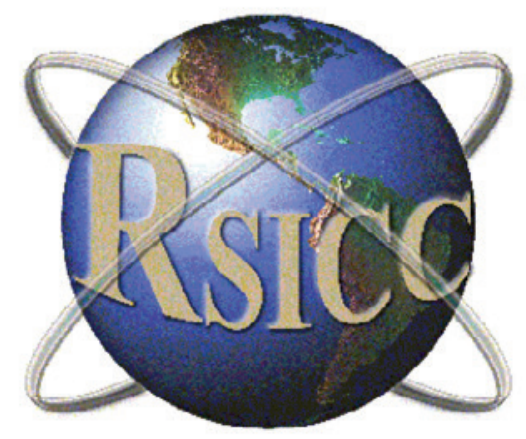

\section{RSICC:}

https://rsicc.ornl.gov

NEA Data Bank:

https://www.oecd-nea.org/dbcps/

RIST:

http://www.tokai.rist.or.jp/nucis/ 


\subsection{SCALE CODE SYSTEM}

The SCALE code system is a widely used modeling and simulation suite for nuclear safety analysis and design that is developed, maintained, tested, and managed by ORNL's Reactor and Nuclear Systems Division (RNSD) and deployed to over 9,000 users in 59 nations. SCALE provides a comprehensive, verified and validated, user-friendly tool set for criticality safety, reactor physics, radiation shielding, radioactive source term characterization, and sensitivity and uncertainty $(\mathrm{S} / \mathrm{U})$ analysis. Since 1980, regulators, licensees, and research institutions around the world have used SCALE for safety analysis and design. The NRC is the primary

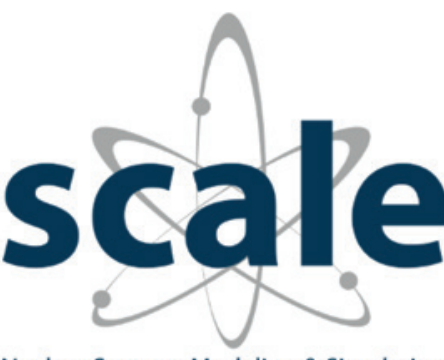

Nuclear Systems Modeling \& Simulation sponsor of SCALE for its application in licensing current and advanced reactors, fuel cycle facilities, and radioactive material transportation and storage. An additional 33 international regulatory bodies are included in the thousands of SCALE users.

SCALE provides a modern, integrated framework with dozens of computational modules, including four deterministic solvers and three Monte Carlo radiation transport solvers from which the user selects based on the desired solution strategy. SCALE includes current nuclear data libraries and problem-dependent processing tools for continuous-energy (CE) and multigroup (MG) neutronics and coupled neutron-gamma calculations, as well as activation, depletion, and decay calculations. SCALE provides unique capabilities for automated variance reduction in shielding calculations, as well as S/U analysis. SCALE's graphical user interfaces (GUIs) assist with accurate system modeling and provide convenient access to desired results. SCALE 6.2 is one of the most comprehensive revisions in the history of SCALE, providing several new capabilities and significant improvements in many existing features.

For more information visit https://scale.ornl.gov

Licensing: SCALE 6.2.3 is available from RSICC, NEA, and RIST as package C00834.

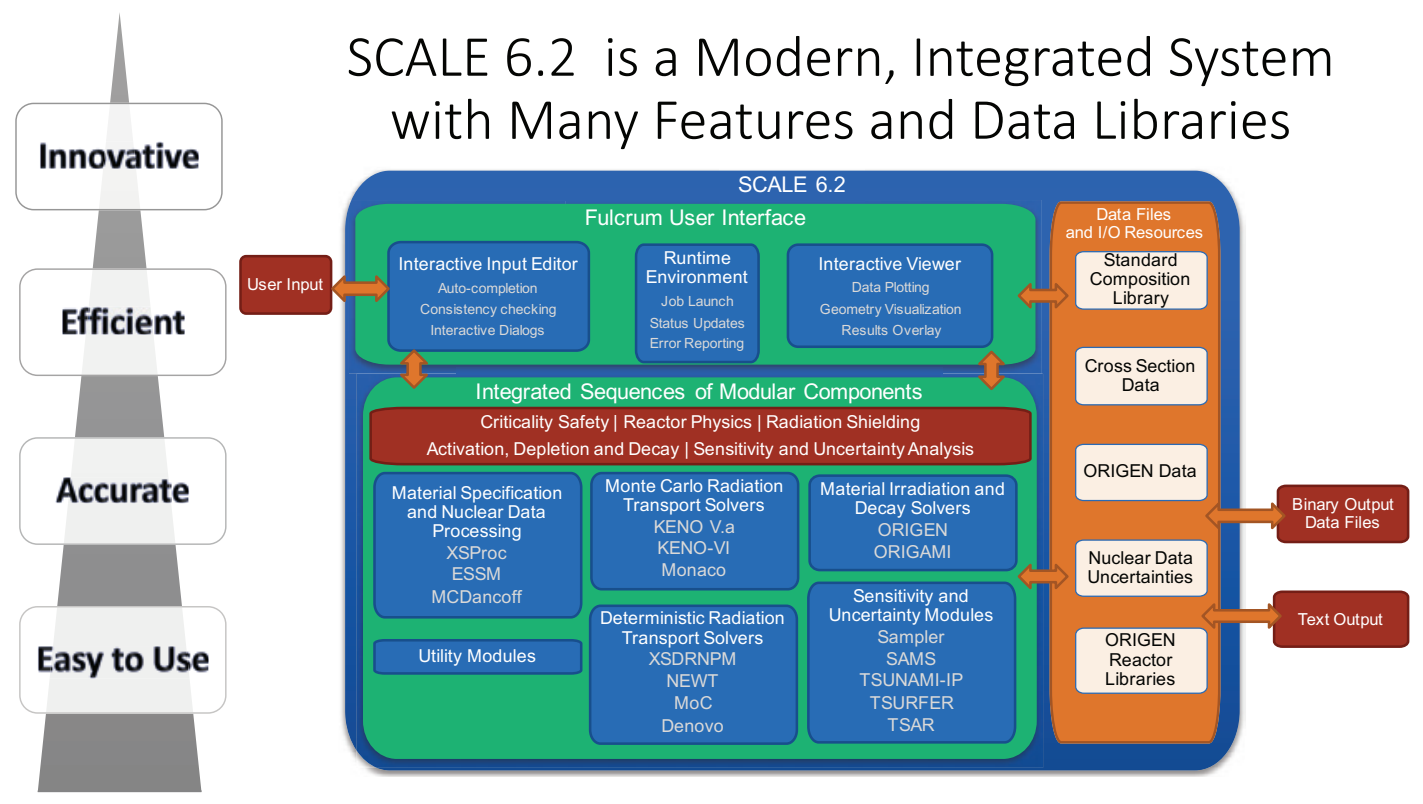

Figure 1. SCALE 6.2 capabilities with features and interdependencies of the user interface (top left), modular computational sequences and modules (bottom left), and data libraries (right). 


\subsection{CASL VERA}

The Consortium for Advanced Simulation of Light Water Reactors (CASL) Challenge Problems range from CRUD to pellet-clad interaction, requiring validated, high-resolution multiphysics predictions of nuclear reactor operation and fuel

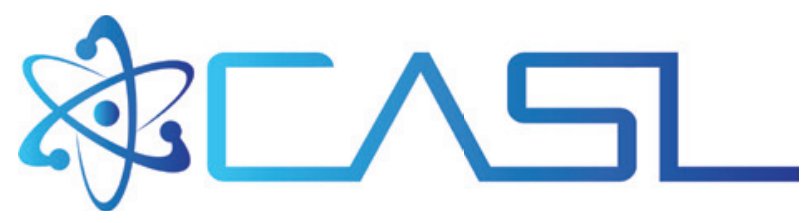
performance throughout the life of a nuclear power plant. The Virtual Environment for Reactor Analysis (VERA) is an ORNL-led collaboration with the University of Michigan, the Massachusetts Institute of Technology (MIT), North Carolina State University (NCSU), Tennessee Valley Authority, Westinghouse, the Electric Power Research Institute, and Idaho, Sandia, and Los Alamos Laboratories, with contributions from many other partners in academia, industry, and the national laboratory system.

The CASL tool sets leverage key components of the SCALE system, most notably the fundamental nuclear data processing and isotopic depletion capabilities, and they have rapidly enhanced the state of the practice for advanced multiphysics simulation of light-water reactors (LWRs). Integrating high-resolution neutronics using (1) the MPACT code, jointly developed with the University of Michigan, with subchannel two-phase flow with CTF and (2) high-fidelity depletion with ORIGEN provides fully coupled estimates of the state of every pin and coolant channel in a pressurized water reactor's core without traditional homogenizing of materials. Coupling with CRUD chemistry (Los Alamos National Laboratory's MAMBA chemistry code) and fuel performance (Idaho National Laboratory's BISON fuel performance codes) enables advanced solutions to complex industry problems.

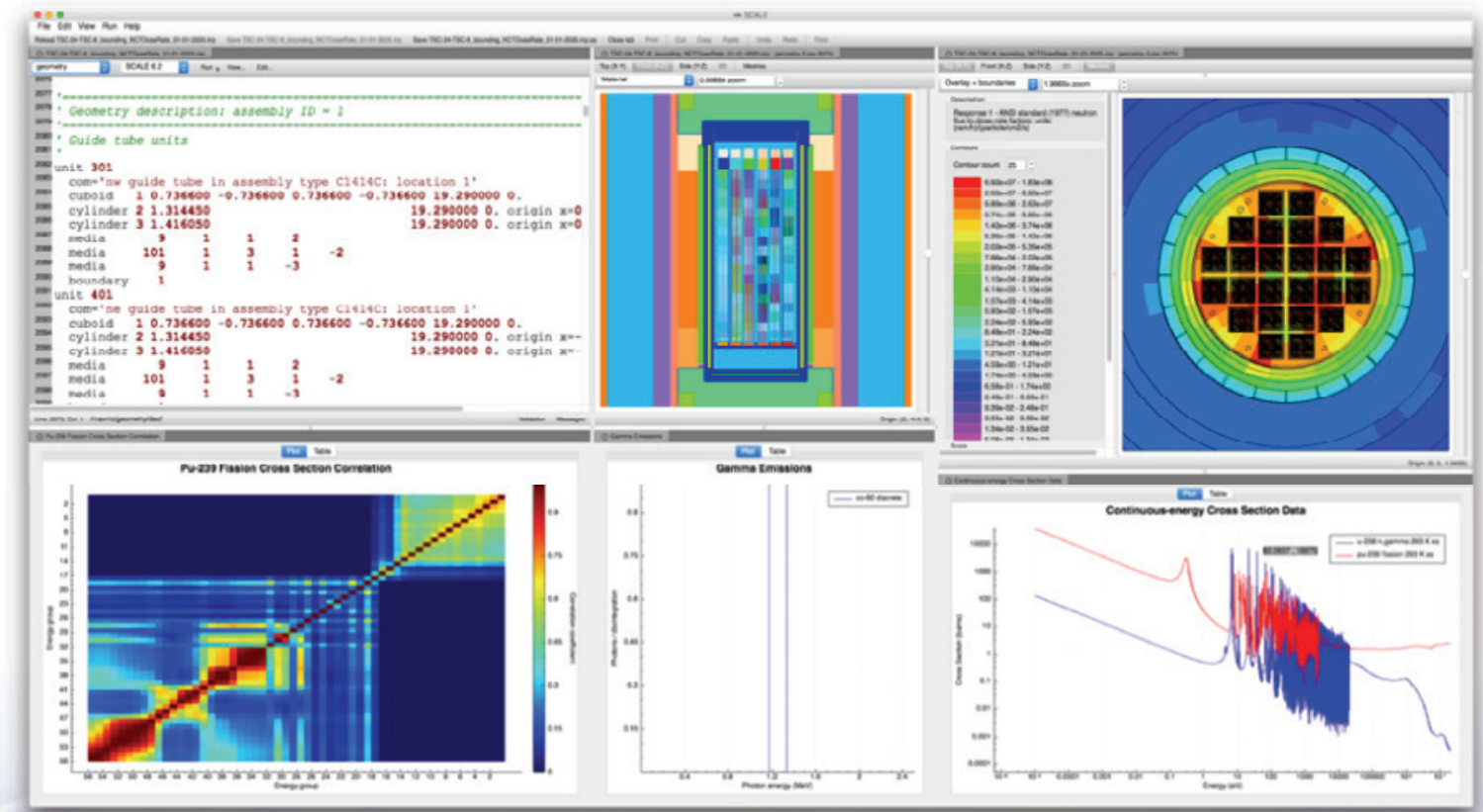

Figure 2. SCALE 6.2 Fulcrum integrated user interface displaying input generation, nuclear data plots, and geometric and results visualization. 
Prediction of CRUD-Induced Power Shift (CIPS) and pellet-clad mechanical interaction (PCMI), along with their effects on operational limits, may enable utilities to safely operate at higher power for longer periods of time with lower enrichment costs, resulting in great returns.

The ORNL-developed Shift Monte Carlo code provides solutions for high-fidelity reactor physics and radiation transport and shielding solutions within VERA. The Shift Monte Carlo code and the Denovo deterministic transport code are part of the Exnihilo massively parallel radiation transport framework. In addition to using Shift for benchmark-quality high-fidelity solutions, the Shift and Denovo capabilities are used with the hybrid methods pioneered by ORNL to provide advanced variance reduction capabilities for ex-core applications. The combination of these technologies is being used to develop state-of-the-art capability for high-fidelity simulation pressure vessel and concrete bioshield fluence of entire reactor operational lifetimes.

\section{For more information visit https://www.casl.gov}

Licensing: VERA is available from RSICC upon request for non commercial licensees, or through the VERA Users' Group for commercial licenses. Contact Andrew Godfrey (godfreyat@ornl.gov) for more information.

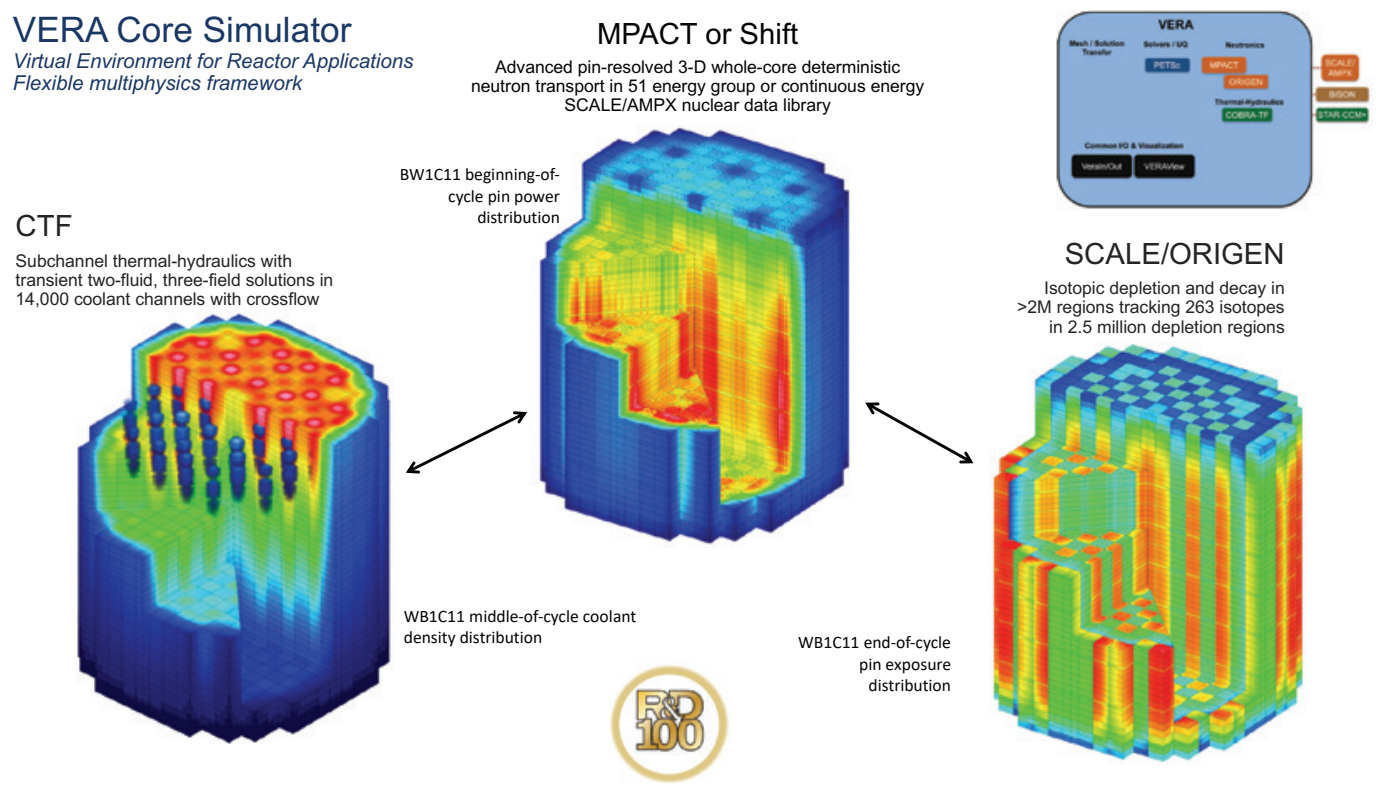

Figure 3. CASL's Virtual Environment for Reactor Applications (VERA).

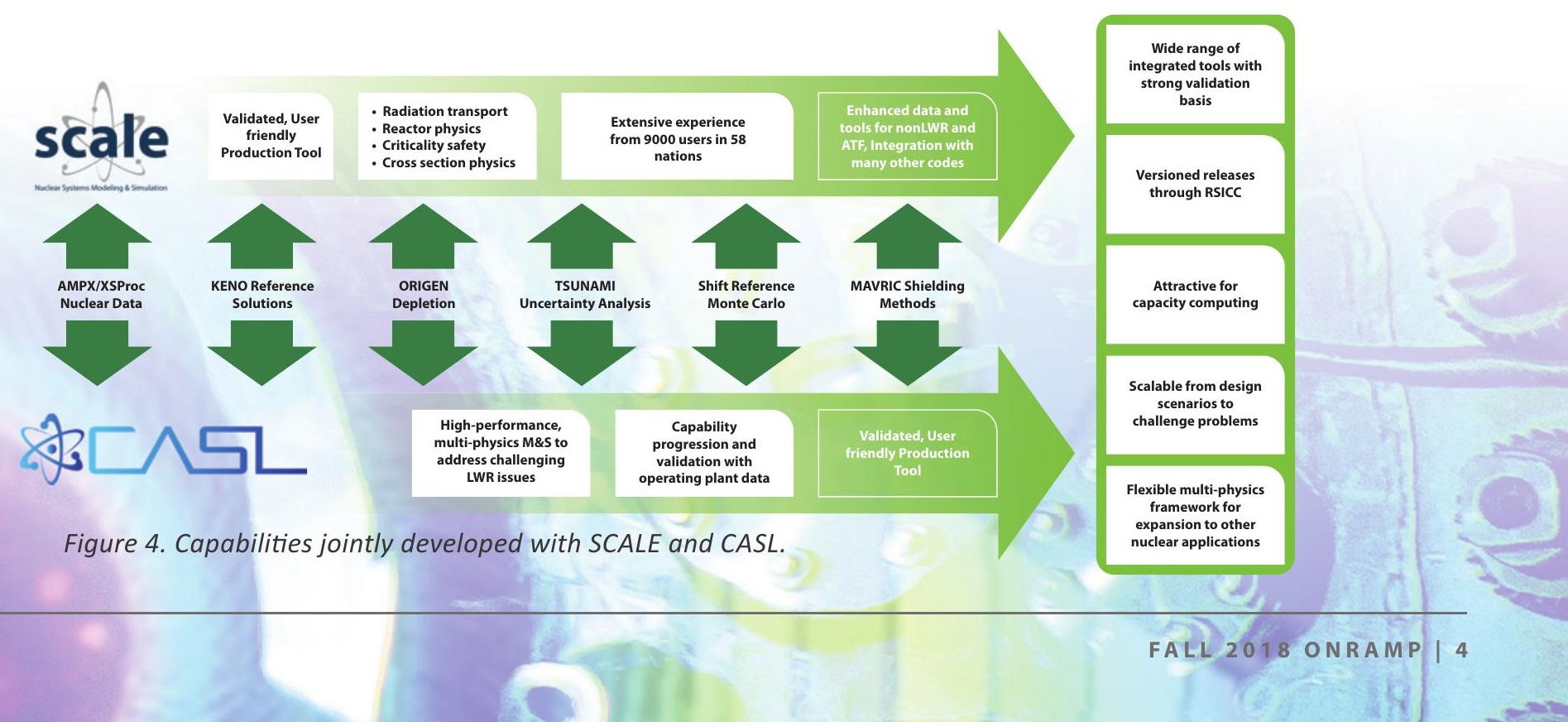




\subsection{CTF}

CTF, jointly developed with NCSU, is a subchannel thermal-hydraulics tool built from the legacy code COBRA-TF. CTF has been adopted for use in the CASL VERA toolset. This project has led to numerous improvements to CTF, including:

- Implementation of new closure models and user features in support of CASL challenge problems, including departure from nucleate boiling (DNB), crud-induced power shift (CIPS), and reactivity insertion accident (RIA)

- $\quad$ Extensive verification and validation testing of the code

- Coupling to the neutron transport code, MPACT, the crud-chemistry code, MAMBA, and the fuel performance code BISON

- $\quad$ Code performance improvements, including a domain decomposition parallelization of the code using the message-passing interface (MPI)

- Integration into the VERA environment, allowing for CTF models to be developed from the VERA common input file and for CTF results to be visualized in the VERAView visualization tool

- Expansion of the code documentation suite to include a software assessment manual, software requirements, a lifecycle process, and a training and change control plan

- Integration of an automated code build and testing system

ORNL jointly maintains CTF with NCSU and participates in the CTF User Group, which is responsible for distributing the code to users outside of CASL, providing user support, and providing a forum where users can share code-related research and improvements.

\section{For more information visit https://www.ornl.gov/division/rnsd/projects/ctf}

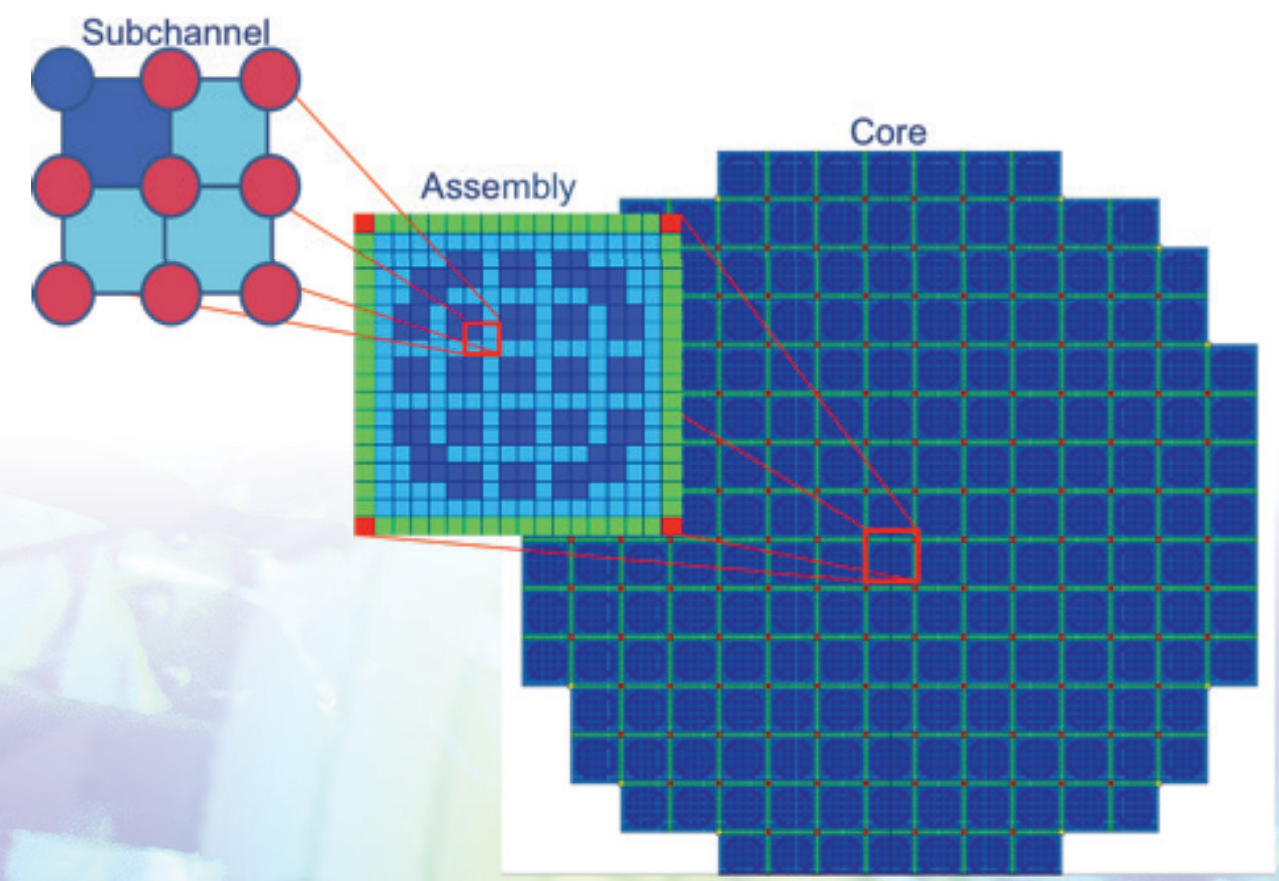

Figure 5. CTF models fluids and solids at pin-level resolution. 


\subsection{ADVANTG}

The Automated Variance Reduction Generator (ADVANTG) software is developed, maintained, and distributed by ORNL to extend the capabilities of the Los Alamos National Laboratory MCNP ${ }^{\circledR}$ code in continuous-energy Monte Carlo simulations of radiation shielding and related applications. ADVANTG automates the process of generating space- and energy-dependent variance reduction parameters that enable MCNP ${ }^{\circledR}$ simulations to obtain uniformly converged tallies over arbitrary regions of interest, including the whole problem domain. Weight-window bounds and biased source distributions are efficiently generated based on three-dimensional (3D) discrete ordinates solutions of the adjoint transport equation using the parallel SCALE Denovo solver. Recent applications of ADVANTG include the estimation of LWR pressure vessel fluence (illustrated below), full-field dose-rate distributions throughout the International Thermonuclear Experimental Reactor (ITER) fusion tokamak facility, high-resolution space- and energy-dependent neutron flux distributions for activation analyses of LWR containment structures for decommissioning planning, and irradiation experiments isotope production and fusion materials research at ORNL's High Flux Isotope Reactor (HFIR).

For more information visit, https://www.ornl.gov/division/rnsd/projects/ automated-variance-reduction-generator-advantg-software

Licensing: ADVANTG 3.0.3 is available from RSICC and NEA as C00831.
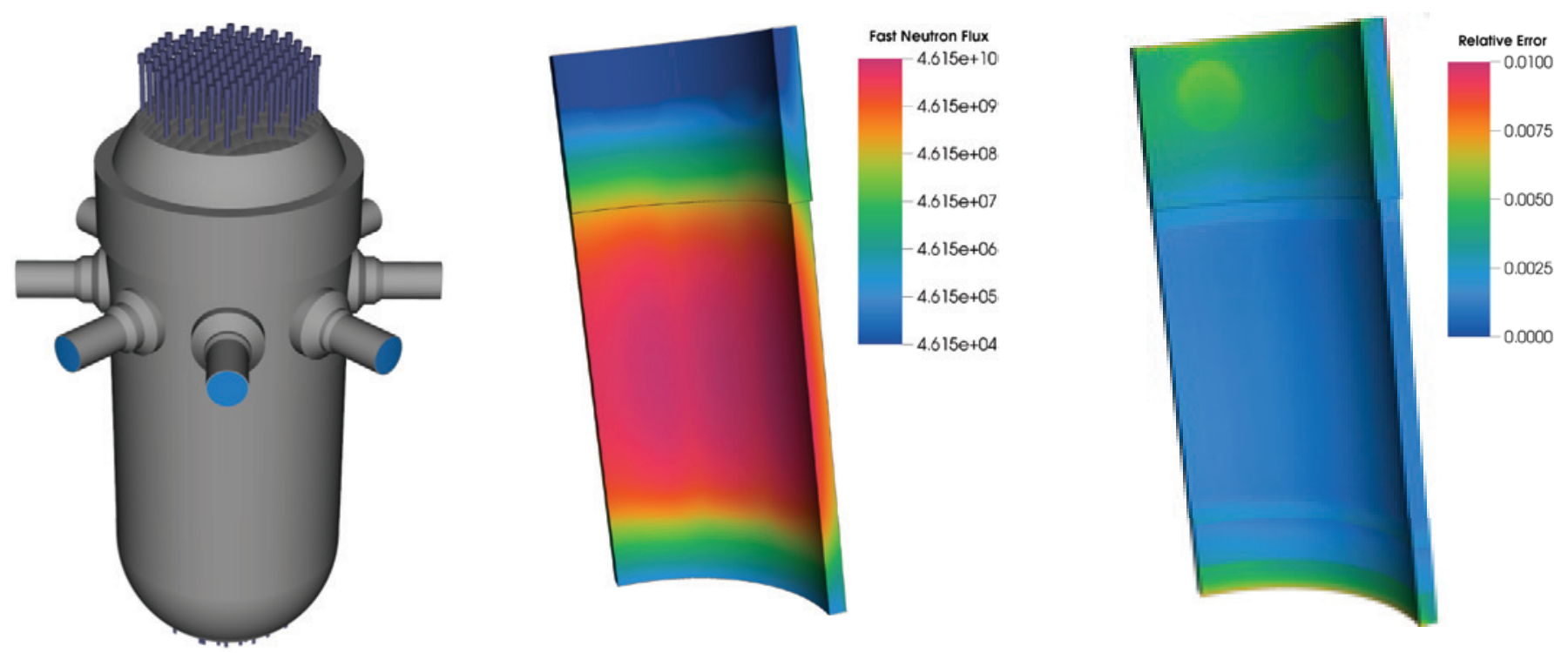

Figure 6. ADVANTG high-fidelity simulations of pressure vessel fluence performed for the NRC. 


\subsection{AMPX}

AMPX is a nuclear data processing code suite that generates continuous-energy and multigroup neutron and gamma libraries used in SCALE and VERA, covariance data used in S/U calculations, and depletion, activation, and decay data for ORIGEN.

Evaluated Nuclear Data File (ENDF) libraries contain the nuclear data for use in transport codes. However, processing is needed to convert the data into a form for use in analysis, including determination of required energy grids and angular distributions. Many types of processing are required for thermal scattering, resolved resonance, unresolved resonance, and fast energy range. Additional data are needed for ORIGEN libraries, especially decay modes from the Evaluated Nuclear Structure Data File (ENSDF) library, activation data from the Joint European Fission Fusion (JEFF) libraries, etc.

Through its many computation modules, integrated user interfaces, and automated scripting, AMPX enables a team to confidently develop quality-assured production libraries for use in design and licensing calculations and provides for exploration of new data sources, group structures, and more.

For more information visit, https://www.ornl.gov/division/rnsd/projects/ampx-cross-section-processing

Licensing: AMPX-6 is distributed with SCALE 6.2.3, which is available from RSICC as C00834.
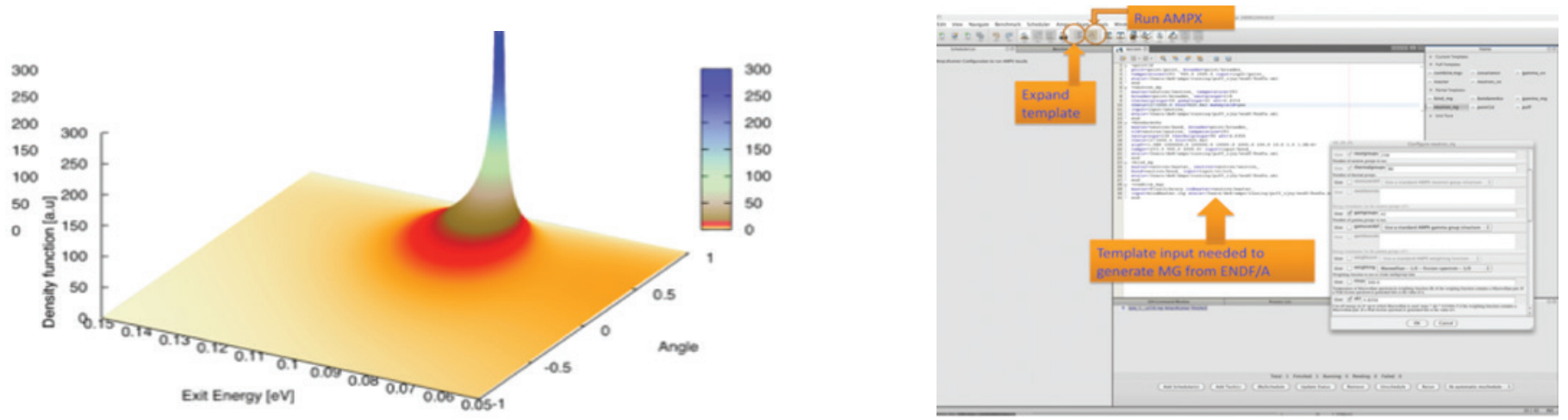

Figure 7. Thermal neutron scattering data (left) and AMPX user interface (right). 


\subsection{SAMMY}

Evaluations of nuclear cross section data include analyzing uncertainties from fundamental experiment data and processing the data into the ENDF format. A physics-based formalism is required to decrease cross section data uncertainties for advanced simulations in nuclear applications.

Bayesian fitting of R-matrix resonance parameters implemented in SAMMY combines prior resonance parameters values and uncertainties with measured data and data uncertainties to yield updated parameter values and uncertainties. This yields new evaluations of partial (elastic, neutron, capture, fission) and total cross sections of neutron, proton, and a-particle-induced reactions in the resolved and unresolved resonance energy ranges.

New cross section evaluations are distributed to the public via ENDF data. It is estimated that $80 \%$ of the resolved resonance data in recent ENDF releases were generated with SAMMY.

https://www.ornl.gov/division/rnsd/projects/sammy-nuclear-cross-section-evaluation-tool

Licensing: SAMMY 8.1.0 is available from RSICC as P00158.

https://ornl.gov/onramp/production-tools

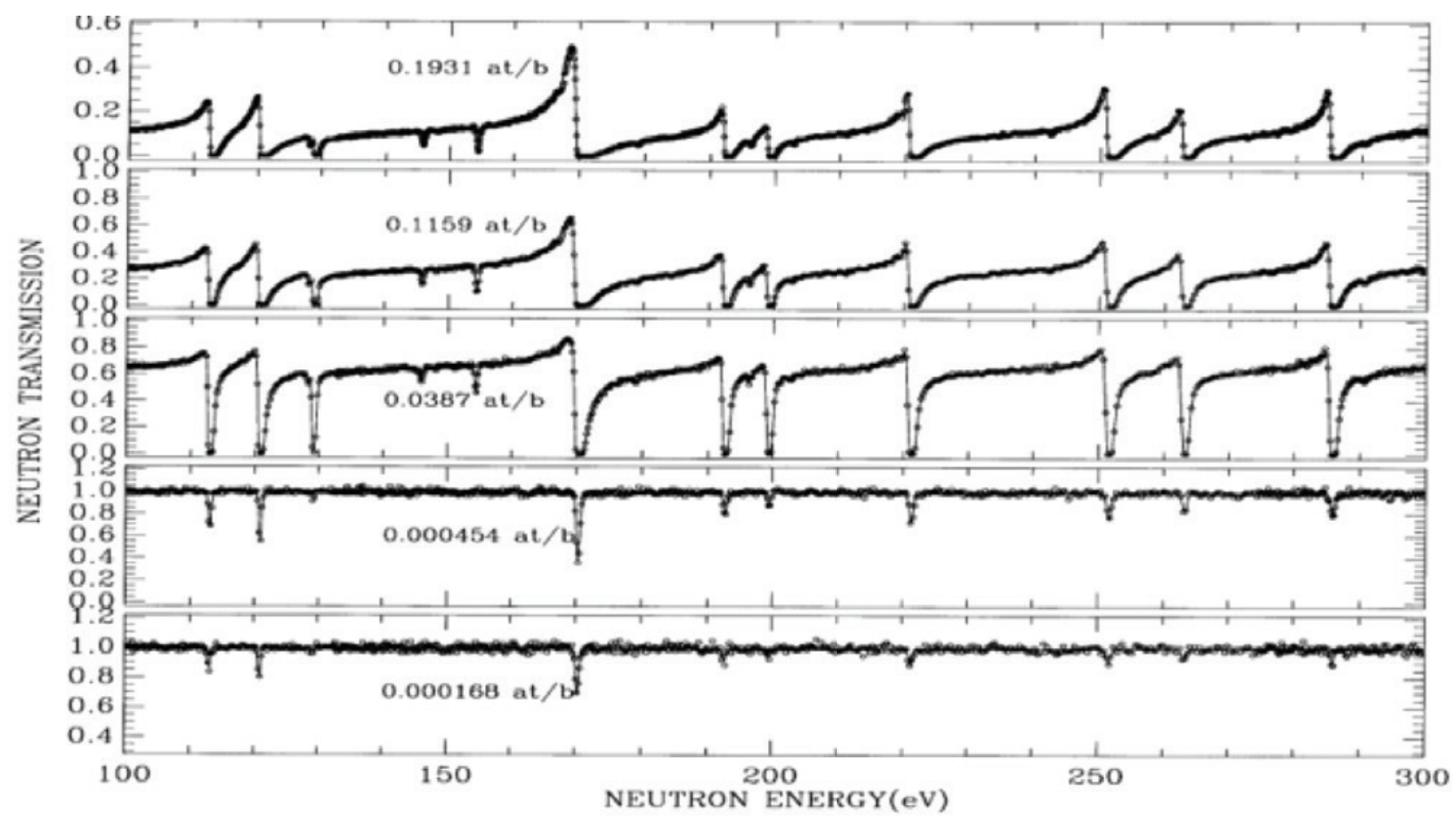

Figure 8. SAMMY neutron transmission of ${ }^{232}$ Th for varying target thickness by Derrien. 


\subsection{CUSTOM-DEVELOPED TOOLS AND DATA}

Leveraging our expertise across diverse teams, ORNL refines existing solutions to support the emerging needs of new technologies, to provide novel approaches for efficiency and accuracy gains, and to create integrated workflows and visualization as needed to meet your needs. Some examples of ongoing projects to provide unique solutions to meet stakeholders' needs are detailed below. Our highly capable teams provide customized solutions with the appropriate quality assurance, deployment, training, and support to ensure success, whether development is performed exclusively at ORNL or in collaboration with domestic and international partners.

\subsection{UNF-ST\&DARDS}

The Used Nuclear Fuel-Storage, Transportation \& Disposal Analysis Resource and Data System (UNF ST\&DARDS) is a comprehensive integrated data and analysis tool being developed for the US Department of Energy (DOE) Office of Nuclear Energy (NE) Spent Fuel and Waste Disposition (SFWD) program, with growing support from the NRC. The overarching goal of UNF-ST\&DARDS is to provide a comprehensive, controlled source of technical data integrated with key analysis capabilities to characterize inputs to the overall US waste management system, beginning with reactor power production through ultimate disposition. UNF ST\&DARDS seamlessly integrates a unified spent fuel system relational database and key analysis capabilities to simplify and automate performance of accurate, efficient spent fuel analyses to support numerous DOE waste management and fuel cycle activities. UNF-ST\&DARDS enables decision making relative to design, safety, and licensing of spent fuel systems and facilities by providing the best information available. Automated analysis sequences have been deployed to characterize the discharge inventory and to perform criticality, thermal, and dose analyses using time-dependent data. UNF ST\&DARDS provides cask-specific as-loaded safety analysis, including criticality, thermal and dose evaluations, and results visualization by integrating capabilities from SCALE and COBRA - Spent Fuel Storage (SFS), jointly developed with Pacific Northwest National Laboratory. UNF-ST\&DARDS provides simple interfaces for incorporating user-specific data into the UNF-ST\&DARDS database, allowing users to perform automated, user-specific spent fuel characterizations. Additionally, UNF-ST\&DARDS provides automated design-basis analysis capabilities for spent nuclear fuel storage and transportation systems.

\section{https://www.ornl.gov/division/rnsd/projects/spent-nuclear-fuel-characterization}

Licensing: UNF-ST\&DARDS is available through RSICC by approval of the program manager. Contact Dr. Kaushik Banerjee (banerjeek@ornl.gov) for more information.

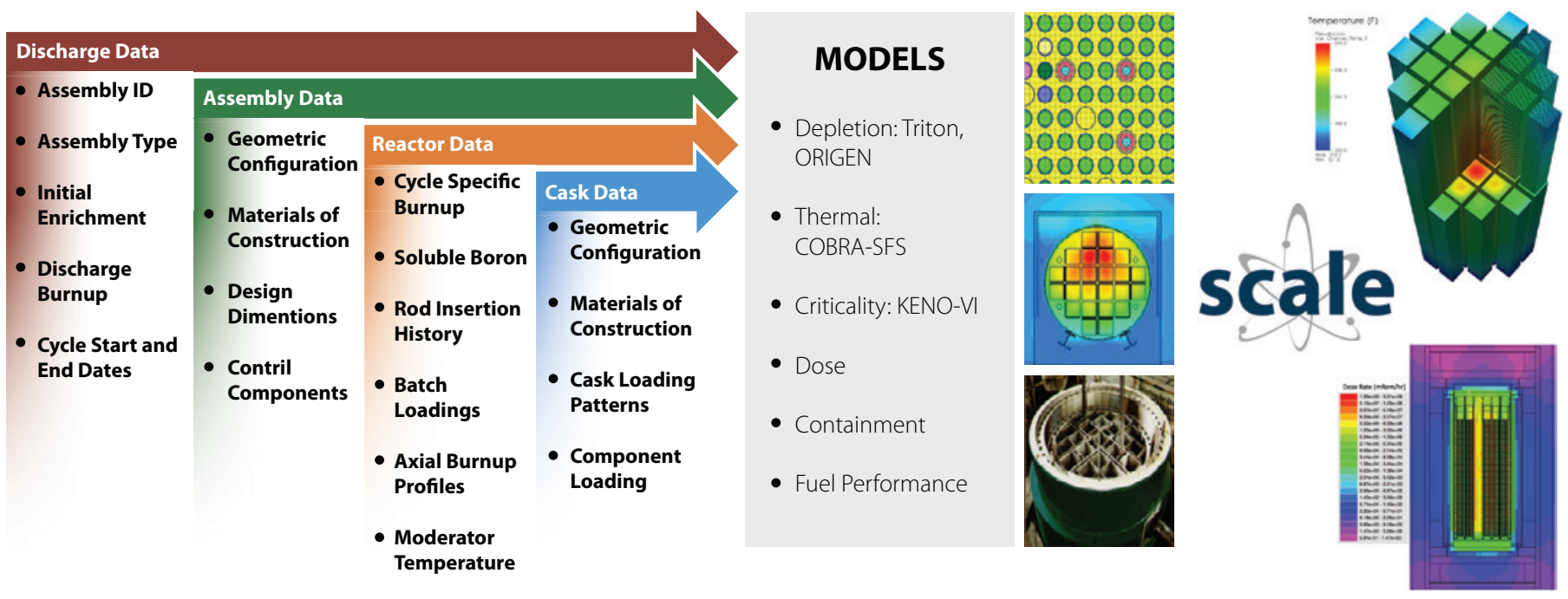

Figure 9. UNF-ST\&DARDS integrated capabilities, ranging from engineering data to licensing results. 


\subsection{NEAMS WORKBENCH}

The Nuclear Energy Advanced Modeling and Simulation (NEAMS) Workbench facilitates the use of multiple tools in analysis, including production tools and high-fidelity tools developed in the CASL and NEAMS programs, by providing a common user interface for model creation, review, execution, output review, and visualization for integrated codes. The workbench can provide a common user input, including engineering-scale specifications that are expanded into code-specific input requirements through the use of customizable templates. The templating process enables multi-fidelity analysis of a system from a common set of input data. Expansion of the codes and application templates and automated workflows available in the NEAMS Workbench facilitates system analysis and design. While users of the workbench are required to license and install the appropriate computational tools, the workbench will provide a more consistent user experience and will ease transition from one tool to the next.

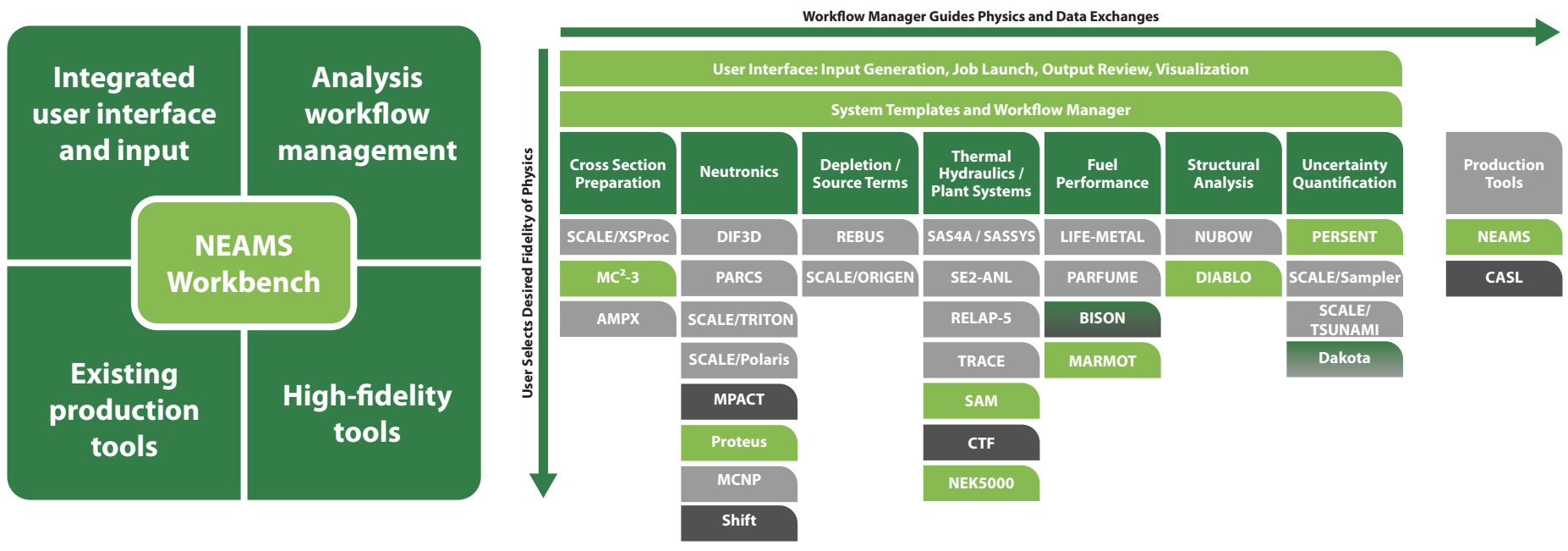

Figure 10. NEAMS Workbench concept for integrated multiphysics workflows with multiple levels of fidelity.

\section{https://www.ornl.gov/division/rnsd/projects/neams-workbench}

Licensing: NEAMS Workbench is available under a three-clause open source software license.

Contact nwb-help@ornl.gov for more information. 


\subsection{TRANSFORM}

The Transient Simulation Framework of Reconfigurable Modules (TRANSFORM) is an ORNL-developed component library created using the Modelica programming language for the investigation of dynamic thermal-hydraulic systems and other multiphysics systems. The TRANSFORM library allows for rapid development of energy systems with a focus on enabling the modeler to customize the components for any application, including instrumentation and control design. The TRANSFORM library has been successfully used for a variety of nuclear applications, including investigations into the performance of nuclear hybrid energy systems (NHESs), nuclear thermal propulsion systems, liquid metal and gas-cooled reactors, and molten salt applications including kinetic behavior and fission product transport (e.g., neutron precursors, xenon, and tritium).

Modelica is a nonproprietary, object-oriented, equation-based programming language used to conveniently model complex physical and cyberphysical systems to include systems containing mechanical, electrical, electronic, hydraulic, thermal, control, etc. components. A key advantage of Modelica is its separation of physical models and the solvers of the models. This separation enables rapid generation of complex physical systems and control design in a single language without deep knowledge of numeric solvers, code generation, etc.

\section{https://info.ornl.gov/sites/publications/files/Pub55919.pdf}

Licensing: TRANSFORM is available under open source licensing:

https://github.com/ORNL-Modelica/TRANSFORM-Library

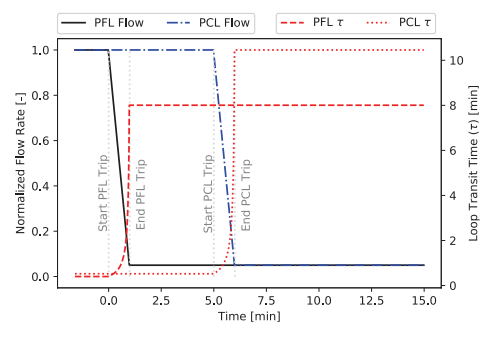

Flow rate and loop transit time

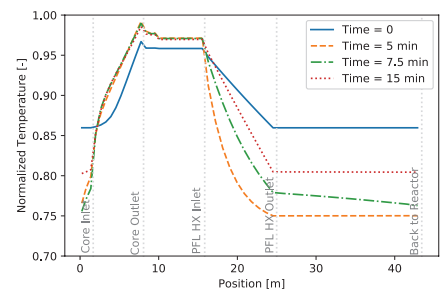

Temperature as a function of position in primary fuel loop (PFL) for a few specific times

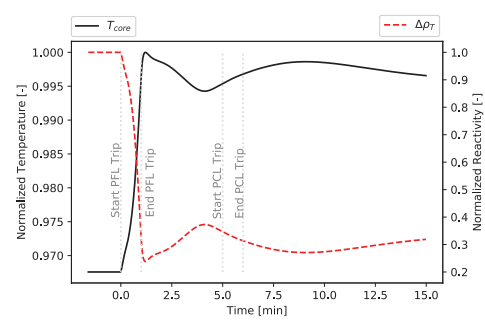

Average core temperature and reactivity

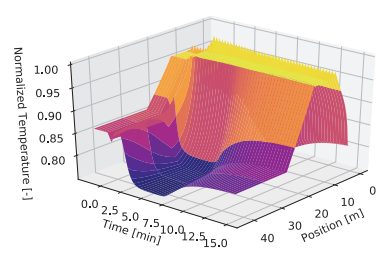

Temperature as a function of time and position in PFL

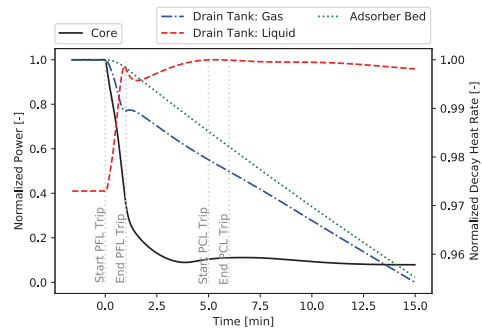

Power deposition

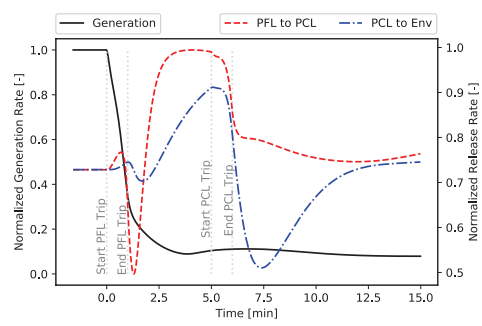

Tritium generation and diffusion behavior

Figure 11. Transform analysis of a sequential pub trips in molten salt reactor (MSR). 


\subsection{SCALE AND VERA ENHANCEMENTS FOR ADVANCED NUCLEAR ENERGY SYSTEMS}

ORNL teams are dedicated to supporting the latest technology advancements, including very large, complex interim storage sites for used fuel; analysis of advanced reactors including molten salt reactors (MSRs), fluoride-salt-cooled high-temperature reactors (FHRs), high-temperature gas-cooled reactors (HTGRs) and sodium-cooled fast reactors (SFRs); analysis of advanced technology fuels (ATFs); and advanced validation approaches for new or challenging systems. A sampling of the enhancements in our production tools to support these technologies is provided here.
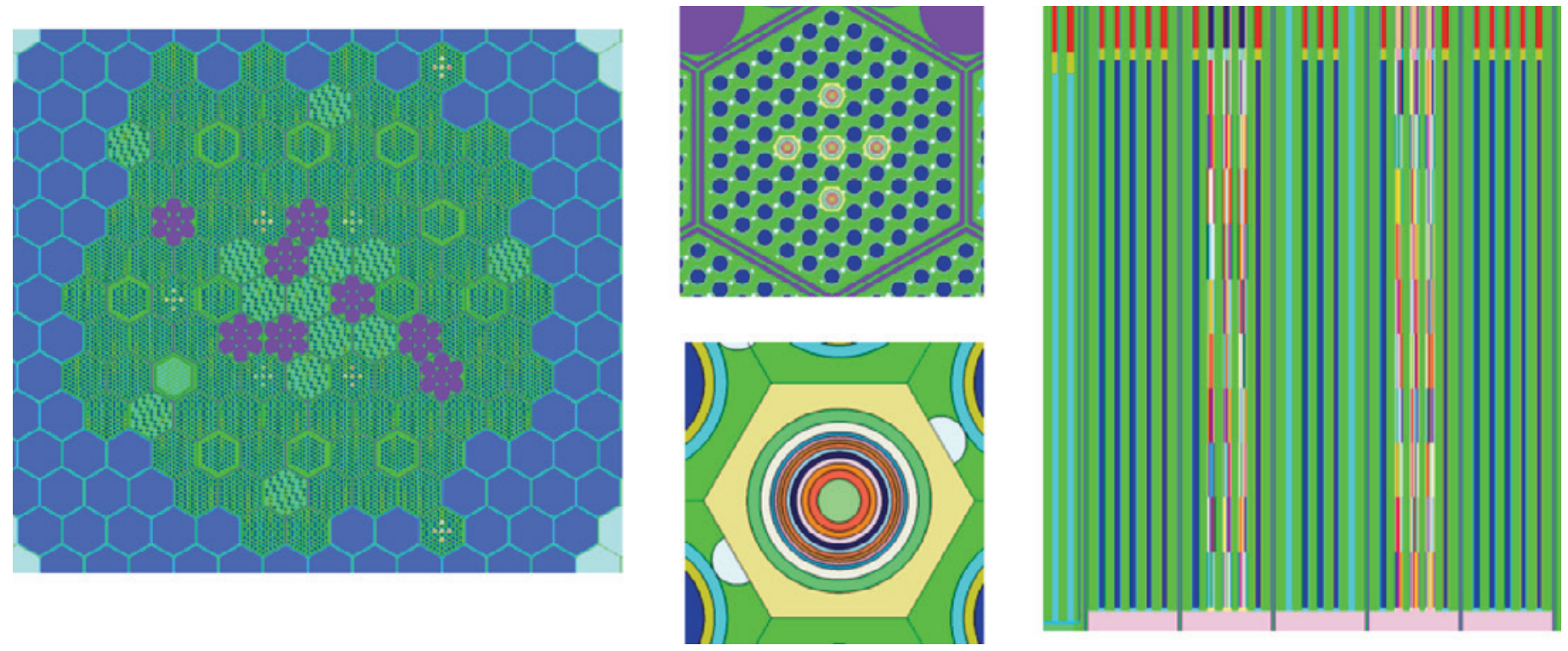

Figure 12. Detailed SCALE/Shift model of Experimental Breeder Reactor (EBR)-II reactor.

A significant activity to support these concepts is the integration and enhancement of the Shift Monte Carlo from CASL for use in SCALE. Shift integration provides criticality, shielding, S/U, and depletion capabilities. Integrated with the TRITON and Polaris sequences, Shift provides reference 3D continuous-energy depletion capabilities. Beyond its application in CASL, Shift is extended to generate nodal cross section data for use in core simulators like PARCS, especially to capture 3D effects important for advanced reactors, including leakage effects and control elements in reflector regions.

The Polaris lattice physics sequence of SCALE is enhanced to support ATF concepts, as well as hexagonal geometry for SFRs, and SCALE neutronics capabilities are integrated with Sandia National Laboratories' MELCORE severe accident tool, as well as the NRC's new FAST fuel performance code.

For HTGRs and FHRs, the Shift Monte Carlo code includes a new random geometry generator that is especially designed to for tristructural-isotropic (TRISO) fuel and pebble loading.

For liquid-fueled MSRs, SCALE is being enhanced to include a delayed neutron precursor drift and chemical feed capability that can be coupled to other tools. The VERA tool from CASL is being expanded to provide a fully integrated multiphysics capability capable of $3 D$ analysis of MSRs with feedback effects in VERA-MSR.

Many of these advanced systems have unique materials and neutron spectra compared to traditional LWRs, so new AMPX nuclear data libraries are being developed and validated to support these technologies.

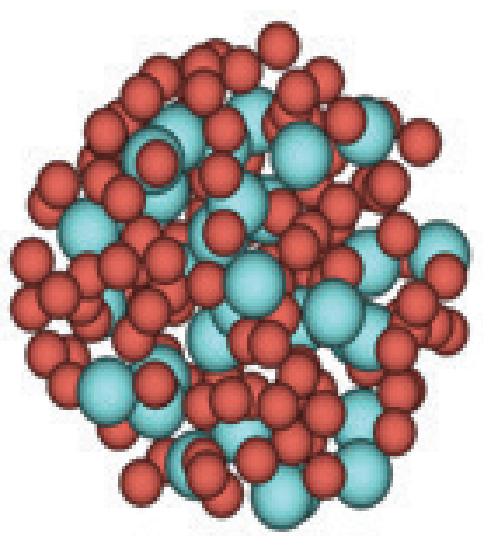

Figure 13. TRISO kernel placement with Shift random geometry generator demonstrating a test case of loading multiple types of TRISOs in a single pebble. 


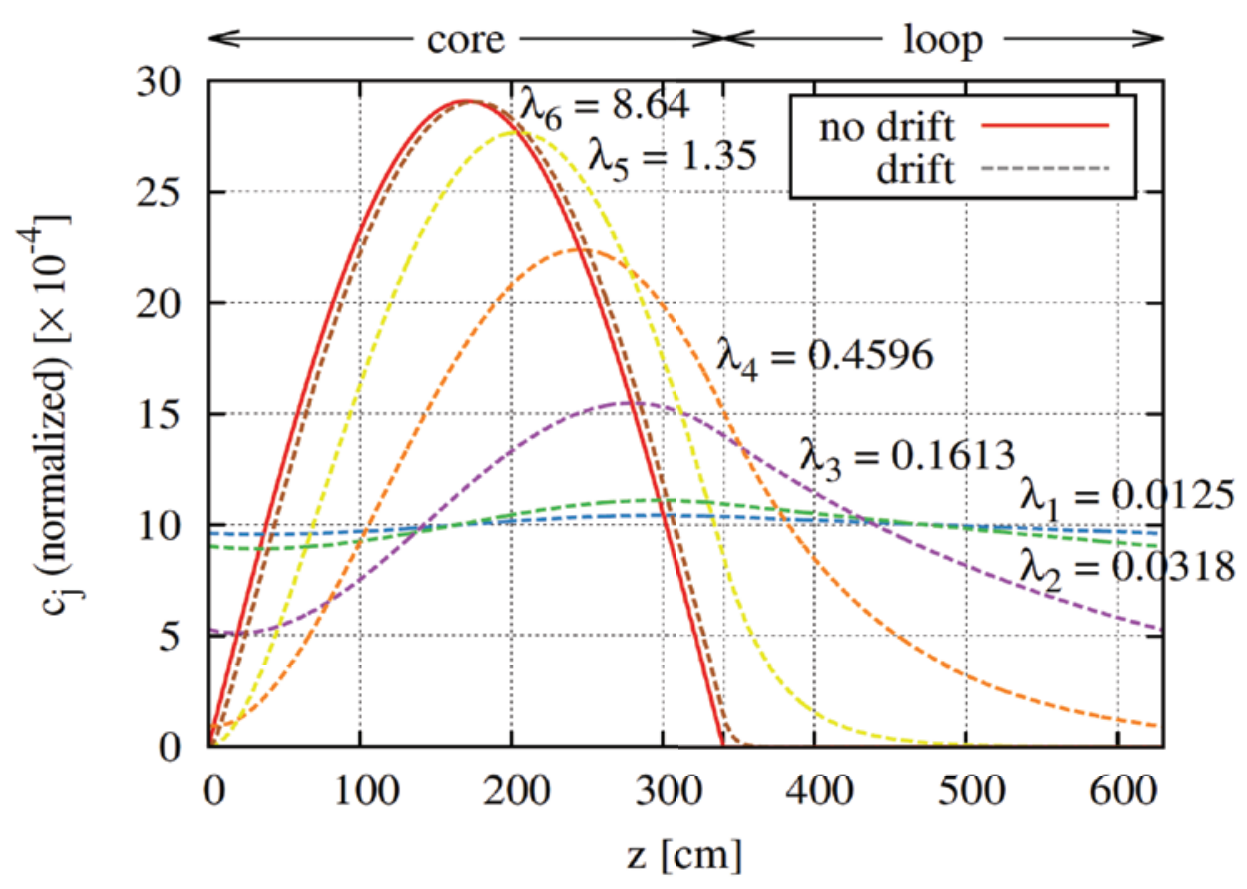

Figure 14. SCALE 6.3 calculation of delayed neutron precursor concentrations in the primary loop of a liquid-fueled MSR.

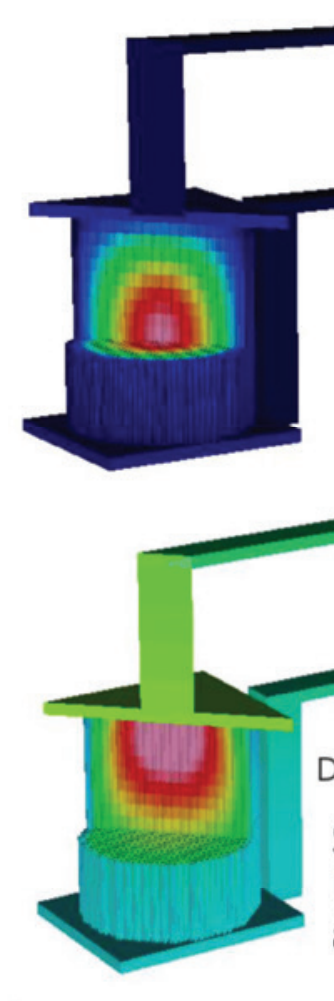

\section{Power}

SCALE/AMPX

Nuclear data

Delayed Neutron Precursor

SCALE/ORIGEN Isotopic compositions and decay constants
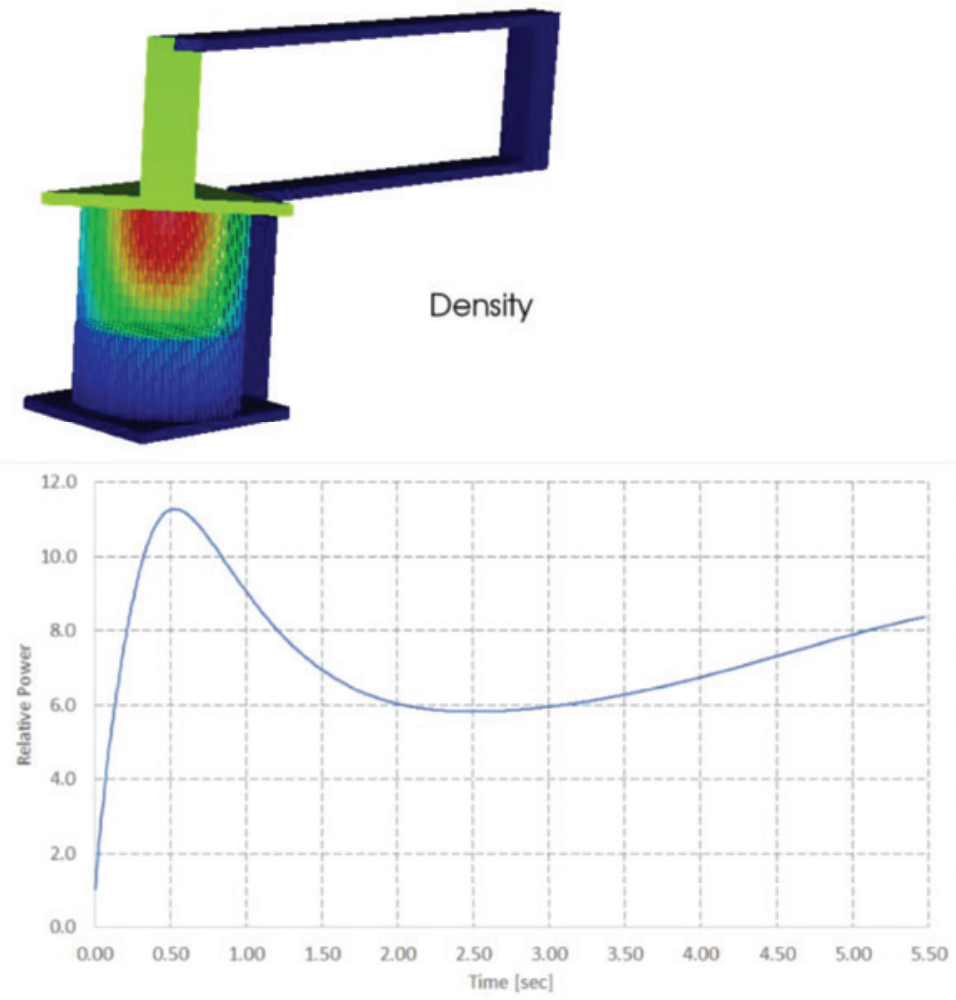

Figure 15. VERA-MSR 3D time-dependent, integrated, multiphysics calculation of a reactivity insertion for the ORNL Molten Salt Reactor Experiment. 


\subsection{FUSION PLASMA PHYSICS}

ORNL has a long history of developing custom applications for simulating a range of plasma physics phenomena supporting the DOE-Fusion Energy Science Program. Example application areas of custom tools are developed with an eye towards taking advantage of the most advanced computational capabilities. These areas include:

- Magnetohydrodynamic (MHD) equilibrium

- Plasma heating and current drive

- Tokamak disruptions and runaway electron dynamics

- Interactions between energetic particles and plasma waves

- $\quad$ Integrated multiphysics simulations for predicting reactor performance

Recent tools developed include the Parallel Variational Moment Equilibrium Code (PARVMEC), which has extended the world-leading 3D MHD equilibrium model VMEC to take advantage of modern computing capabilities. This is the community standard model for 3D equilibria in experiments such as stellarators and is currently being extended to allow for islands and stochastic fields in the SIESTA code. ORNL also leads development of models for heating and current drive using radiofrequency waves, with the AORSA code being the only full-wave simulation capable of treating perpendicular wavelengths on the scale of the ion Lamor radius or smaller. ORNL is also developing community-leading simulation of energetic particles in fusion plasmas, including one example through the full-orbit KORC code which was developed to provide high-fidelity modeling of runaway electron dynamics following tokamak disruptions. Models of the interaction of energetic particles with waves in plasma, including both Alfvenic instabilities and externally driven modes, are being developed using the gyrofluid approximation in 2D (TAEFL) and 3D (FAR3D). ORNL has also developed expertise in coupled plasma simulations using the Integrated Plasma Simulation (IPS) framework. This framework is used to build integrated simulations for a variety of needs. As an example, the FASTRAN modeling tool combines a large set of simulation components, including models for plasma equilibrium, stability, and transport, providing the predictive capability needed to develop advanced tokamak scenarios and other simulations. This approach is currently being extended into CESOL, which includes models for the plasma boundary layer. Various other integrated simulation capabilities are being developed, such as coupling plasma models with materials simulations to model plasma-surface interactions.

\subsection{NUCLEAR SECURITY}

ORNL creates focused tools on emerging, difficult radiological questions in support of US government agencies. Tools in the nuclear security area are generally made available within select communities at the discretion of sponsoring agencies.

Recently developed tools include the Defense Land Fallout Interpretive Code (DELFIC) Airborne Planning Tool that predicts the sample characteristics of debris collected from the air after a nuclear detonation. This tool is based on DELFIC and builds on the success of a previous tool, the DELFIC Fallout Planning Tool, which was used by the interagency nuclear forensics community since 2009. Our Inverse Depletion Theory (INDEPTH) tool is being applied to international safeguards efforts to predict and confirm declarations of spent fuel characteristics such as burnup, initial enrichment, and cooling time. This tool uses the ORIGEN code and numerical methods to minimize the difference between spent fuel measurements and model predictions to infer reactor parameters. Another recently developed tool is the INVERSE GUI, which was created in partnership with Los Alamos National Laboratory. The INVERSE GUI uses advanced uncertainty quantification and various computer speedup techniques 
to infer shielded source characteristics from first responders' measurements of radioactive material. Major analysis projects include an ORNL-led multilaboratory venture for the NNSA to improve prediction of plutonium production in reactors of concern using modeling and simulation capabilities. ORNL also plays a major role in another NNSA venture project to apply modeling and simulation to urban searches for radioactive sources where the confounding signals of background are being considered in detail. These capabilities are also being used to predict and calculate experimental observables such as the optical properties of uranium oxides, fluorides, oxyfluorides, and related compounds. Modeling and simulation capabilities are also being developed to help gain understanding of the solidstate chemistry, structure, and dynamics of actinide compounds. Genetic algorithms are being used to predict crystal structure of novel uranium oxide phases. The fundamental chemistry of actinide materials is also being investigated using density functional theory and ab initio molecular dynamics codes employed on HPC clusters. Software for nuclear material holdup characterizing is also being developed. The SNAPSHOT software uses generalized geometry to characterize material left in a glovebox or other handling facility. Research is also being performed to develop transformative image reconstruction capabilities for radiological source characterization.

\subsection{EXASCALE COMPUTING PROJECT}

The DOE Exascale Computing Project (ECP) project office is located at ORNL. The ECP mission is to deliver exascale-ready applications and solutions that address currently intractable problems of strategic importance and national interest; to create and deploy an expanded

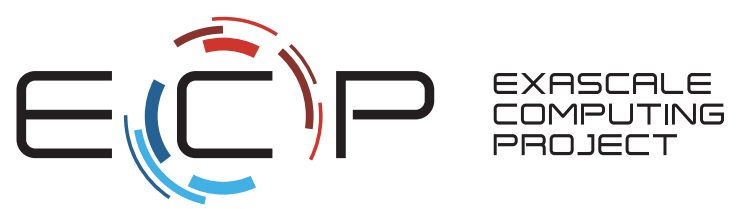
and vertically integrated software stack on DOE HPC exascale and pre-exascale systems, defining the enduring US exascale ecosystem; and to leverage US HPC vendor R\&D activities and products into DOE HPC exascale systems. The vision is to accelerate innovation with exascale simulation and data science solutions to national problems that enhance US economic competitiveness, improve our quality of life, and strengthen our national security.

ECP supports 22 application development projects that are being designed and optimized for use on the proposed Frontier exascale platform that will debut at ORNL's Leadership Computing Facility (OLCF) in 2023. The application development teams consist of principal investigators and members throughout the DOE national laboratory complex, spanning scientific fields including nuclear energy, materials, astrophysics, climate, and others. The nuclear energy application ExaSMR is led by ORNL and includes researchers and developers from ORNL, Argonne National Laboratory (ANL), MIT, and Idaho State University. ORNL is leading the ECP Energy Security Applications area, and within that portfolio, ORNL leads the ExaSMR project for modeling and simulation of small modular reactors (SMRs).

The ExaSMR project is focused on developing a virtual test reactor for advanced designs via experimental-quality simulations of reactor behavior with the aim of design and commercialization of SMRs. ExaSMR is coupling the most accurate available methods to perform virtual experiment simulations. Coupled neutronics and fluid dynamics will be used to create virtual experimental datasets for SMRs under varying operational scenarios. The Monte Carlo radiation transport capabilities in the

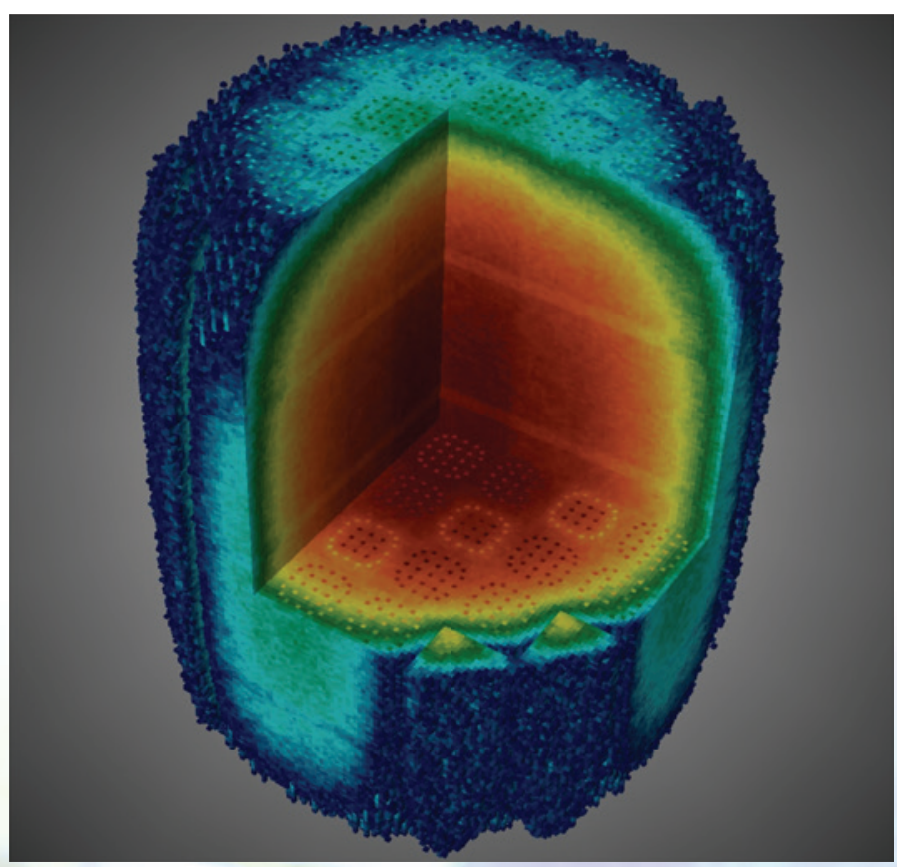

Figure 16. Total neutron interaction rate in an SMR core using Shift in the ExaSMR project. 
ORNL Shift code are being significantly enhanced to perform simulations on exascale computing architectures, and high-resolution computational fluid dynamics (CFD) tools are also being prepared. This powerful multiphysics capability will be applied to fundamental design parameters, including the turbulent mixing conditions necessary for natural circulation and steady-state critical heat flux margins between the moderator and fuel, providing validation for low-order engineering simulations and reducing conservative operational margins resulting in higher updates and longer fuel cycles.

\subsection{SOFTWARE DEVELOPMENT ENVIRONMENT AND TESTING}

Software quality assurance (SQA) is an integral component of ORNL analysis software development practices. ORNL has specific expertise in the application of international consensus standards such as ISO-9001-2008, American Society of Mechanical Engineers [ASME] NQA-1, DOE orders (DOE 414.1D), and NRC guidelines (NUREG/BR-0167) to nuclear system analysis software. ORNL maintains the Standards-Based Management System, which documents quality assurance activities and SQA plans and activities which are reviewed regularly by established ORNL SQA boards.

The success of any ongoing software project requires routine compilation and testing of software and data, along with continual support for the latest hardware and compilers. Major development projects maintain dedicated hardware with appropriate testing infrastructure to keep up with the pace of development and maintain a production release schedule.

Continuous integration hardware is available to fulfill SQA for a large team on multiple platforms with different compilers and configurations. Continuous deployment for Linux, Mac, and Windows operating systems enables timely production releases and immediate collaboration on newly developed features not yet officially released.

ORNL has broad expertise in solution verification, including the evaluation of discretization uncertainty and numerical solver convergence, for radiation transport, thermal hydraulics, structural mechanics, fuel/material performance, plasma physics, and radiation activation/depletion analysis. ORNL also has specific expertise in uncertainty quantification, which is the propagation of input uncertainties through the simulation or model, using a variety of direct and indirect assessment methods. ORNL develops a variety of custom software tools to automate and support these functions and partners with external teams to develop others.

https://ornl.gov/onramp/custom-developed-tools-data 


\subsection{ANALYSIS EXPERTISE}

The world-class teams at ORNL that provide support and technical analyses to DOE, NRC, NNSA, the National Aeronautics and Space Administration (NASA), industry, and many international partners are available to address your most challenging issues. Our experienced teams can provide support for your needs, assisting in creating models, implementing technical guidance, or designing customized approaches. The analysis expertise of our teams does not rely exclusively on ORNL-developed tools; we draw from a broad collection of commercial and DOE software that can be leveraged across a broad range of technical areas including the following:

- Nuclear data

- Radiation shielding and criticality safety

- Reactor neutronics

- Thermal hydraulics and CFD

- Nuclear materials

- Thermomechanics and fuels

- Reactor core analysis

- Accident analysis

- Fusion plasma physics
- Nuclear safeguards and security

- Fuel cycle analysis

- Nuclear transportation and storage analysis

- Probabilistic risk assessment (PRA)

- High-performance computing

- Parametric design sensitivity

- Advanced meshing capabilities

- Client application deployment

The expertise at ORNL is applied to effectively leverage our advanced software and computer hardware capabilities to identify, develop, and deliver custom solutions for your problems. Your team can benefit from working directly with ORNL teams for short- or long-term visits as guest scientists, especially within ORNL's high tech collaboration spaces.

\subsection{COLLABORATION SPACE}

ORNL provides state-of-the art facilities for hosting guest scientists, including a 3,000 $\mathrm{ft}^{2}$ collaboration space within the Virtual Office, Community, and Computing (VOCC) facility. VOCC provides multiple collaboration workspaces, each accommodating a small team with dockable tabletops and shared displays, a 3D visualization cave, a 1,000 $\mathrm{ft}^{2}$ dedicated training room for 20 workstations with state-of-the-art wall-sized high-resolution displays, and comprehensive audiovisual equipment for remote collaboration sessions between teams.

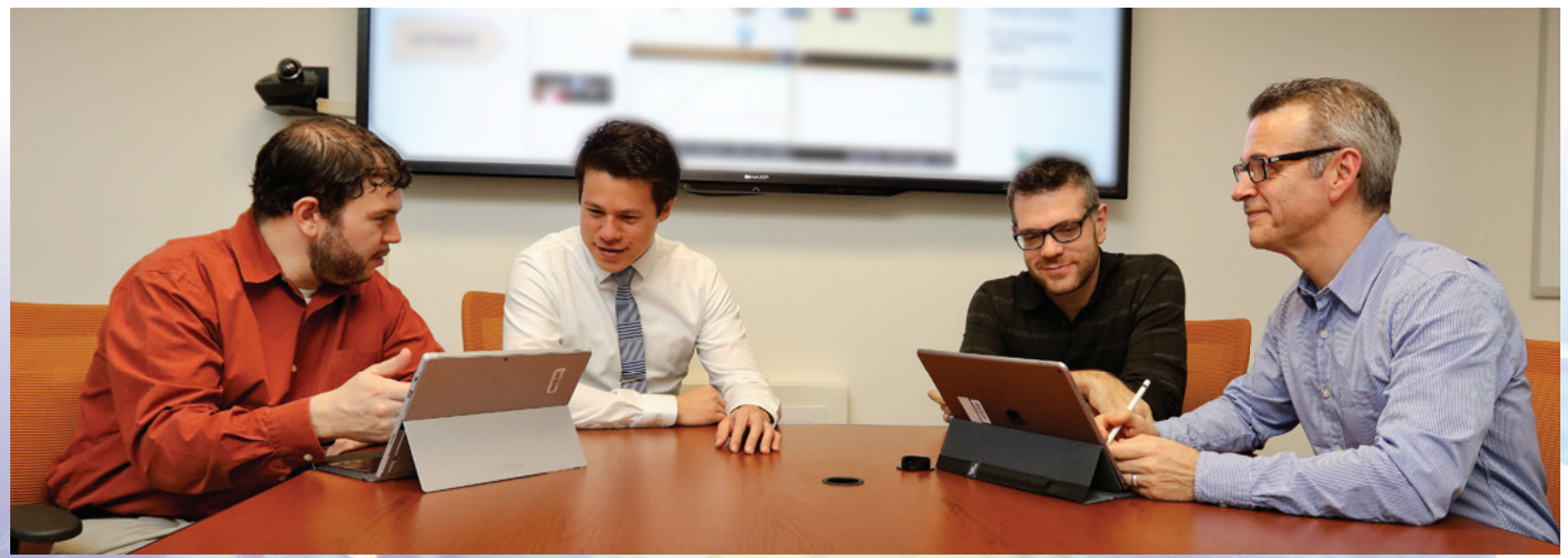

Figure 17. ORNL team collaborating. 


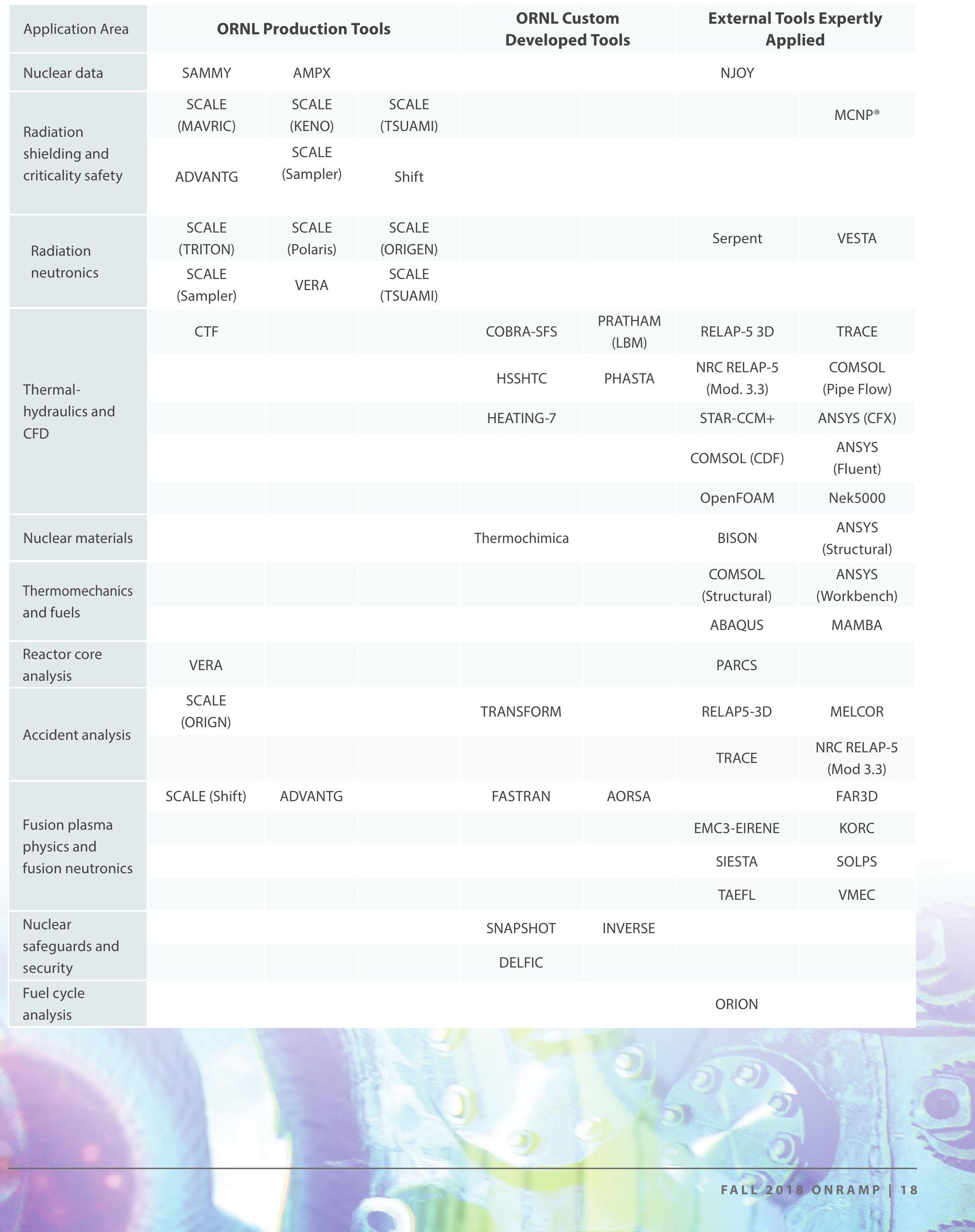




\begin{tabular}{|c|c|c|c|c|c|c|c|}
\hline \multirow{5}{*}{$\begin{array}{l}\text { Application Area } \\
\text { Nuclear } \\
\text { transportation } \\
\text { and storage } \\
\text { analysis }\end{array}$} & \multicolumn{3}{|c|}{ ORNL Production Tools } & \multicolumn{2}{|c|}{$\begin{array}{c}\text { ORNL Custom Developed } \\
\text { Tools }\end{array}$} & \multicolumn{2}{|c|}{ External Tools Expertly Applied } \\
\hline & $\begin{array}{l}\text { SCALE } \\
(\text { ORIGN) }\end{array}$ & $\begin{array}{c}\text { SCALE } \\
\text { (MAVRIC) }\end{array}$ & & UNF-ST\&DARDS & COBRA-SFS & LS-DYNA & $\begin{array}{l}\text { ANSYS } \\
\text { (DYNA) }\end{array}$ \\
\hline & SCALE (KENO) & $\begin{array}{c}\text { SCALE } \\
\text { (TSUNAMI) }\end{array}$ & & & & & \\
\hline & $\begin{array}{l}\text { SCALE } \\
\text { (TRITON) }\end{array}$ & $\begin{array}{c}\text { SCALE } \\
\text { (POLARIS) }\end{array}$ & & & & & \\
\hline & $\begin{array}{l}\text { SCALE } \\
\text { (Sampler) }\end{array}$ & & & & & & \\
\hline $\begin{array}{l}\text { Probabilistic risk } \\
\text { assessment }\end{array}$ & & & & TRANSFORM & & SAPHIRE & RAVEN \\
\hline HPC analysis & VERA & Shift & Denovo & & & Nek5000 & \\
\hline $\begin{array}{l}\text { Parametric } \\
\text { design sensitivity }\end{array}$ & $\begin{array}{c}\text { SCALE } \\
\text { (Sampler) }\end{array}$ & & & & & HEEDS & DAKOTA \\
\hline $\begin{array}{l}\text { Advanced } \\
\text { meshing } \\
\text { capabilities }\end{array}$ & & & & CartGen++ & & ICEM CFD & HEXPRESS \\
\hline Advanced & & & & & & $\begin{array}{c}\text { ANSYS } \\
\text { (SpaceClaim) }\end{array}$ & SolidWorks \\
\hline modeling & & & & & & $\begin{array}{c}\text { Creo } \\
\text { Parametric }\end{array}$ & \\
\hline $\begin{array}{l}\text { Client } \\
\text { application } \\
\text { deployment }\end{array}$ & & & & & & $\begin{array}{l}\text { COMSOL } \\
\text { (Server) }\end{array}$ & $\begin{array}{l}\text { COMSOL } \\
\text { (Application } \\
\text { Builder) }\end{array}$ \\
\hline
\end{tabular}

Table 1. Software tools expertly applied for nuclear analysis 


\subsection{NUCLEAR DATA}

ORNL generates and deploys nuclear data evaluation and processing software, fundamental physics evaluations, and nuclear data libraries for a wide range of applications that involve neutron and gamma transport; activation, depletion, and decay; and uncertainty analysis. The capabilities and expertise at ORNL span the entire nuclear data lifecycle, including:

- Assessment of nuclear data needs that could improve the prediction of or reduce the uncertainty in safety and design calculations

- Differential measurement of new data at neutron scattering facilities

- Evaluation of fundamental data for incorporation with ENDF distributions

- Processing of data from ENDF and other sources to generate libraries for production use and distribution

Many emerging nuclear data needs are originating in areas where data are poorly quantified, especially for advanced reactors, isotope production, and nuclear security applications. The use of data gathered from irradiation experiments in HFIR, coupled with advanced S/U methods, provides an opportunity to improve the fundamental understanding of the physics and accelerate the deployment and use of improved data that are more predictive for new applications. If your team has a specialized nuclear data need, we can provide a comprehensive solution.

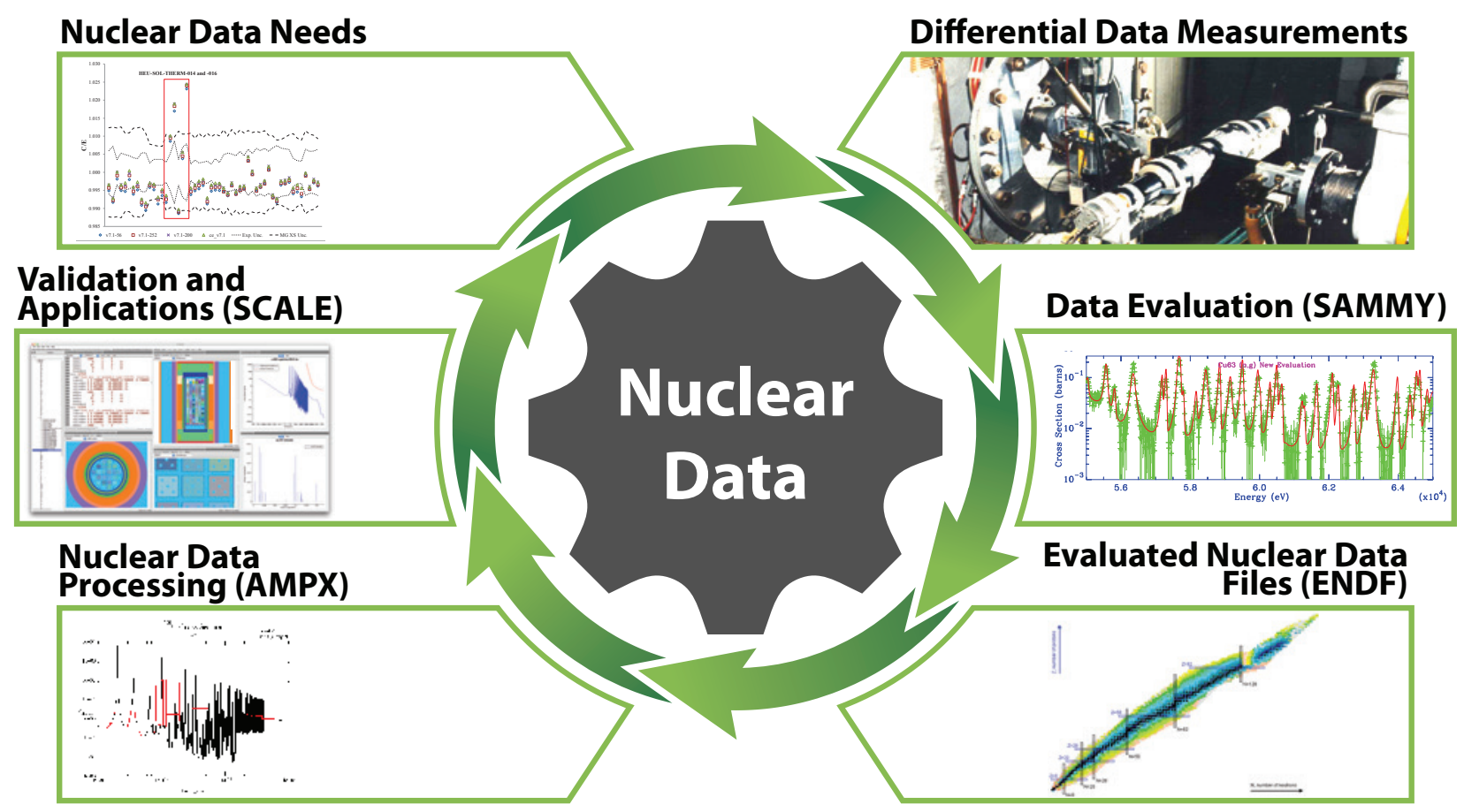

Figure 18. Nuclear data life cycle from identification of needs through validation and application analysis. 


\subsection{RADIATION SHIELDING AND CRITICALITY SAFETY}

ORNL provides advanced capabilities in radiation transport for criticality safety and shielding analysis, especially through hybrid methodologies that implement deterministic solvers to optimize high-fidelity Monte Carlo calculations for systems that are too challenging to be addressed by conventional means. ORNL has expertise in application scenarios that require these unique tools for high-fidelity analysis, such as:

- Shielding analysis of used nuclear fuel transportation and storage packages

- Pressure vessel fluence calculations

- Criticality accident alarm system analysis throughout a process facility

These analyses are supported with the use of multigroup and continuous-energy SCALE Monte Carlo transport codes (KENO, MAVRIC, and Shift) as well as the use of MCNP ${ }^{\circledR}$ alone or with variance reduction through ADVANTG.

\subsection{REACTOR NEUTRONICS}

ORNL has a long history of reactor analysis using multigroup and continuous-energy physics with deterministic and Monte Carlo methods. The breadth of reactor neutronics includes:

- Multigroup cross section processing

- Neutron transport and diffusion

- Isotopic depletion, decay, and transmutation

These methods are regularly implemented in a wide variety of applications, including:

- Lattice physics for core analyses

- High-fidelity LWR core analyses

- Analysis and optimization of research reactors

- Optimization of advanced reactor designs and fuel cycle analyses

- Isotope production and material irradiation experiments in research reactors 


\subsection{THERMAL HYDRAULICS}

Thermal hydraulics modeling and simulation at ORNL relies on a combination of custom code development, leveraging of open source software, and extension of commercial codes. These codes span a range of resolutions, including:

- Direct numerical simulation (DNS) capabilities that provide fully resolved numerical solutions of the Navier-Stokes equations

- Large eddy simulation (LES) capabilities that fully resolve large scale turbulence structures and use engineering models to describe structures smaller than the computational mesh elements

- Reynolds-averaged Navier-Stokes (RANS) simulation capabilities that rely on engineering models to describe all turbulence

- Advanced mesoscopic lattice Boltzmann method (LBM) for simulating turbulent flows

- Multiphase CFD using the level set and volume of fluid methods

- Subchannel models which provide reduced order lumped parameter representations of thermal hydraulic phenomena

- Lumped thermal-hydraulics component models to simulate an entire nuclear system including the balance of plant

A list of our primary thermal-hydraulics codes and software tools is provided in Table 1. Expert assistance is readily available to support your specific application needs.

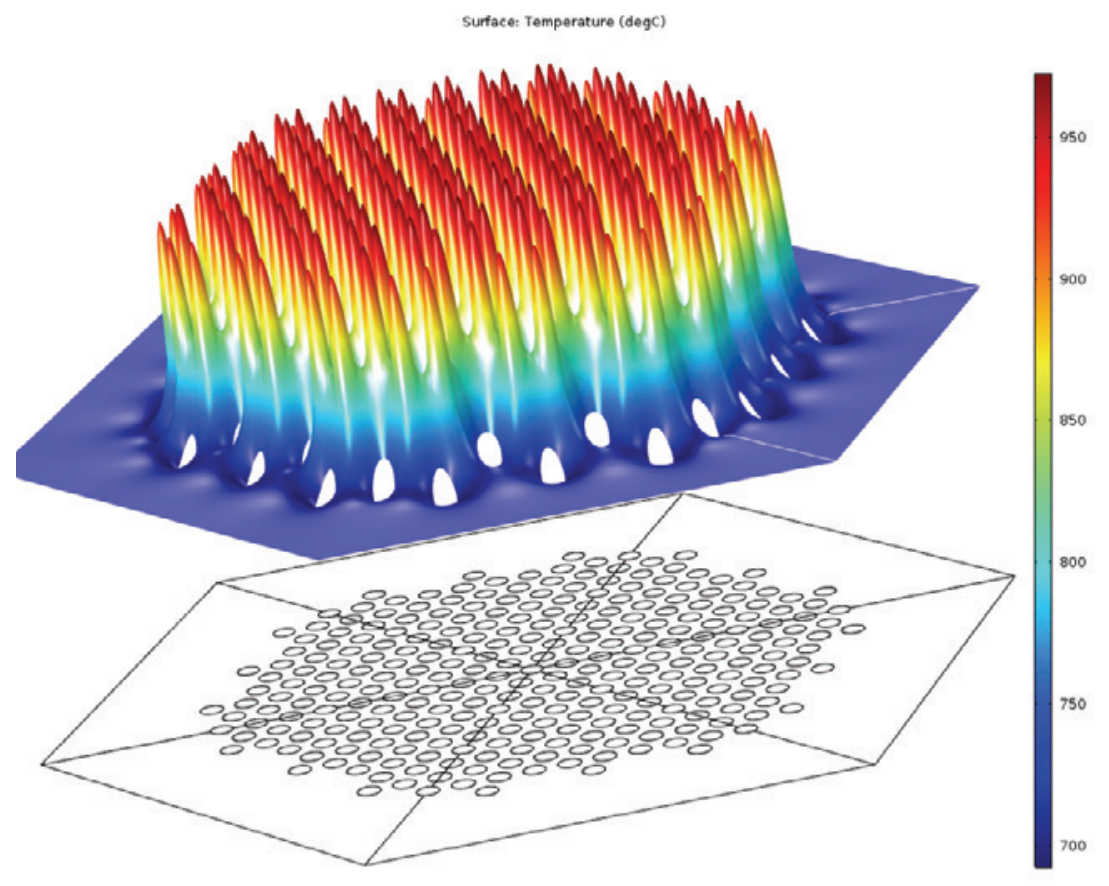

Figure 19. Thermal-hydraulics model of a fluoride high-temperature demonstration reactor. 


\subsection{NUCLEAR MATERIALS}

ORNL maintains a very broad portfolio of experimental research related to nuclear materials that includes a complementary modeling and simulation component. The MAMBA code provides surface chemistry modeling of crud on the surface of nuclear fuel rods. ORNL has built extensive experience using the BISON fuel performance code for a wide range of nuclear fuel performance assessments in commercial and research reactor fuels. This experience includes development and validation of material models, user support for simplification of modeling for standard LWR fuel, analysis of fuels for advanced reactors, including metallic fuels and TRISO coated particle fuel, and integration of fuel performance codes with reactor physics software.

Additionally, studies are being conducted at the mesoscale level to build an accurate and physically based fission gas release model for application in integrated fuel performance codes, as the fission gas models in standard fuel performance codes are a primary source of code uncertainty. Furthermore, the model development will be informed by results from massive atomistic and mesoscale simulations of the three stages of fission gas release: (1) diffusion and intra-granular bubble formation, (2) bubble growth and coalescence on grain faces, and (3) transport of gas through interconnected grain edge tunnels to free surfaces. The simulation tools will also undergo rigorous uncertainty quantification and validation against existing experimental data.

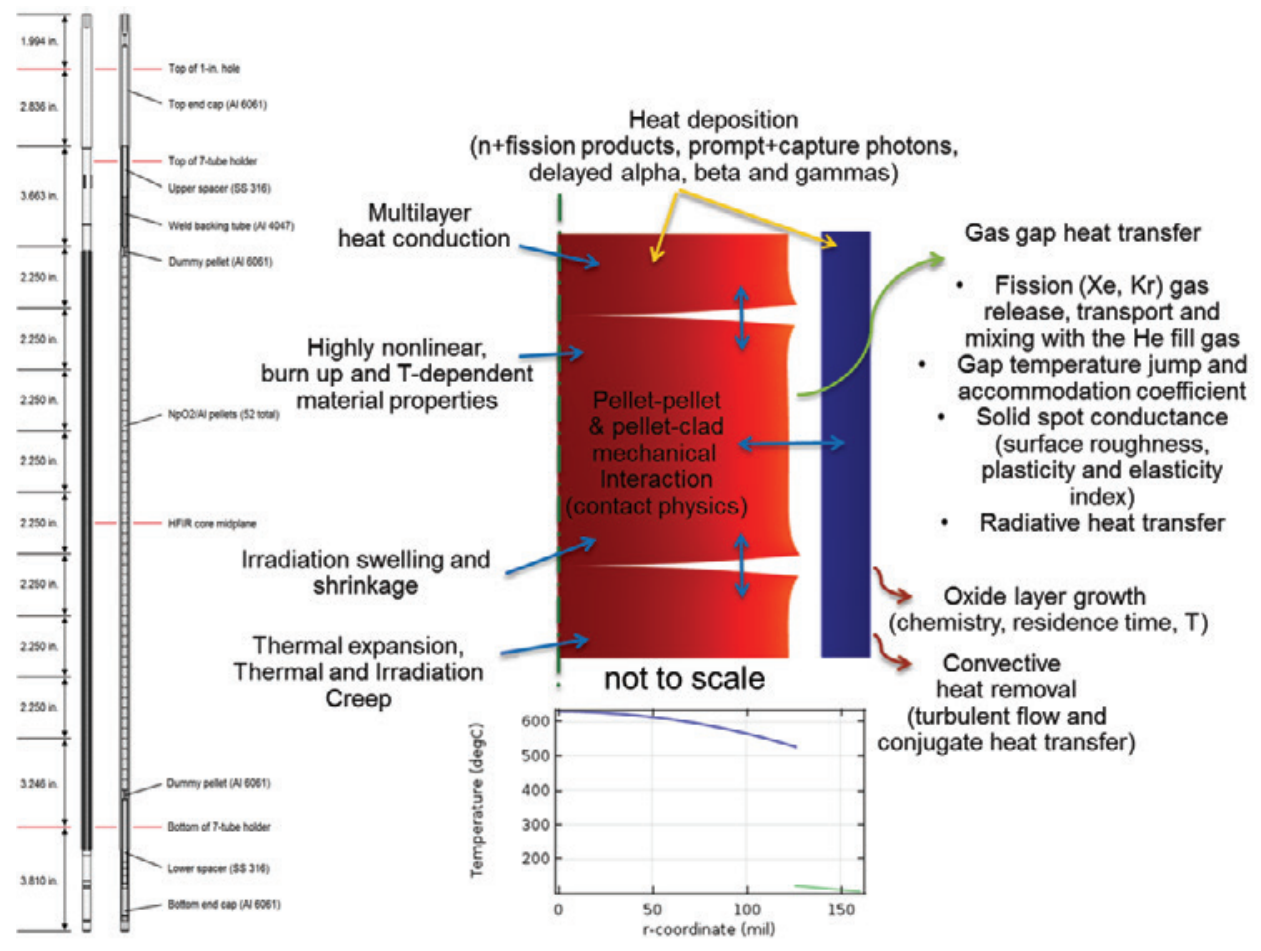

Figure 20. COMSOL fuel performance model to support production of ${ }^{238} \mathrm{Pu}$ in HFIR.

Another objective is the advanced use of integrated fuel performance codes to help design advanced reactors and their associated fuel systems for both DOE and private companies that want to partner with ORNL, to support and plan irradiation testing needed to qualify advanced fuels, and to support regulatory assessment of advanced fuels. 


\subsection{THERMOMECHANICS}

Because of broad industrial usage, structural mechanics codes are generally very well developed in comparison to codes in other physics areas. Instead of independently developing structural mechanics codes, ORNL integrates the capabilities of commercial structural mechanical solvers like ANSYS and Abaqus with other physics codes to solve multiphysics problems. ORNL also maintains a structural mechanics analysis capability in the commercial simulation framework COMSOL for application in multiphysics simulations, including flow-induced vibration. For HFIR's low-enriched uranium (LEU) conversion and experiment design, ORNL expertly applies the commercial ANSYS thermomechanics software.

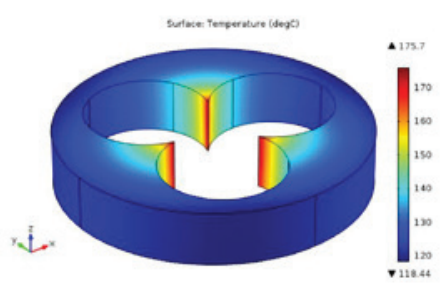

a. Aluminum housing

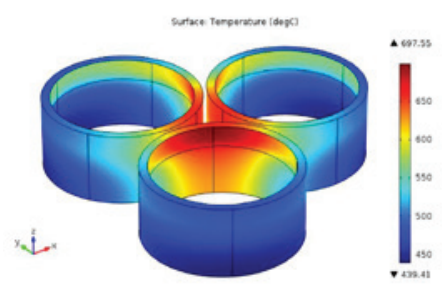

c. Vanadium holders

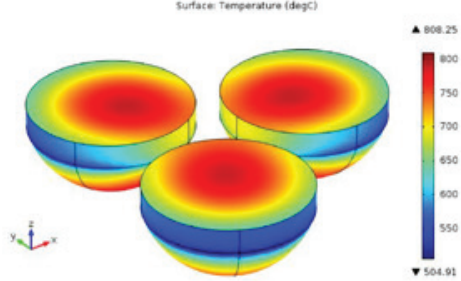

b. RuSe Specimens

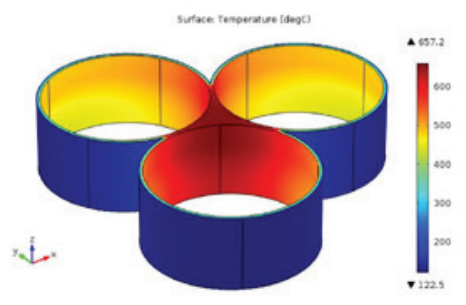

d. Helium ring region

Figure 21. COMSOL thermo-mechanics model to support irradiation of ruthenium selenide in HFIR.

\subsection{REACTOR CORE ANALYSIS}

Reactor core analysis at ORNL is performed using traditional core diffusion (SCALE, PARCS, NESTLE, SIMULATE) and high-fidelity software (VERA) to model the coupled physics environment of advanced, commercial, and research reactors. This includes application and coupling of the reactor neutronics, thermal-hydraulics, thermomechanics and fuels, and nuclear materials software. The analyses performed at ORNL include research related to:

- Understanding and predicting key challenges within the commercial nuclear industry, such as crud-induced power shift (CIPS) or risk of fuel failure during flexible power operation

- Design optimization of advanced reactor concepts

- Validation and confirmatory analysis of software and design changes for the NRC

- Quantification of safety parameters for use in accident analysis

\subsection{ACCIDENT ANALYSIS}

ORNL has recognized expertise in the development, extension, and validation of codes for the assessment of system thermal hydraulics, system dynamics, and reactor safety. TRANSFORM is uniquely suited for system dynamics analysis and instrumentation and control design. ORNL also evaluates and validates the NRC system analysis code TRACE for LWR applications and develops modified branches of the TRACE system analysis code for advanced reactor applications. ORNL also evaluates and validates the system safety analysis code RELAP5 for LWR and advanced reactor applications. ORNL maintains material property functions for a variety of reactor coolants and structural materials for use in these codes.

Through SCALE, ORNL also provides the NRC and the nuclear industry with the radionuclide inventories and decay heat generation rates for severe accident analysis, especially for interoperability with the MELCOR severe accident code. ORNL had a leading role in support of DOE and NRC in response to the Fukushima Daiichi incident. 

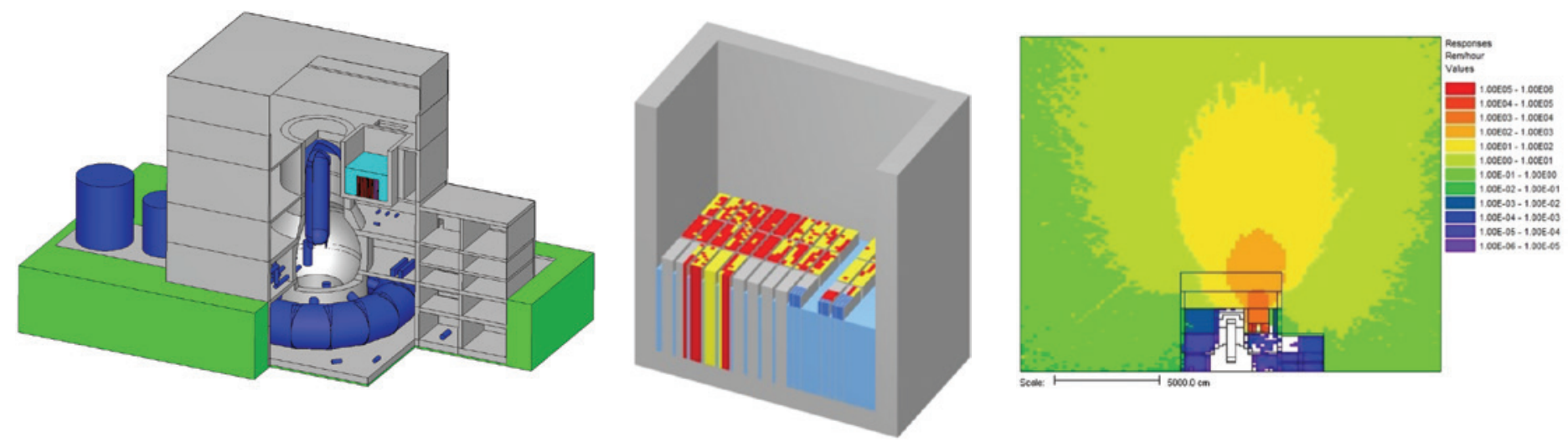

Figure 22. SCALE analysis of Fukushima Daiichi Unit 4 with plant model (left), assembly-specific radioactive source term quantification for spent fuel pool (center), dose rate from spent fuel (right).

\subsection{FUSION PLASMA PHYSICS AND FUSION NEUTRONICS}

ORNL provides analysis of a wide range of fusion phenomena supporting the domestic theoretical and experimental fusion energy program, as well as international collaborations, including ITER. The custom simulation capabilities described above are all used in these analysis activities, along with additional tools in which ORNL has expertise. These include the ADVANTG and Shift Monte Carlo transport codes, which are used in hardware activation analyses, as well as the SOLPS and EMC3-EIRENE plasma and neutral transport codes used to model the boundary plasma and design edge solution for future experiments. Various simulation capabilities are combined to provide integrated plasma prediction for the analysis, development, and optimization of operational scenarios for existing experimental facilities and for planning future fusion reactors.

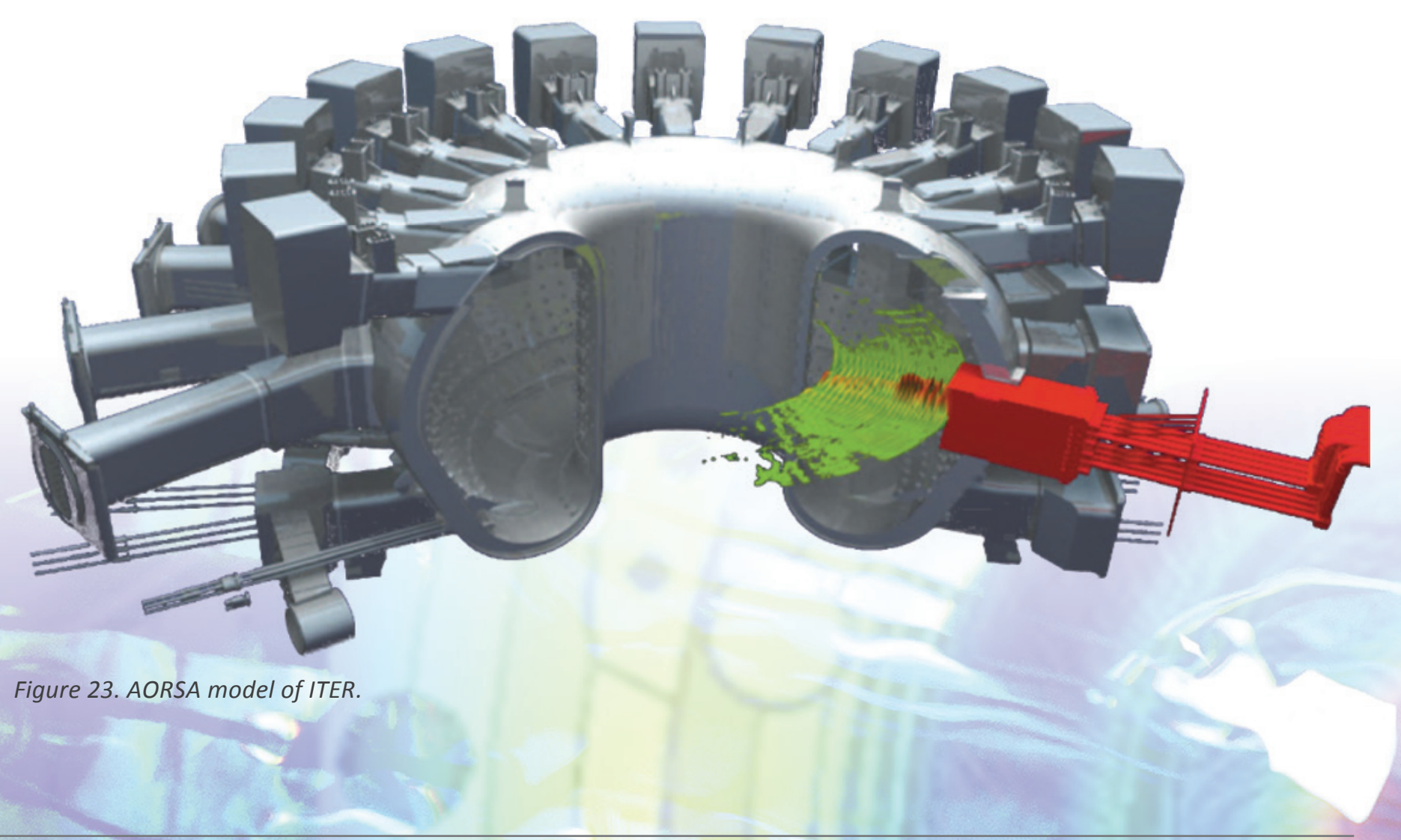




\subsection{NUCLEAR SAFEGUARDS AND SECURITY}

ORNL creates focused tools and provides detailed analysis and solutions on difficult emerging radiological questions for DOE, DoD, DHS, intelligence agencies, and the national security community using state-of-the-art modeling and simulations. Tools for nuclear security area are generally made available within select communities at the discretion of sponsoring agencies. These tools and analyses span a wide variety of applications, including the following:

- Material production and detection

- Nuclear chemical engineering

- Nuclear fuel safeguards modeling

- Nuclear forensics

- Nuclear weapon effects and fallout

- Radiation detection modeling

- Radiation transport applications

- Detector response modeling

- Statistical data sampling analysis

- Inverse analysis and modeling

\subsection{FUEL CYCLE ANALYSIS}

ORNL uses ORION, a systems dynamics fuel cycle code developed and maintained by the National Nuclear Laboratory (NNL) in the United Kingdom, to model fuel cycle scenarios. ORION can simulate the full range of nuclearrelated facilities, including storage facilities, fabrication and enrichment plants, reprocessing facilities, and reactors. A GUI allows the user to define these facilities and connect them to form a fuel cycle model. The code can track over 2,500 nuclides and can model decay and in-reactor irradiation. While ORION can track an extremely large number of nuclides, it can also follow a much simpler series of decay chains involving any number of nuclides or even idealized (lumped) material types (e.g., fission product, uranium, transuranic material). The simulations defined in ORION are time dependent, so the evolution of these quantities can be tracked over time, including transition time from one fuel cycle to another.

Cross sections used in ORION are generated using lattice physics models in SCALE. With recent ORION developments, direct coupling to SCALE/ORIGEN has been developed, and the ORIGEN application programming interface (API) has been integrated to provide flexibility during model development when the specifics regarding reactor operations and fresh fuel compositions are not fully known.

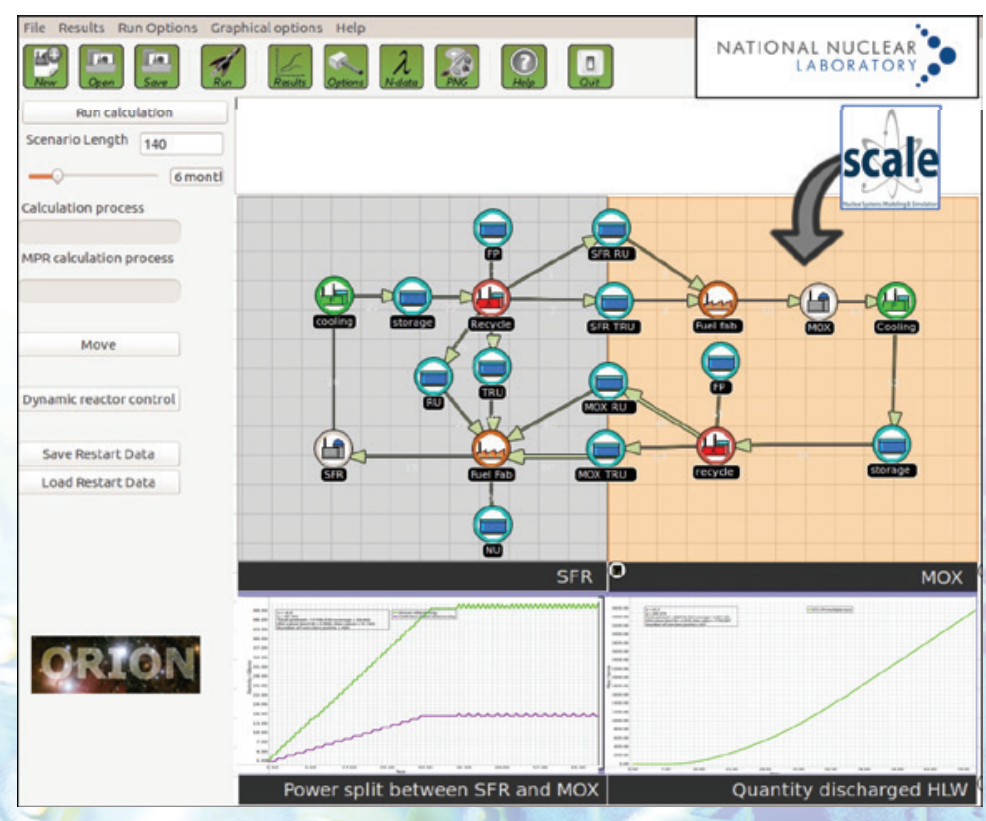

Figure 24. Fuel cycle analysis with ORION and SCALE. 
A dynamic reactor control functionality in ORION enables automated deployment of reactors based on various conditions such as fissile material in store, growth rate of nuclear energy, and commissioning or decommissioning profiles of reactors in the model. ORION can predict the availability of fissile material and assess which reactor type to build. The user can also set stream priorities to favor specific fissile material pathways into a reprocessing facility with various fractions of feed from different streams.

Finally, recent interest in modeling MSRs prompted an effort to include capabilities in ORION to simulate the continuous flow of material through MSRs, as recipes cannot be applied to analyze MSRs in ORION.

\subsection{NUCLEAR TRANSPORTATION AND STORAGE ANALYSIS}

Examination of materials irradiated in a reactor, specifically the used fuel, provides the basic data that serve as the building blocks upon which all future reactor, fuel cycle, and disposal facility designs, safety evaluations, models, reactor and fuel codes, and licensing bases will be based. This information is critically needed by industry vendors, the NRC, utilities, concerned stakeholders, and DOE to allow the programs currently active and those being planned to successfully move forward to completion. Many of the facilities, tests, and information necessary to support the development and licensing of new nuclear fuels are dependent on the same or similar post-irradiation examination (PIE) data required to support the spent fuel storage, transportation, and disposal programs.

By applying ORNL's combination of experience in modeling and simulation development, regulatory licensing support, hot cell capabilities, and PIE experience gained testing numerous types of spent nuclear fuel over several decades, we can synergistically provide the information needed to support new fuel development, spent fuel characterization, advanced reactor licensing, and modeling and simulation validation programs.
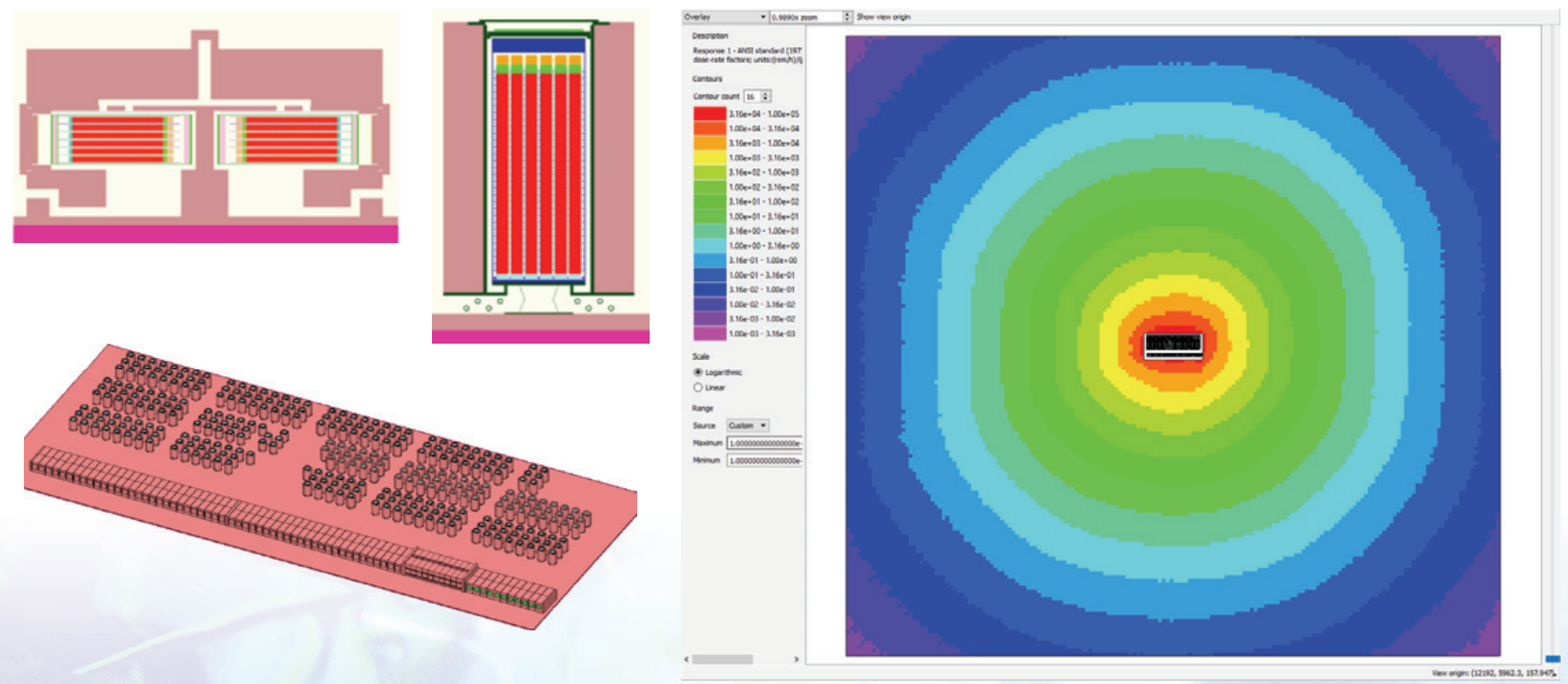

Figure 25. SCALE and UNF-ST\&DARDS model of Waste Control Specialists consolidated interim storage facility with 467 used fuel canisters on a concrete pad with dimensions of $250 \mathrm{~m} \times 100 \mathrm{~m}$ (bottom left), detailed geometry for horizontal and vertical packages where assembly-by-assembly radioactive source terms are provided (top left), and dose rate to the site boundary with overall dimensions of $2.7 \mathrm{~km} \times 2.5 \mathrm{~km}$ and a height of nearly $1 \mathrm{~km}$ (right). 


\subsection{PROBABILISTIC RISK ASSESSMENT}

ORNL has developed a time-dependent reliability analysis tool which is capable of evaluating simulation-based time-dependent component failure rates of risk-important components. The time-dependent rates act as inputs for PRA of complex dynamic systems, such as NHESs. Non-Markovian stochastic Petri nets (SPNs) are used for modeling and evaluation of complex dynamic subsystem interactions and their performance and reliability. The reliability model, coupled with the plant simulator using Modelica-based libraries such as TRANSFORM and the optimizer model in the Risk Analysis Virtue Environment (RAVEN), provides a method for analyzing the evolving performance of complex systems through life as a function of operational history.
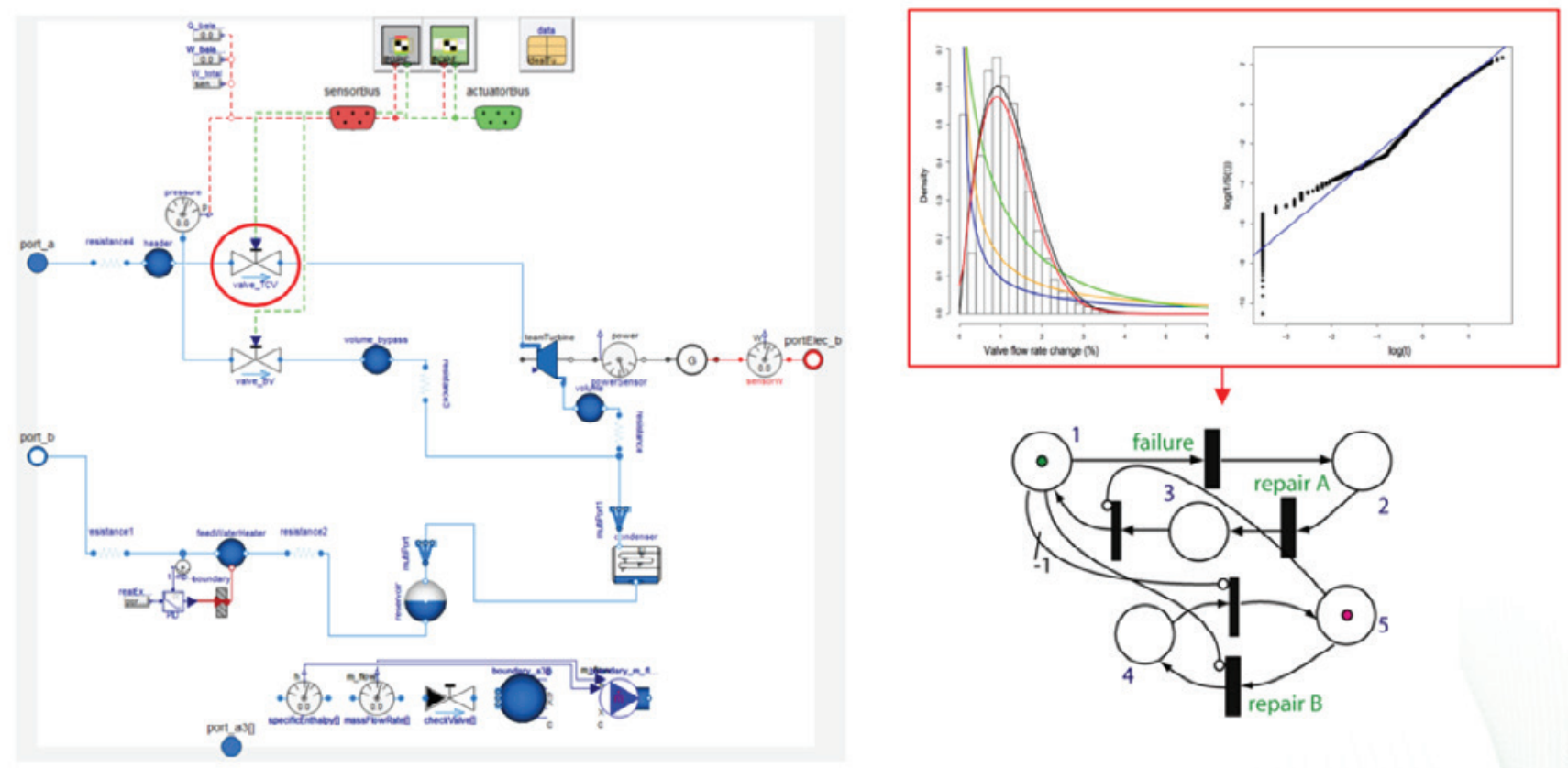

Figure 26. Dynamic PRA analysis of a component in an NHES (red circle), the calculated reliability data (red box), and its representation in the SPN subsystem model.

\subsection{HIGH-PERFORMANCE COMPUTING}

ORNL's OLCF provides large-scale nuclear engineering analysis. Almost all nuclear engineering simulations performed at OLCF have been accomplished using ORNL-designed applications such as Shift, Denovo, and VERA. Ongoing development activities for the Exascale Computing Project (ECP) provide unique tools capable of best utilizing emerging hardware enhancements on currently available hardware and beyond.

ORNL computing and computational sciences teams are leading initiatives to development applications for quantum computing, and opportunities exist to investigate algorithms that implement computational nuclear engineering approaches using this emerging hardware.

https://ornl.gov/onramp/analysis-expertise 


\subsection{WORKSHOPS AND TRAINING}

ORNL is a leader in providing workshops on today's most relevant topics, as well as hands-on training courses on production tools for a wide range of applications. We provide a modern conference facility that can accommodate over 200 participants and a state-of-the-art dedicated training venue especially designed for hands-on software courses.

\subsection{WORKSHOPS}

ORNL workshops attract the global community to a venue that encourages innovation and excitement in a place where so much nuclear history has evolved. Recent meeting series that are especially applicable to ONRAMP include:

- CASL Industry and Science Council: https://caslmeetings.ornl.gov/

- Molten Salt Reactor Workshop: https://msrworkshop.ornl.gov/

- NEAMS Integration Product Line and Nuclear Data and Benchmarking Program: https://neamsmeetings.ornl.gov/

- SCALE Users' Group Workshop: https://scalemeetings.ornl.gov/

Many workshops are planned for the future, and we

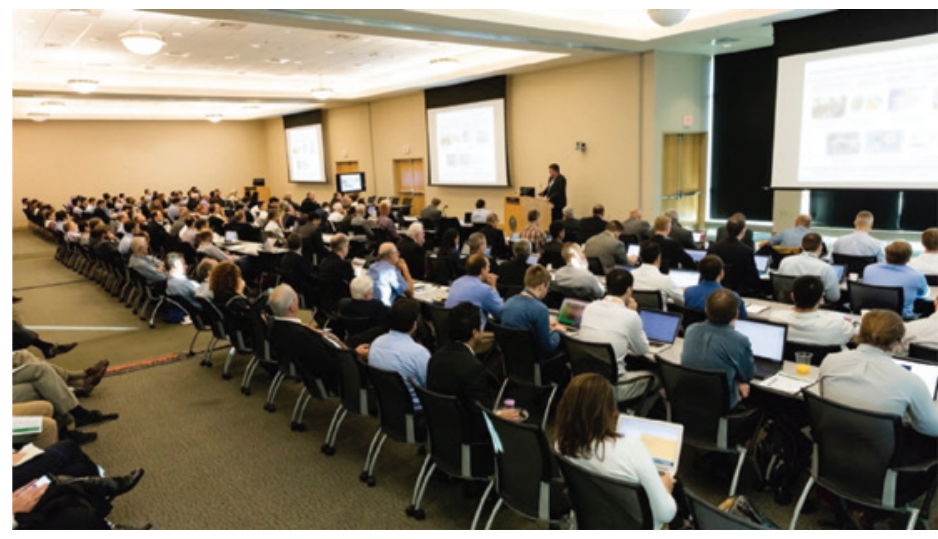

Figure 27. MSR Workshop in the ORNL Conference Center. welcome suggestions and partnerships for further opportunities.

Recurring workshops:

- CASL/VERA Users' Group (annual)

- MSR Workshop (annual)

- SCALE Users' Group (annual)

Possible future topics may include, but are not limited to:

- CFD community of practice (broader than nuclear)

- Experimental facilities, validation, and experiment design

- HPC in nuclear applications

- Hybrid variance reduction techniques

- Modeling and simulation for advanced reactors

- Modeling and simulation for fusion plasma physics and neutronics

- Modeling and simulation for neutron science facilities

- Modeling and simulation for research reactors 
- Nuclear data needs and opportunities

- Nuclear security modeling

- Sensitivity analysis and uncertainty quantification

Currently planned workshops are provided online at https://ornl.gov/onramp/workshops-training

\subsection{TRAINING}

Training is provided by developers and expert users from our teams, with current courses offered to address a variety of technical areas including but not limited to the following:

- Nuclear criticality safety

- LWR and advanced reactor modeling

- Reactor safety analysis

- Radiation shielding

- Spent nuclear fuel characterization for transportation/storage package designs, decommissioning and disposal

- Verification, validation, and uncertainty quantification

- Nuclear safeguards and security applications

- Nuclear data processing and libraries generation

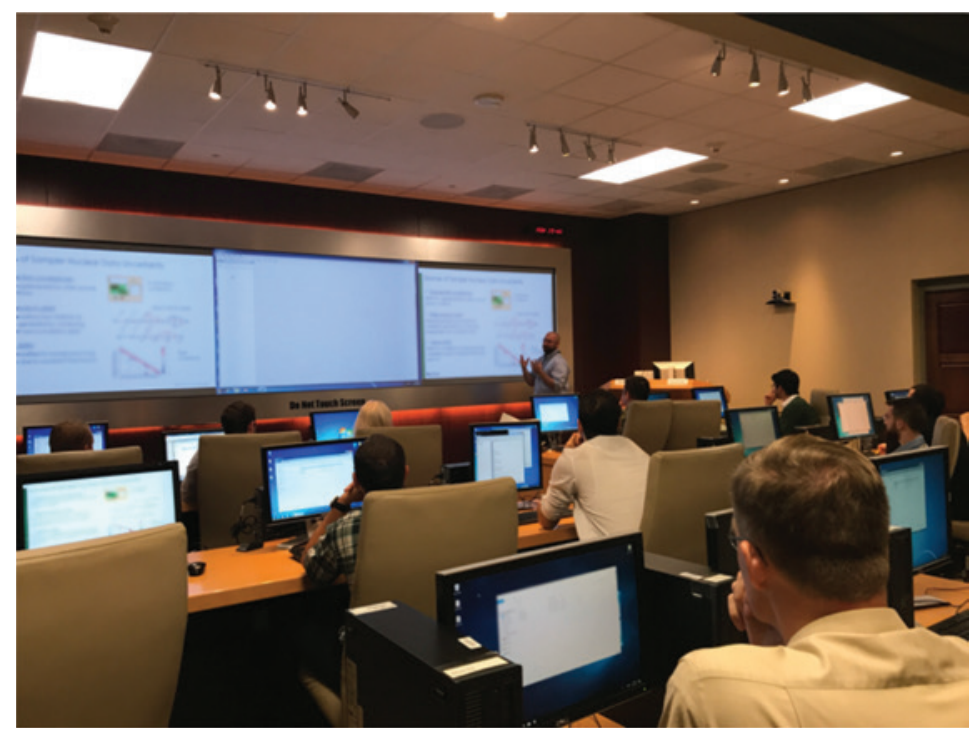

Figure 28. SCALE training course in the ORNL VOCC facility.

Additionally, many related workshops are presented at conferences and universities.

We are growing our public training offerings to cover a wider range of application areas and to include more computational tools. In 2019, we will offer new courses on (1) ADVANTG, which is developed and maintained by ORNL, (2) VERA, which is developed through an ORNL-led collaboration of many partners in academia, industry, and the national laboratory system as part of a larger effort under CASL, (3) the Nuclear Data Fundamentals and AMPX Libraries Generation Course, and (4) System-coupled Multiphysics CFD for Nuclear Analysis.

Current course offerings are listed online at https://ornl.gov/onramp/workshops-training 


\subsection{COMPUTING RESOURCES}

ORNL operates the ORNL Leadership Class Computing Facility (OLCF), one of DOE's Advanced Scientific Computing Research (ASCR) facilities (https://science.energy.gov/ascr/facilities). OLCF is the home of the world's past and present fastest super computers. Although these machines are not often required for routine calculations, the expertise of teams who are successfully awarded machine allocations will be leveraged in developing software and performing calculations on these leadership class machines.

\subsection{COMMODITY CLUSTERS FOR PRODUCTION CALCULATIONS}

ORNL has a large inventory of computer hardware that is actively managed. A subset of hardware accessible to projects with appropriate export control and IP environments for production-quality computational analysis is provided to ONRAMP users with over $13 \mathrm{~K} \mathrm{CPU}$ cores and 50 TB RAM.

Dedicated computer clusters can be procured and maintained at ORNL for projects so that work can proceed at the highest priority and sufficient computing capacity will be available for design iterations.

\subsection{SECURE CLOUD COMPUTING}

Access to industry-class computers using a secure access protocol is available to ensure that the requirements of nuclear export control are satisfied. This provision is through RSICC and its International Secure Platform for Export-Controlled Computing Tools (InSPECT) capability and application-specific cloud license. The cloud license allows users to submit analysis to ORNL's industryclass computing resource without having access to the application (SCALE, MCNP ${ }^{\circledR}$, RELAP-5, etc.) executables or source code. This provides ONRAMP users with the fastest access to configuration- and export-controlled tools and analysis capabilities.

\subsection{CADES}

ORNL's Compute and Data Environment for Science (CADES) provides eligible customers with an OpenStack cloud computing solution with customizable virtual machines (VMs). This resource, called CADES Cloud, enables customers to leverage self-service portals to rapidly request these VMs for production, testing, and development.

https://cades.ornl.gov/

https://ornl.gov/onramp/computing-resources

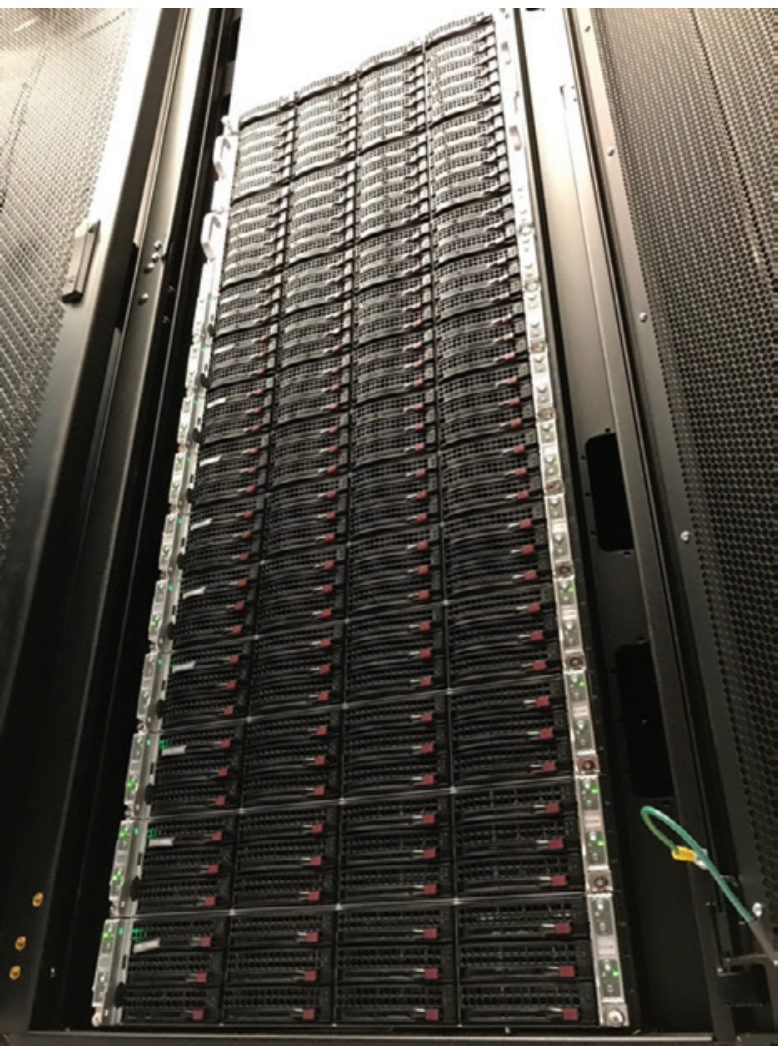

Figure 29. ORNL commodity computing cluster Apollo.

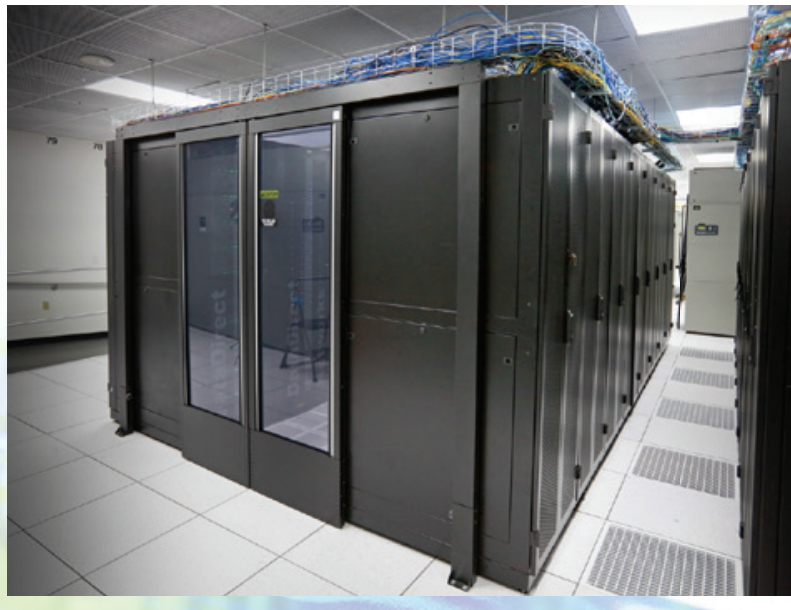

Figure 30. CADES computing condo. 


\subsection{VALIDATION}

Validation is the characterization of the suitability of a selected mathematical model and data to correctly predict and describe real-world physical phenomena. This places validation at the intersection of modeling, simulation, and experimental methods. ORNL has broad validation experience, including the collection and qualification of experimental validation data, leadership in international benchmark handbooks, development of problem-specific validation criteria, as well as comparison and visualization of large data sets.

ORNL experts participate in numerous international standards organizations, OECD/NEA, and IAEA expert groups, and other bodies that define validation standards and develop international benchmark databases. Our experts are available to partner with you to improve the validation basis for your tools in your application domains.
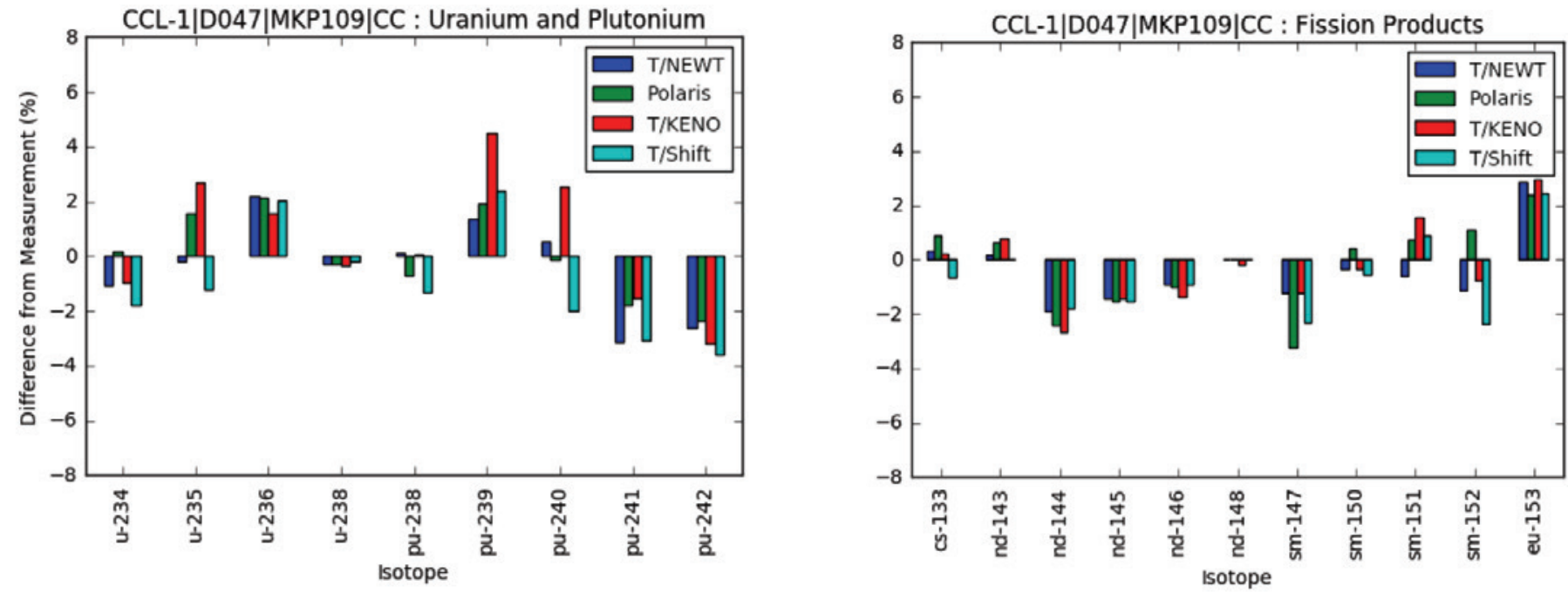

Figure 31. Validation of SCALE reactor depletion isotopics results using the multi-cycle depletion and PIE data from SFCOMPO.

Because of their origins as NRC and industry licensing tools, ONRAMP neutronics tools such as SCALE and VERA are built on a robust validation basis. For SCALE, continuous-energy and multigroup neutronics data and tools are validated against 600 nuclear criticality experiments from the International Criticality Safety Benchmark Evaluation Project (ICSBEP) and the International Reactor Physics Benchmark Evaluation Project (IRPhEP). The validation suite itself is maintained under a quality assurance and configuration management program known as the Verified, Archived Library of Inputs and Data (VALID). Burnup calculations are validated on a nuclide-specific basis, with over 100 post irradiation examination measurements of commercial reactor fuel from the Spent Fuel Composition (SFCOMPO) database. Decay heat calculations are validated against another suite of over 100 commercial reactor spent fuel assemblies whose heat generation rates were measured at the Swedish Central Interim Spent Fuel Storage Facility (Clab) assembly calorimeter. For short-term calculations of decay heat, burst fission measurement data experiments are used for validation.

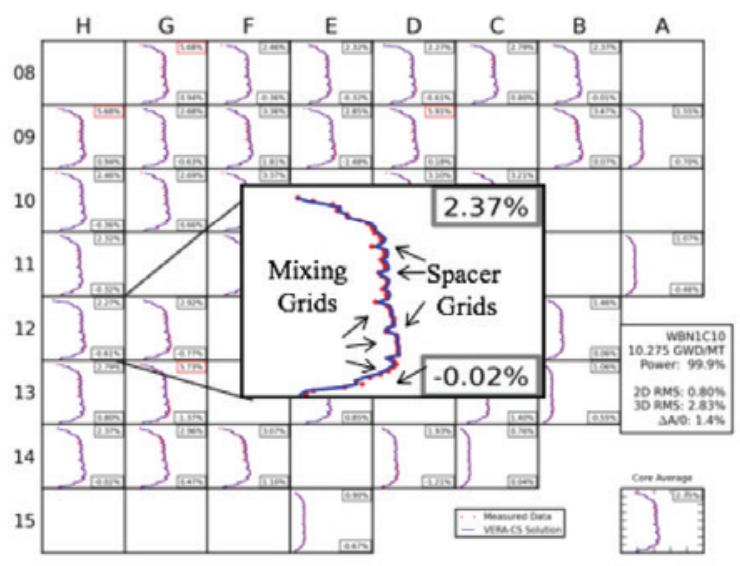

Figure 32. VERA validation with in-core flux map data. 
The TSUNAMI S/U tools of SCALE are specifically designed to support advanced neutronics validation approaches and are routinely applied to quantify important aspects of application systems for validation, to identify the best available experimental data to apply, to combine experimental data from many sources to build a cumulative validation basis, and where validation gaps exist, to assign an appropriate safety margin or design a new, optimized experiment that could fill this gap in the future.

The VERA tools that implement the same nuclear data and physics foundations as SCALE build upon these validated results to create extended multiphysics capabilities. For validation of the integrated reactor analysis capabilities of VERA, data from operating power plants are applied, including startup criticality tests, boron letdown data, and detailed in-core flux maps. VERA has been validated with data from 16 reactors with over 100 operating cycles.

\subsection{EXPERIMENT DESIGN AND OPERATION}

ORNL has decades of experience in nuclear experimentation and irradiation testing, as well as supporting a robust network of the users of our neutron experimental facilities (HFIR and Spallation Neutron Source [SNS]). This makes ORNL an experienced leader in the design and execution of nuclear materials testing and experimentation. By leveraging our expertise in the integration of design, modeling and simulation, fabrication, testing, qualification, irradiation, and interrogation, we can customize solutions to meet the unique needs of our ONRAMP partners.

Our production and custom-developed tools provide validated models for simulation and optimization of experiments to best meet targeted needs within resource availability.

\subsection{IRRADIATION EXPERIMENTS}

ORNL irradiation testing capabilities combine thermal, fluid, and structural analysis methods with sophisticated experimental techniques to develop effective solutions for evaluation and optimization of material performance in radiation environments. ORNL provides comprehensive support for design, planning, scaling and similarity analysis, instrumentation development execution, data analysis, closure model development, and high-fidelity simulation.

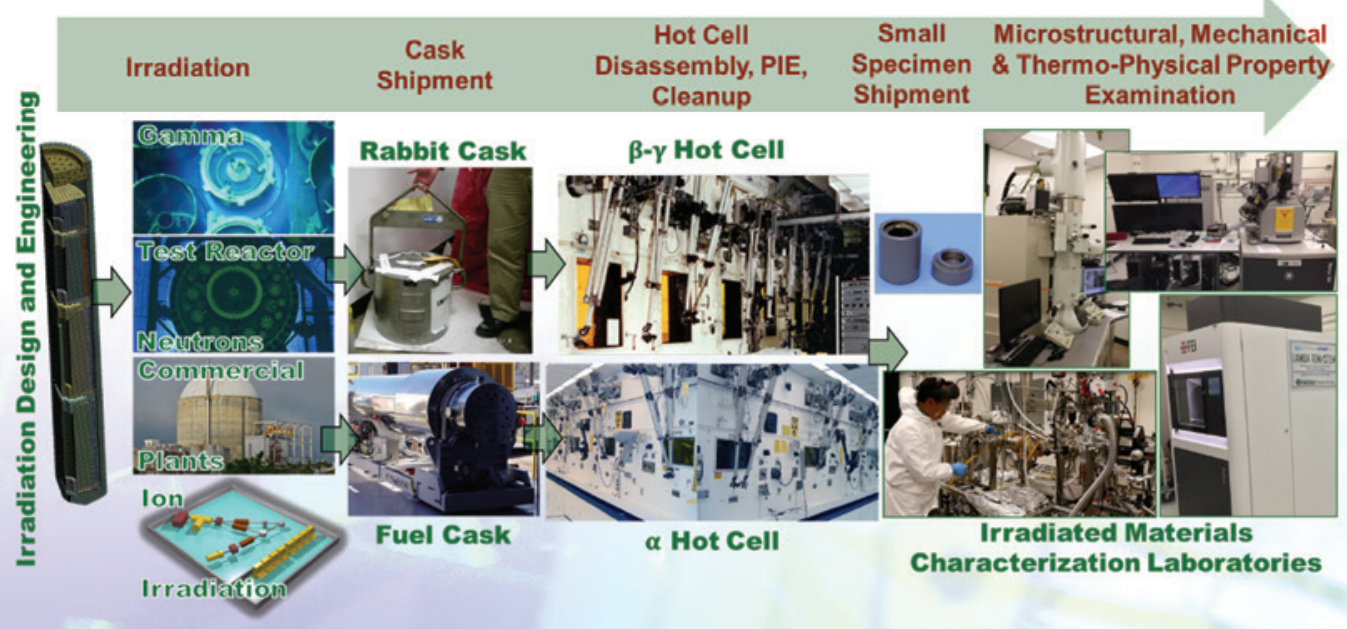

Figure 33. ORNL provides comprehensive support for evaluation and optimization of material performance in irradiation environments.

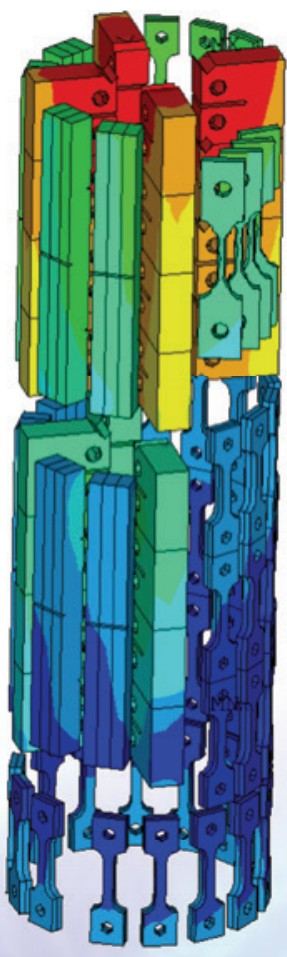

Figure 34. Computational model of an irradiation experiment capsule. 


\begin{tabular}{|c|c|c|}
\hline \multirow{11}{*}{$\begin{array}{l}\text { Fuels and } \\
\text { Materials } \\
\text { Irradiation }\end{array}$} & Facility & Description \\
\hline & $\begin{array}{l}\text { High Flux Isotope Reactor } \\
\qquad \text { (HFIR) }\end{array}$ & $\begin{array}{l}\text { A versatile } 85-\mathrm{MW} \text { isotope production, research, and test reactor with } \\
\text { the capability and facilities for performing a wide variety of irradiation } \\
\text { experiments and a world-class neutron scattering science program. HFIR } \\
\text { is a beryllium-reflected light water-cooled and moderated flux-trap type } \\
\text { swimming pool reactor that uses highly enriched }{ }^{235} \mathrm{U} \text { as fuel. HFIR typically } \\
\text { operates seven } 23-27 \text {-day cycles per year. }\end{array}$ \\
\hline & HFIR Gamma Irradiation Facility & Provides high gamma doses for studying the effects of radiation on materials \\
\hline & $\begin{array}{l}\text { HFIR Neutron Activation } \\
\text { Analysis (NAA) Laboratory }\end{array}$ & $\begin{array}{l}\text { Provides an inexpensive, precise, accurate screening of samples for fissile } \\
\text { material content to support forensic science, environmental research and } \\
\text { materials research }\end{array}$ \\
\hline & $\begin{array}{l}\text { Materials Irradiation Facility at } \\
\text { HFIR }\end{array}$ & $\begin{array}{l}\text { Unique facility that can host fully instrumented experiments in a } \\
\text { high-neutron-flux environment with the advantage of monitoring and } \\
\text { acquiring in situ data and changing capsule operating conditions in real } \\
\text { time during irradiation, thus enabling measurement of a variety of material } \\
\text { properties such as conductivity and fission product composition }\end{array}$ \\
\hline & $\begin{array}{l}\text { Thermosyphon Irradiation } \\
\text { Facility (concept tested out of } \\
\text { pile) }\end{array}$ & $\begin{array}{l}\text { Provides hydraulic isolation, allows fuel/clad irradiation testing under } \\
\text { prototypic LWR conditions, offers irradiation in a high heat secondary } \\
\text { coolant without contaminating the HFIR primary coolant }\end{array}$ \\
\hline & $\begin{array}{l}\text { Irradiated Materials } \\
\text { Examination and Testing } \\
\text { Facility (IMET) }\end{array}$ & $\begin{array}{l}\text { Includes } 6 \text { well-equipped hot cells providing physical and mechanical } \\
\text { properties testing, examination of irradiated materials, irradiated specimen } \\
\text { storage and sample preparation }\end{array}$ \\
\hline & $\begin{array}{l}\text { Irradiated Fuels Examination } \\
\text { Laboratory (IFEL) }\end{array}$ & $\begin{array}{l}\text { A Category } 2 \text { nuclear facility with } 6 \text { hot cells that permit the safe handling } \\
\text { of increased levels of radiation in the chemical, physical, and metallurgical } \\
\text { examination of nuclear reactor parts by providing nondestructive and } \\
\text { destructive testing capabilities }\end{array}$ \\
\hline & $\begin{array}{l}\text { Low Activation Materials } \\
\text { Development and Analysis } \\
\text { Laboratory (LAMDA) }\end{array}$ & $\begin{array}{l}\text { Provides post irradiation examination capabilities utilizing small, compact } \\
\text { samples; allows researchers to leverage cutting-edge microstructural } \\
\text { characterization and test equipment to study materials phenomenon } \\
\text { not possible at a hot cell }\end{array}$ \\
\hline & & $\begin{array}{l}\text { Multipurpose radiochemical processing and research facility that includes } \\
\text { laboratories, glove boxes, and }\end{array}$ \\
\hline & $\begin{array}{l}\text { The Radiochemical Engineering } \\
\text { Development Center (REDC) }\end{array}$ & $\begin{array}{l}\text { Heavily shielded hot cells; includes personnel with radiochemical processing } \\
\text { expertise and special equipment and systems to support the nation's } \\
\text { R\&D needs in the production of unique radionuclides for use in research, } \\
\text { defense, medical, and industrial applications }\end{array}$ \\
\hline
\end{tabular}

Table 2. ORNL irradiation experiment facilities and capabilities 


\subsection{THERMAL HYDRAULICS EXPERIMENTS}

ORNL designs, builds and operates a wide range of thermal hydraulics experiments for (1) evaluation and optimization of fluid flow and heat transfer systems and for (2) validation of associated analysis software for light water fission reactor, advanced fission reactor, accelerator facility and nuclear fusion system technologies. These tests support development and operation of ORNL's own operating nuclear facilities such as SNS, facilities outside ORNL such as ITER, as well as development of next-generation systems such as FHRs and MSRs. ORNL provides comprehensive support for design, planning, scaling/similarity analysis, instrumentation development, execution, data analysis, closure model development and high-fidelity simulation.

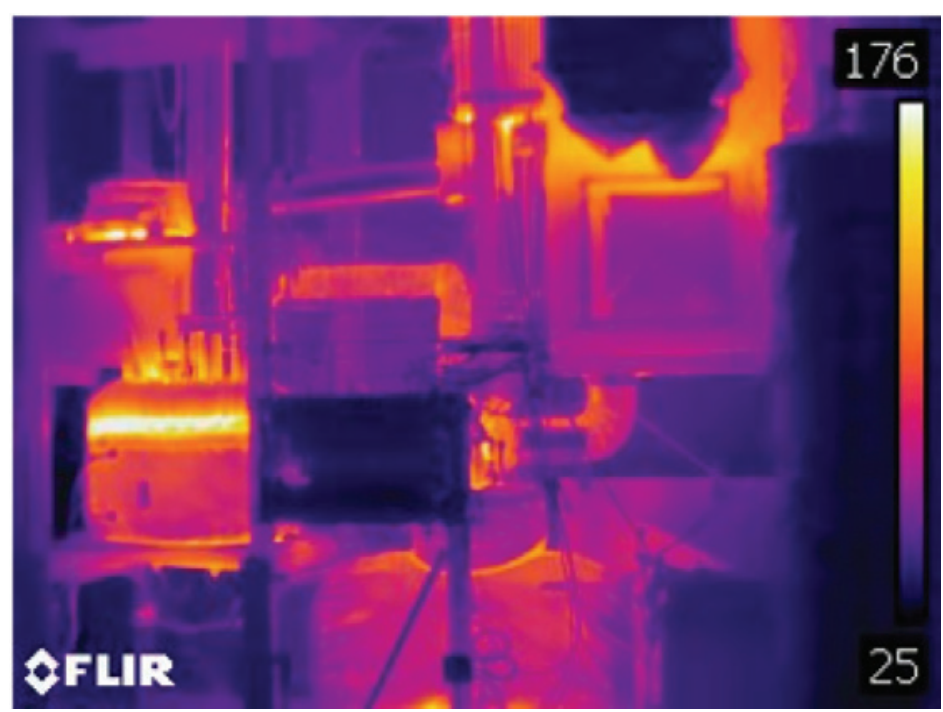

Figure 35. Temperature profile of ORNL's FHR Liquid Salt Test Loop (LSTL).

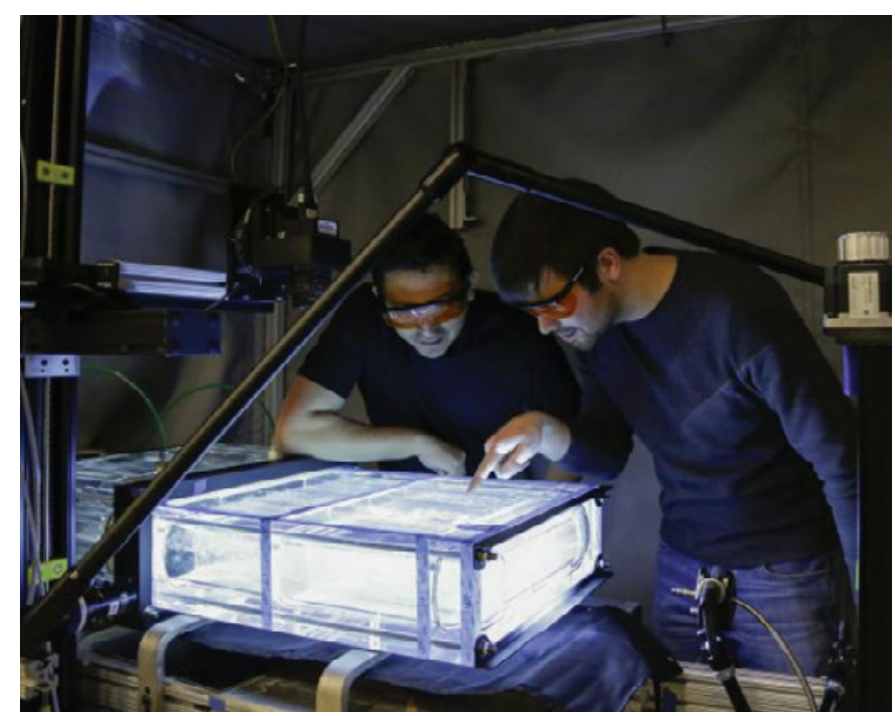

Figure 36. Flow visualization and application of PIV and PLIF to measure velocity distributions inside an SNS target

\begin{tabular}{|c|c|c|}
\hline \multirow{4}{*}{$\begin{array}{l}\text { Thermal } \\
\text { hydraulics }\end{array}$} & Facility/Capability & Description \\
\hline & $\begin{array}{l}\text { Water Thermal Hydraulics Loop } \\
\text { (WTHL) }\end{array}$ & $\begin{array}{l}\text { Low-pressure multipurpose water loop with the capability to perform } \\
\text { particle image velocimetry (PIV) diagnostics on the SNS target test } \\
\text { facility, to test ultrasonic flow meters in metallic pipe lines, to test } \\
\text { various nozzle designs for a concave wall gas injection system, and to } \\
\text { test pressure drop for various irradiation capsules designs }\end{array}$ \\
\hline & Thermosyphon Test Loop (TSTL) & $\begin{array}{l}\text { Natural convection water loop for boiling and condensation testing at } \\
\text { typical boiling water reactor (BWR) or PWR temperatures and pressures; } \\
\text { includes test section design for custom heater configurations; nominal } \\
\text { fuel rods are simulated by three } 0.5 \mathrm{~m} \text { long rods of standard outer } \\
\text { diameter with electric heaters designed to produce a total of } 80 \mathrm{~kW} \\
(53 \mathrm{~kW} / \mathrm{m} \text {, or } 16 \mathrm{~kW} / \mathrm{ft} \text {, per rod) }\end{array}$ \\
\hline & Liquid Salt Test Loop (LSTL) & $\begin{array}{l}\text { A versatile facility for the development and demonstration of } \\
\text { high-temperature fluoride-salt technology. Operates at up to } \\
700^{\circ} \mathrm{C} \text { with a range of instrumentation and control options. Provides } \\
\text { infrastructure to deliver up to } 250 \mathrm{~kW} \text { of heating power through } \\
\text { a nonintrusive, inductive heating technique that can be used for } \\
\text { thermal/fluid experimentation, to measure heat transfer characteristics } \\
\text { in molten salt-cooled structures such as pebble beds, and to } \\
\text { demonstrate the use of } \mathrm{SiC} \text { as a structural material for use in molten } \\
\text { salt systems }\end{array}$ \\
\hline
\end{tabular}


Facility/Capability

FLiNaK salt purification system

FLiBe salt purification system

Liquid metal test loop supporting the Target Test Facility (TTF)

Ultra-high pressure testing

Artificial sun

Thermal

hydraulics

Reactive flows

Laser diagnostics and measurements

Advanced Instrumentation

\section{Description}

Provides clean salt to be used for research activities by removing water, oxygen and impurities; large-scale system capable of cleaning $160 \mathrm{~kg}$ batches of fluoride salts

Provides clean salt to be used for research activities by removing water, oxygen, and sulfur; can accommodate up to $6 \mathrm{~kg}$ of salt powder/ up to 3.2 $\mathrm{L}$ of liquid FLiBe salt in one batch

Liquid metal loop with an inventory of $20,000 \mathrm{~kg}$ of mercury and maximum flow rate of $600 \mathrm{gpm}$; the low Pr number fluid loop provides infrastructure for heat transfer experiments, two-phase flow $\mathrm{He}-\mathrm{Hg}$, instrumentation, surface wettability, natural convection, heat exchangers, among others

Facilities for testing materials under very high pressure; typical experiments are performed under GPa constant pressures

High-density infrared processing, shown to be a cost effective technique for rapid, clean, and non-contact high-temperature processing of materials; facility provides up to $750 \mathrm{~kW}$ of power; current applications include processing of refractory materials for fusing and claddings

Several ORNL facilities designed to evaluate and optimize processes involving reactive flows such as the Roll-to-Roll (R2R) facility for coating of gas diffusion media, providing infrastructure that can be leveraged for custom solutions to reactive flow problems

Validation and verification of CFD codes for engineering problems can be performed by comparing full field measurements, modeling transport species (momentum, mass, energy) using LASER-based diagnostics that provide nonintrusive measurements with high spatial and temporal resolution; PIV and Planar Laser Induced Fluorescence (PLIF) provide simultaneous nonintrusive full-field velocity and temperature measurements, where conventional measurement techniques are usually intrusive and provide single-point readings; visualization of the phenomena provides insight about the problem at hand, and mechanistic models can be improved based on measured quantities

ORNL-developed custom instrumentation solutions for measurement of flow, temperature, and structural data in extreme environments; available facilities to support instrument qualification and calibration in high-temperature molten salt systems and other challenging environments

Table 3. ORNL thermal hydraulics experiment facilities and capabilities 


\subsection{NUCLEAR DATA MEASUREMENTS}

Many new nuclear data needs are emerging in areas where data are poorly quantified, especially for advanced reactors, isotope production, and nuclear security applications. With limited science facilities remaining for nuclear data measurements, ORNL teams work broadly throughout the community to utilize the best-available facilities for the targeted need. When coupled with our nuclear data evaluation and process capabilities and modeling and simulation tools for validation, high-quality nuclear data evaluations with associated uncertainties can be generated to improve previous results or to close gaps in nuclear data to address new needs. Through the application of SCALE's S/U tools, nuclear data needs are identified and prioritized to maximize the limited resources available to improve nuclear data libraries.

\subsection{NUCLEAR CRITICALITY EXPERIMENTS}

Nuclear criticality experiments are the fundamental validation basis for radiation transport, criticality safety, and reactor dynamics simulation tools. The ORNL team supports the development, review, archival documentation, and use of nuclear criticality experiments around the globe. SCALE's S/U capabilities are applied in the design of optimized criticality experiments at US and international facilities to best meet targeted validation needs with the most efficient use of resources. This work is primarily performed in support of the US DOE Nuclear Criticality Safety Program.

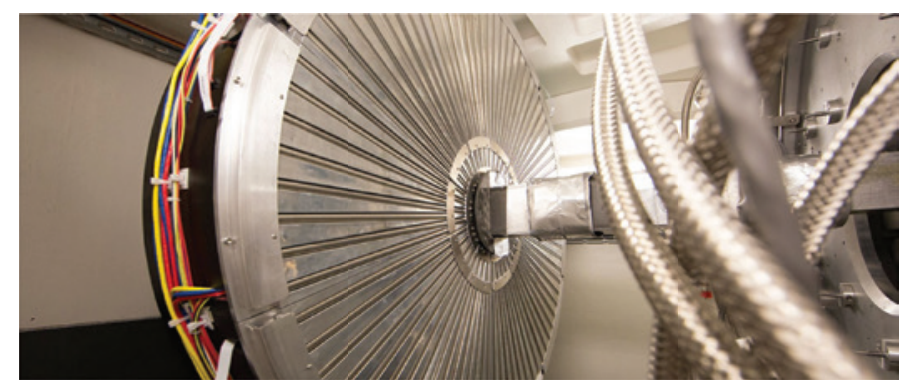

Figure 37. VISION vibrational spectrometer instrument at the ORNL's SNS.

\begin{tabular}{|c|c|c|}
\hline \multirow{5}{*}{$\begin{array}{l}\text { Nuclear } \\
\text { data }\end{array}$} & Facility/Capability & Description \\
\hline & SNS Thermal Scattering & $\begin{array}{l}\text { Temperature-dependent thermal neutron scattering measurements } \\
\text { and models on reactor materials and other materials using the VISION } \\
\text { vibrational spectrometer instrument }\end{array}$ \\
\hline & HFIR irradiations & $\begin{array}{l}\text { Integral cross sections of short-lived, rare, and/or low cross section } \\
\text { isotopes using irradiation capsules with PIE at ORNL's REDC }\end{array}$ \\
\hline & $\begin{array}{l}\text { Joint Research Center, } \\
\text { IRMM, Geel, Belgium }\end{array}$ & $\begin{array}{l}\text { The neutron time-of-flight facility, Geel Linear Electron Accelerator } \\
\text { (GELINA) is based on an electron linear accelerator (LINAC) which } \\
\text { provides a pulsed electron beam that impinges on a rotating uranium } \\
\text { target cooled by liquid mercury. The Bremsstrahlung induced in the } \\
\text { uranium target by the electron beam produces neutrons that are used } \\
\text { for neutron scattering measurements. ORNL uses both elemental and } \\
\text { isotopic samples to perform nuclear data measurements. The resulting } \\
\text { experimental data are used to generate nuclear data evaluations using } \\
\text { the SAMMY R matrix code and ultimately the neutron cross sections } \\
\text { for radiation transport code use. }\end{array}$ \\
\hline & $\begin{array}{l}\text { Rensselaer Polytechnic Institute, } \\
\text { Gaerttner LINAC Laboratory }\end{array}$ & $\begin{array}{l}\text { This lab and LINAC were designed and built to perform time-of- } \\
\text { flight measurements in the thermal-to-MeV neutron energy range. } \\
\text { ORNL performs differential neutron scattering measurements in the } \\
\text { resonance region and uses the SAMMY R-matrix code to perform } \\
\text { nuclear data evaluations that are used to generate neutron cross } \\
\text { sections for radiation transport code use. }\end{array}$ \\
\hline
\end{tabular}

Table 4. Nuclear data facilities and capabilities utilized by ORNL teams 

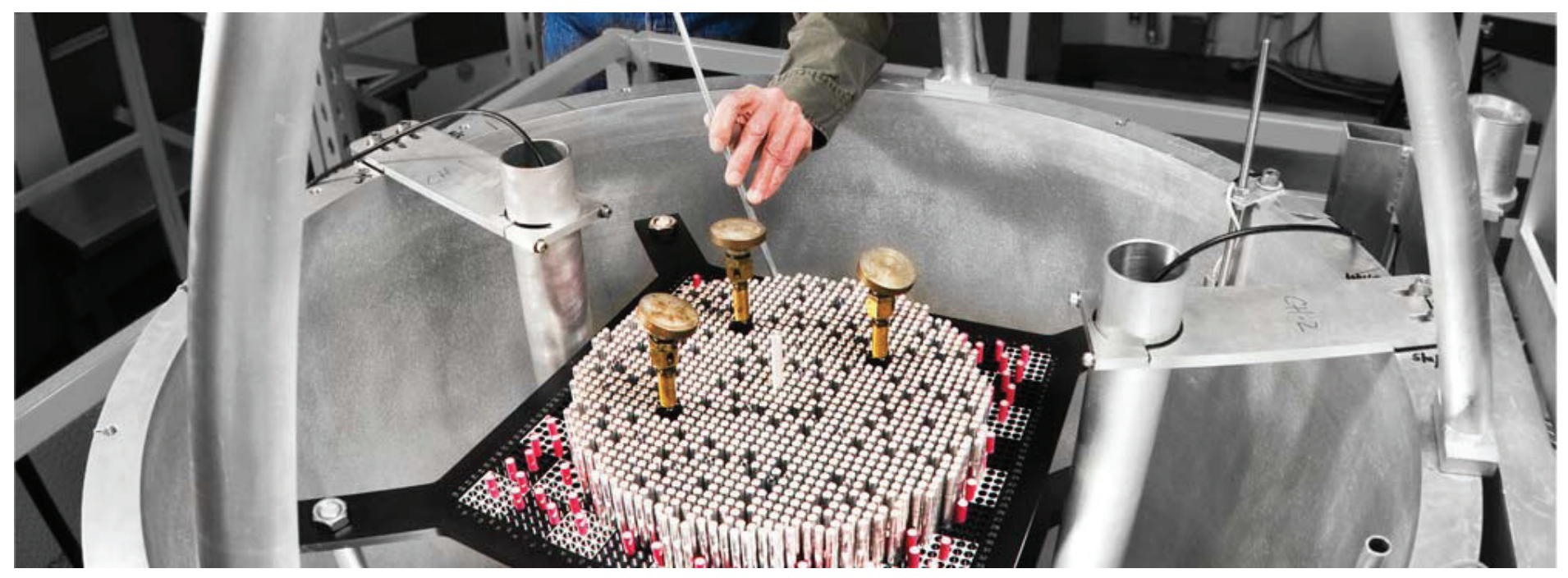

Figure 38. Nuclear criticality experiment at SPR/CS.

\subsection{FUSION EXPERIMENTAL CAPABILITIES}

Experimental validation of modeling and simulation for fusion systems is often limited by the available facilities and their unique diagnostic measurement capabilities. At the same time, each magnetic confinement device has a range of engineering parameters that must be configured to execute experiments including heating power, plasma density, and magnetic field strength. Often it is not straightforward to design an experiment in which the outcome is unambiguous and sufficiently quantifiable to validate or falsify modeling and simulation predictions. ORNL has decades of experience in partnering to perform domestic and international fusion energy experiments, including linear plasma devices, tokamaks, and spherical tori and stellarators. ORNL maintains staff members at many of these facilities. In addition, our team includes recognized experts in fusion measurement science, including active and passive plasma spectroscopy, laser-plasma diagnostics and diagnostics to characterize power exhaust, and particle control such neutral pressure measurements, infrared surface thermography, and bolometry. Our team can help plan a strategy for experimental validation and can examine any needs for new measurement or analysis tools that may require specially tailoring.

\section{https://ornl.gov/onramp/experiment-design-operation}

\begin{tabular}{|c|c|c|}
\hline \multirow{3}{*}{$\begin{array}{l}\text { Nuclear } \\
\text { criticality } \\
\text { experiments }\end{array}$} & Facility & Description \\
\hline & $\begin{array}{l}\text { National Criticality Experiment } \\
\text { Research Center (NCERC) }\end{array}$ & $\begin{array}{l}\text { NCERC performs integral experiments with the Godiva, Comet, } \\
\text { Flattop, and Planet critical assemblies. Experiments involve subcritical, } \\
\text { delayed critical, and prompt supercritical experiments with a variety } \\
\text { of fissionable and nonfissionable materials. Many integral experiments } \\
\text { are used for nuclear data verification activities and radiation transport } \\
\text { code validation to support nuclear criticality safety and other } \\
\text { applications. }\end{array}$ \\
\hline & Sandia National Laboratories & $\begin{array}{l}\text { Sandia performs integral experiments with the SPR/CS critical } \\
\text { assembly. Experiments involve delayed critical experiments with } \\
\text { LEU fuel pins. Most integral experiments are used for nuclear data } \\
\text { verification activities and radiation transport code validation to } \\
\text { support Nuclear Criticality Safety and other applications. }\end{array}$ \\
\hline
\end{tabular}

Table 5. Nuclear criticality safety experiment facilities supported by ORNL teams 


\subsection{FACILITY OPERATION SUPPORT}

ORNL is a global leader in neutron sciences and operates two of the world's most powerful neutron sources. HFIR provides one of the highest steady-state neutron fluxes of any research reactor in the world and is used for cold and thermal neutron scattering, isotope production, materials irradiation, and neutron activation analysis. SNS is an accelerator-based system that provides an intense source of neutrons to world-class instruments for neutron scattering applications. In concert with supplementary ORNL world-leading research facilities and modeling and simulation expertise, HFIR and SNS provide a diverse set of tools and expertise needed for neutron-based experiments across a wide range of scientific and engineering disciplines.

\section{https://neutrons.ornl.gov/hfir}

https://neutrons.ornl.gov/sns

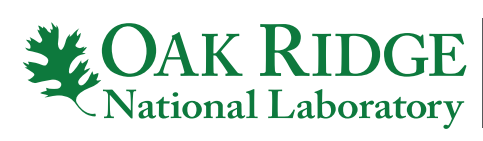

HIGH FLUX ISOTOPE REACTOR
SPALLATION NEUTRON SOURCE

Safe, reliable operation of a nuclear facility requires facility-specific modeling and analysis tools and expertise. Nuclear modeling and analysis tools are used for many facility needs, including but not limited to establishing, maintaining, and implementing the safety basis; redesigning components; designing, optimizing, and qualifying experiments; and upgrading instruments. Nuclear facilities must adhere to SQA requirements as a means of preventing defects or mistakes when delivering software to a customer. A configuration-controlled process is required to ensure that the computing software and hardware utilized are appropriately pedigreed. The rigor of SQA required is often dictated by the facility's regulatory body, the facility's hazard category level, the software categorization (i.e., safety, research, general software), the software grading level, and the software type (i.e., commercial off the shelf, custom developed).

Software verification is always performed during the SQA process to confirm that the code is working as intended by the original code developers. This typically consists of executing a set of developer-supplied inputs and comparing the results with known solutions. Validation is performed during or after the SQA process to compare calculation results to operating data, experiments, tests, or analytical data to confirm that the code solutions are simulating the phenomena to a reasonable degree of accuracy. Validating methods such as software, models, assumptions, and data are important to ensure that each method is accurate within the facility's operating conditions and to establish any potential biases.

Nuclear facilities require established production tools (i.e., for neutron and gamma transport, depletion, thermalhydraulics, transient analysis) such as those discussed in the "Production Tools" section above for safety-basis and research needs. ORNL has a very strong background in developing, applying, and deploying modeling and simulation tools. These tools have a high pedigree, a large user base, and their own quality assurance programs, thus providing increased confidence in the software's ability to support the facility.

Off-the-shelf production tools and data are not always adequate for modeling and simulating unique systems or experiments. Custom-developed tools and data sets such as those described in Section 2.0, "Custom-Developed Tools and Data," are thus required to model and analyze these unique and challenging systems. For example, HFIR can be considered a complex reactor because of its unique geometry consisting of involute-shaped fuel plates containing fuel that is contoured across the arc of the involute. The HFIR safety-basis employs the HFIR steady-state heat transfer code (HSSHTC) that was developed for and tailored to analyze HFIR. ORNL is also actively developing HFIRCON, an automated, integrated, flexible, parallel performance-tuned depletion tool for HFIR analysis. This tool is being developed and tested with the commodity computing resources provided by CADES, as described in Section 5.0, "Computing Resources." ORNL has also developed a design- and safety-basis thermal-hydraulics model of HFIR in COMSOL for the existing highly enriched uranium core and for the proposed designs of LEU cores to support its conversion in future. 
Most operating facilities have access to small-scale computational clusters that limit an analyst's ability to perform high-fidelity, computationally intensive calculations. This often results in the analyst making conservative assumptions and simplifications so the computations can complete in a reasonable time. However, making use of state-of-the-art production or custom tools that can accurately model the facility of interest and that can be performance-tuned to large-scale computational clusters results in efficient, high-fidelity modeling and simulation. In turn, more realistic results are calculated which can be advantageous for many reasons, such as reducing conservatism in the facility's safety basis or increasing the amount of material that can be loaded into an irradiation experiment.

As described in Section 3.0, "Analysis Expertise," ORNL's world-class teams provide support and technical analyses to partners and facilities around the globe. A nuclear facility may be constrained by a lack of staff or computational resources or a lack technical expertise in a nuclear field that requires updates or development. With its broad range of expertise, ORNL can provide facility support in many technical areas such as those described in Section 3.0 above. ORNL provides specialized workshops and software training courses as discussed in Section 4.0, "Workshops and Training." Staff development is important to nuclear facilities to ensure that staff members are informed of ongoing advances in their technical fields, and participation in workshops and training courses is an effective means of continuous training and skills development.

We invite facility operators to learn more about the rich resources available at ORNL through ONRAMP.

\section{https://ornl.gov/onramp/facility-operation-support}

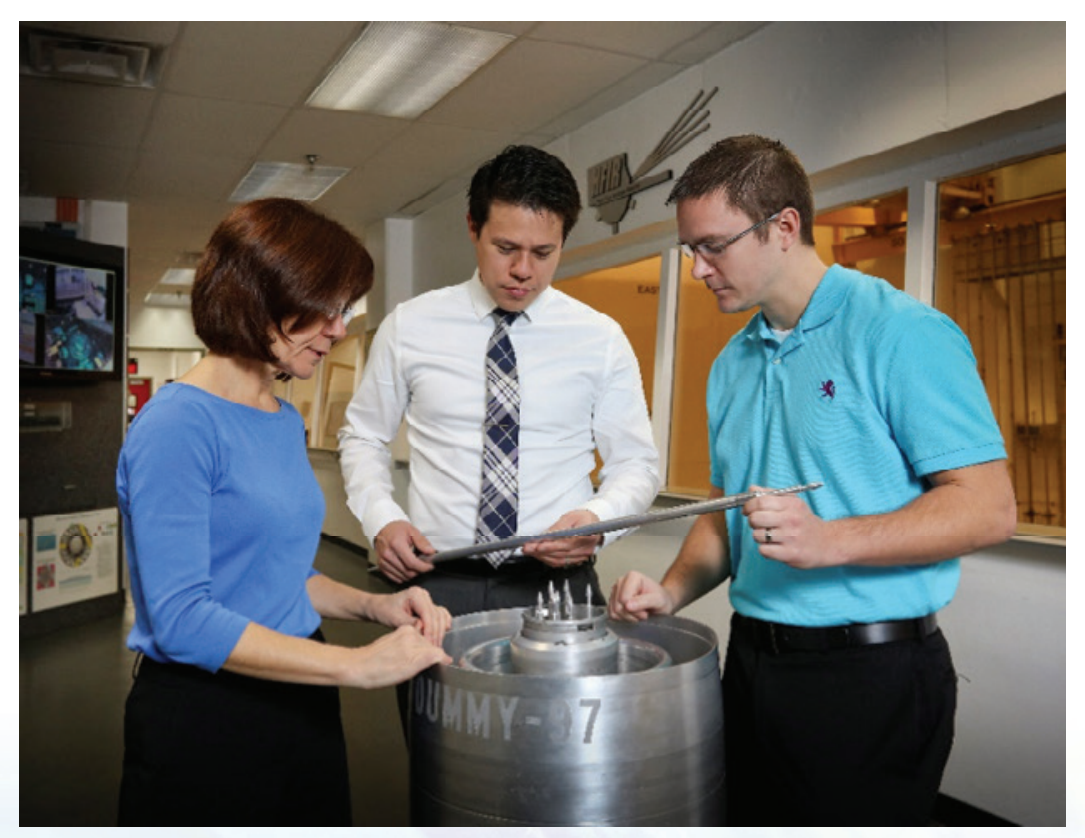

Figure 39. ORNL staff examining a full-size replica of the HFIR core and target rods. 


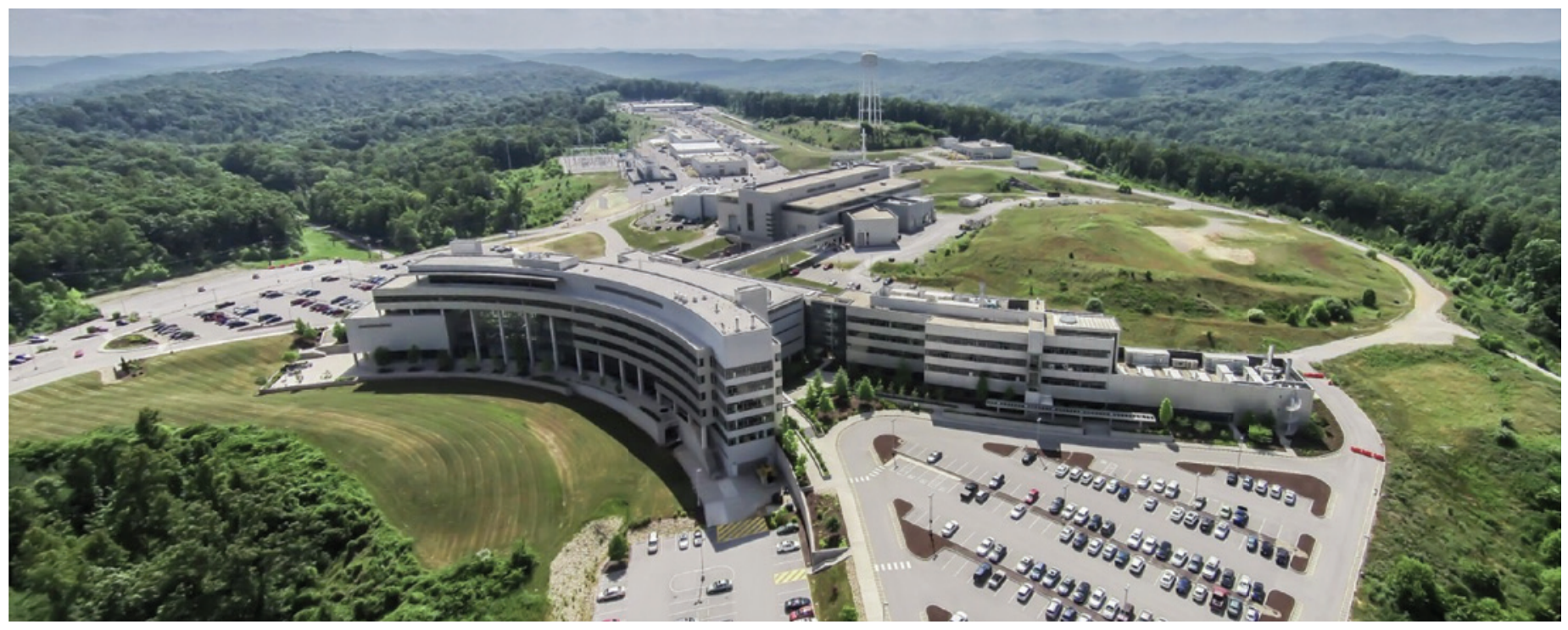

Figure 40. ORNL's Spallation Neutron Source complex.

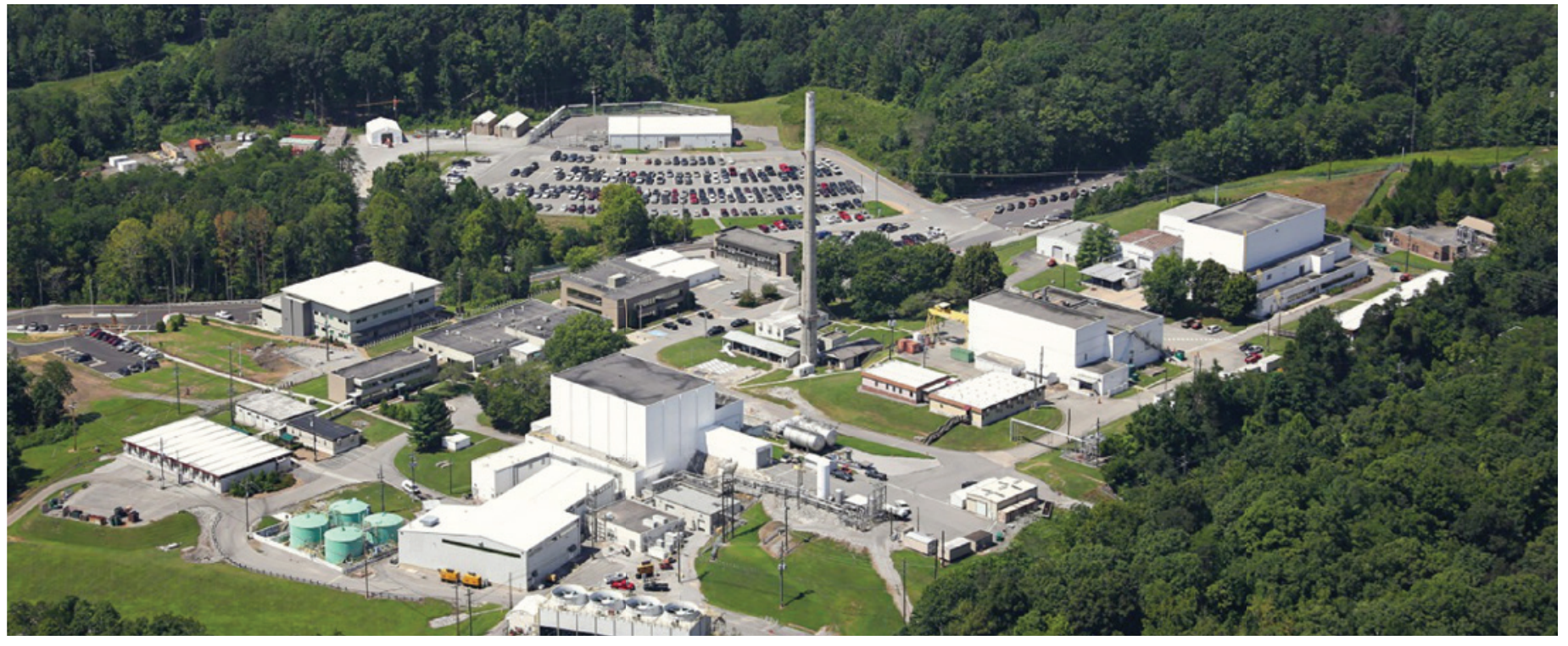

Figure 41. ORNL's HFIR complex

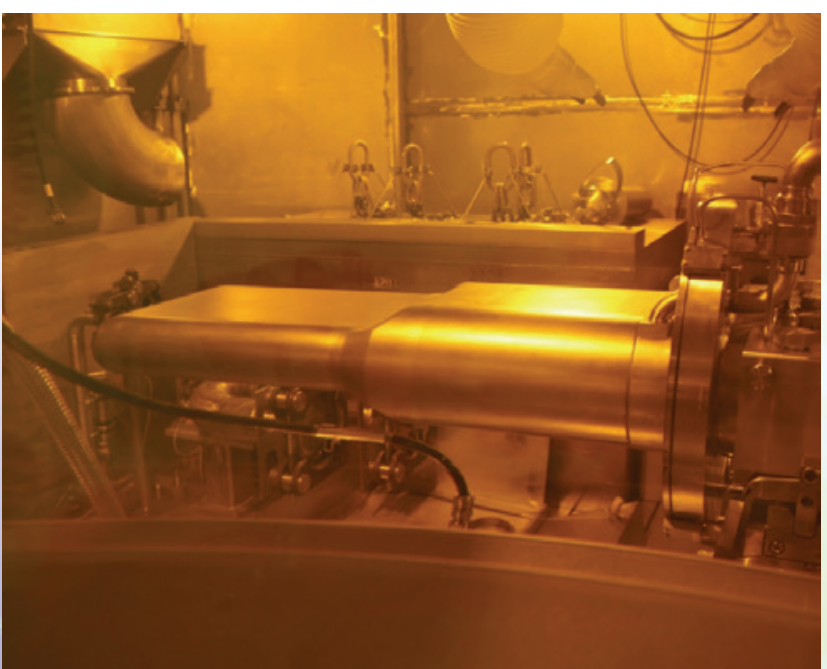

Figure 42. SNS mercury target.

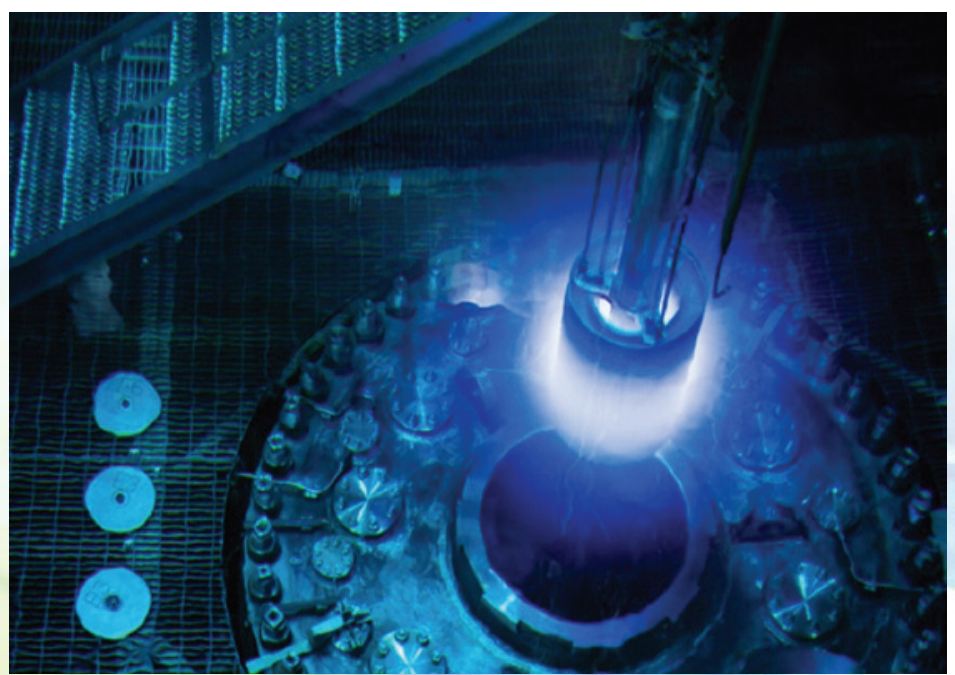

Figure 43. Reactor core replacement at ORNL's HFIR. 


\subsection{PARTNERSHIPS}

ONRAMP provides current and future stakeholders with centralized access to the rich resources available from ORNL teams. Through these partnerships, ORNL offers the full breadth of modeling and simulation solutions for the entire nuclear fuel life cycle that encompasses current operating LWRs, next generation LWRs (including SMRs), the spectrum of advanced reactors under development such as molten salt reactors (solid and liquid fuel), gas-cooled reactors, and sodium fast reactors, as well as research reactors, fusion energy systems, and more.

\subsection{OPPORTUNITIES FOR PARTNERS}

Inform:

Educate:

Analyze:

Enhance:

Validate:

Deploy:

Commercialize:
Participate in workshops and symposia to present current approaches and find out what is possible using ORNL's advanced techniques and computing resources. Tour ORNL facilities to observe state-of-the-art practices in facility operation and experimentation.

Choose from a wide array of training courses to gain hands-on experience using advanced tools.

Partner with ORNL for specialized analysis of your systems, working in our collaboration space, and accessing world class computing resources.

Establish partnerships to develop enhanced computational methods and data to better meet specialized needs and to realize the possibilities of HPC.

Quantify your validation basis by applying advanced approaches to assess available experiments and then enhance understanding through the design and operation of new benchmark quality experiments for licensing.

Reap the benefits of quality assurance and archival analysis for licensing and deployment.

In certain cases, commercial licensing opportunities are available. These agreements may be on an exclusive or non-exclusive basis if they are limited to a specific field of use. Said licenses may be for technologies that are bound by export control obligations.

We seek to meet the needs of the nuclear community, and we can customize a partnership to meet your expectations. Building on experience with previous, ongoing, and proposed partnerships, several areas of collaboration and associated benefits are available, as outlined below. 


\section{FIRST-OF-A-KIND COLLABORATIVE MODELING AND ANALYSIS}

The development and application of advanced analysis capabilities and methodologies are critical for the introduction of new nuclear technologies to the commercial market in areas such as design optimization, safety evaluation, operational performance, and regulatory licensing. ONRAMP provides the opportunity for direct collaboration with ORNL, with a focus on developing high value, high impact solutions for problems specific to the partnering organizations. Such collaborations bring the breadth of ORNL's modeling and simulation expertise to solve complex, challenging problems, with potential benefits being accelerated technology deployment, elimination of barriers to technology adoption, and direct transfer of knowledge and expertise to the partner organization.

\section{COMMERCIAL NUCLEAR MARKET EXPOSURE}

ONRAMP brings together a multitude of commercial nuclear market stakeholders across the spectrum of nuclear fuel cycle activities, including nuclear utilities, vendors, component suppliers, and service companies. From the perspective of a commercial entity, a partnership allows for direct access to future clients via the ONRAMP network, as well as market recognition exposure. Partners benefit through having company information and logos featured in highly visible ONRAMP literature.

\section{CUSTOMIZED CODE MODEL AND FEATURE DEVELOPMENT}

The addition of new models and software features is critical to enhancing a code's predictive capability and usability for the performance of nuclear analyses. This is especially helpful as additional data become available through experimental test programs and reactor and fuel measurements. Incorporation of the end user requirements and feedback, as an essential part of the software development process, is a cornerstone of ONRAMP, ensuring that tools provide appropriate levels of fidelity and timely performance for integration and use by the ONRAMP community.

\section{DESIGN AND OPERATION OF NEW EXPERIMENTS}

Development and deployment of new reactors and fuel products require data to fill knowledge gaps in physical models and to provide a basis for model validation. High-fidelity simulations, combined with expert knowledge of data requirements, can help define experiments that provide the maximum value for the resources invested. Virtual experiments performed with ONRAMP simulation software can be used to optimize experimental design to focus on the key quantities of interest. The goal is to maximize the quality and amount of data obtained with the minimum number of experiments.

\section{ACCESS TO COMMODITY COMPUTING RESOURCES}

ONRAMP provides access to software on industry-class, high performance computers using secure access protocols that ensure the requirements of proprietary data restrictions and satisfy the nuclear export control regulations. The software provided is configured to meet SQA standards, with operating systems and code versions maintained according to the current release. ONRAMP users have access to the latest software releases, eliminating the need for local software installation and configuration.

\section{ACCESS TO AND KNOWLEDGE TRANSFER FROM ORNL MODELING EXPERTS}

ONRAMP partners benefit from access to ORNL's software developers and nuclear modeling experts, whose expertise spans the spectrum of nuclear applications. This includes expertise in all areas related to nuclear technology, including reactor physics, radiation transport, thermal-hydraulics, nuclear fuels and materials, chemistry, and structural mechanics. More importantly, ORNL has extensive experience in coupled multiphysics modeling and 
analysis that is critical for reactor transient and safety analysis. ORNL subject matter experts can lead and support the model development and qualification activities, thus saving time and resources for the partnering organizations in addressing challenging issues. Collaboratively developed and qualified models can be hosted and maintained (with software upgrade support) on the ORNL commodity clusters for partners to gain secure access.

\section{VALIDATION OF CODES FOR SPECIFIC APPLICATIONS}

Nuclear analysis performed for a given application requires a validation basis, especially if the analysis is to be used in a regulatory environment. ONRAMP can assist users in developing a validation framework for specific applications using publicly available data as well as proprietary data. Validation test data from our current and previous experimental programs can be made available to fulfill specific needs.

\section{ASSISTANCE IN PROPOSAL PREPARATION FOR FUNDING OPPORTUNITY ANNOUNCEMENTS AND HPC RESOURCE ALLOCATIONS}

As a DOE laboratory, ORNL has extensive experience in developing proposals and can aid ONRAMP partners in responding to government funding opportunity announcements (FOAs), as well as proposals for HPC resource allocations on leadership class machines.

We can also collaborate through direct funding mechanisms with domestic and international companies and government agencies through a commercial technology licensing agreement, a Strategic Partnership Project (SPP), a Cooperative Research and Development Agreement (CRADA), or a streamlined agreement for specialized workshops and training opportunities.

\section{PRIORITY USER SUPPORT}

Partners have access to software user support that is important for developing and maintaining an experienced user base for the ONRAMP codes. Priority user support is designed for users who regularly work with application analyses with completions that are time critical, such as reactor operations support.

\section{ONRAMP USERS' COMMUNITY}

The ONRAMP users' community is comprised of all users of ONRAMP codes, with all users having access to beta releases of the software. This community is critical to the software testing and feedback process. Regular training courses for ONRAMP software products are offered as a means to ensure that an experienced user base is maintained. Training courses include code packages (theory and use) and code applications of interest to the user community. Code user groups supplement training by facilitating a group interaction of users' shared experiences. Code user groups provide a feedback mechanism to the code developers, and they may suggest new code capabilities and features. Special topic application workshops are offered based on the interest of the ONRAMP community. Such workshops may be based on standard nuclear analyses, as might be performed for licensing basis calculations, or they may be based on addressing emerging industry, regulatory, or research issues. In addition, such workshops may be based on demonstrating new, first-of-a-kind code capabilities and the new applications that are made possible. Workshops may be suggested by the ONRAMP users' group community. The ONRAMP newsletter informs the community of all beta releases, training courses, workshops, and code users' group meetings.

https://ornl.gov/onramp/partnerships 


\section{GLOSSARY}

\begin{tabular}{|c|c|}
\hline ADVANTG & Automated Variance Reduction Generator \\
\hline ANL & Argonne National Laboratory \\
\hline API & application programming interface \\
\hline ASCR & Advanced Scientific Computing Research \\
\hline ASME & American Society of Mechanical Engineers \\
\hline CADES & Compute and Data Environment for Science \\
\hline CASL & Consortium for Advanced Simulation of Light Water Reactors \\
\hline CE & continuous-energy \\
\hline CFD & computational fluid dynamics \\
\hline CIPS & CRUD-Induced Power Shift \\
\hline Clab & Central Interim Spent Fuel Storage Facility \\
\hline CPU & central processing unit \\
\hline CRADA & cooperative research and development agreement \\
\hline DELFIC & Defense Land Fallout Interpretive Code \\
\hline DHS & Department of Homeland Security \\
\hline DNS & Direct numerical simulation \\
\hline DoD & US Department of Defense \\
\hline DOE & US Department of Energy \\
\hline EBR-II & Experimental Breeder Reactor \\
\hline ECP & Exascale Computing Project \\
\hline ENDF & Evaluated Nuclear Data File \\
\hline ENSDF & Evaluated Nuclear Structure Data File \\
\hline exaSMR & Exascale Small Modular Reactor \\
\hline FHR & fluoride-salt-cooled high-temperature reactor \\
\hline FOA & funding opportunity announcement \\
\hline GELINA & Geel Linear Electron Accelerator \\
\hline GUI & graphical user interface \\
\hline HFIR & High Flux Isotope Reactor \\
\hline $\mathrm{HPC}$ & high-performance computing \\
\hline HSSHTC & HFIR steady-state heat transfer code \\
\hline HTGR & high-temperature gas-cooled reactor \\
\hline IAEA & International Atomic Energy Agency \\
\hline ICSBEP & International Criticality Safety Benchmark Evaluation Project \\
\hline IFEL & Irradiated Fuels Examination Laboratory \\
\hline IMET & Irradiated Materials Examination and Testing Facility \\
\hline INDEPTH & Inverse Depletion Theory \\
\hline InSPECT & International Secure Platform for Export-Controlled Computing Tools \\
\hline IPS & Integrated Plasma Simulation \\
\hline IRMM & Institute for Reference Materials and Measurements \\
\hline
\end{tabular}




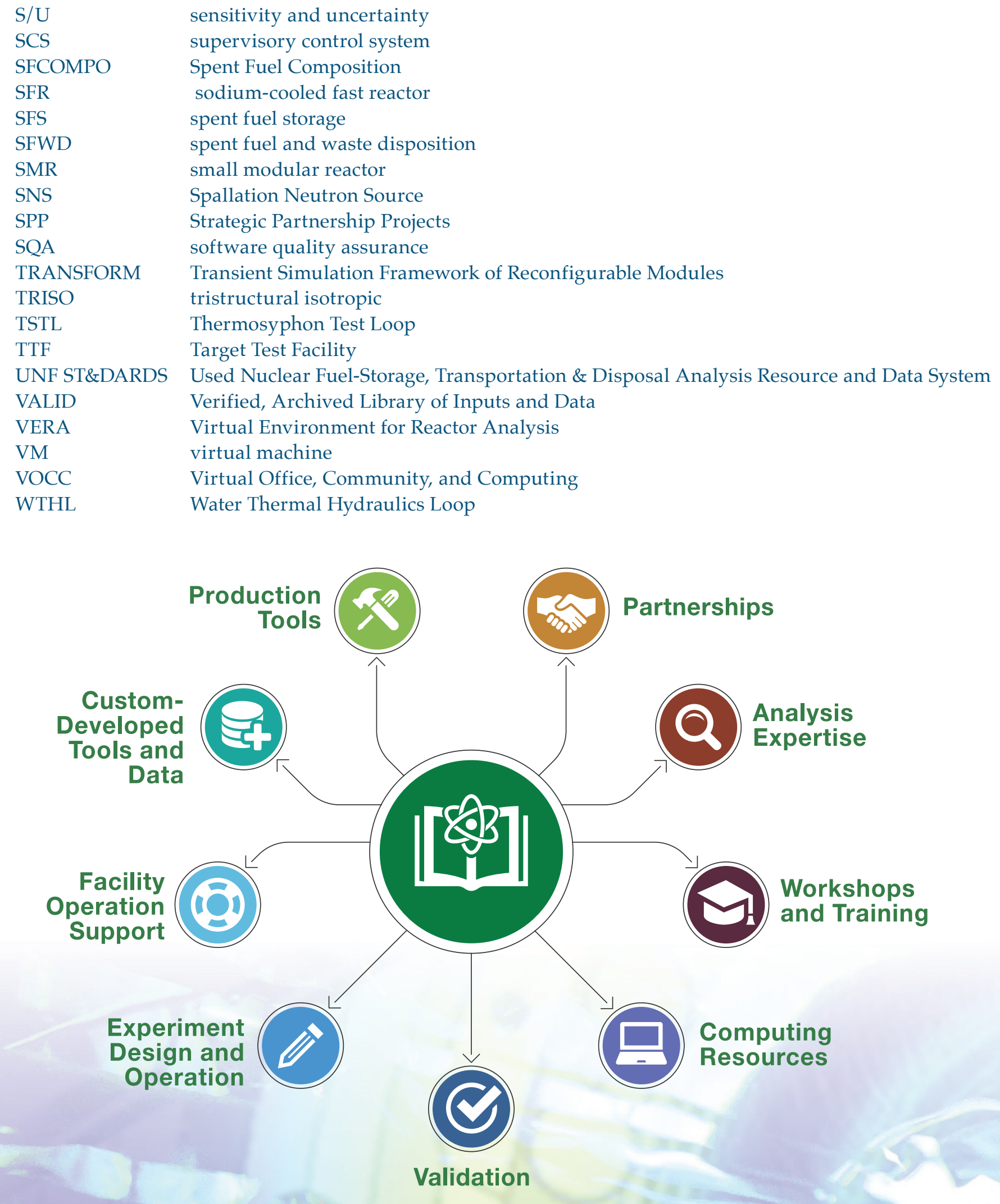


\section{ONRAMP LEADERSHIP}

\section{LEADER, MODELING AND SIMULATION INTEGRATION}

Dr. Bradley T. Rearden

\section{EXECUTIVE COMMITTEE}

Dr. John M. Canik

Dr. Kevin T. Clarno

Dr. David Chandler

Dr. Thomas M. Evans

Dr. Robert E. Grove

Dr. Susan L. Hogle

Dr. David J. Kropaczek

Mr. Jordan P. Lefebvre

Mr. Robert A. Lefebvre

Dr. W. David Pointer

Dr. Mallikarjun Shankar

\section{FACILITATOR}

Dr. James D. White

\section{Contact Information}

https://ornl.gov/onramp

onramp@ornl.gov 


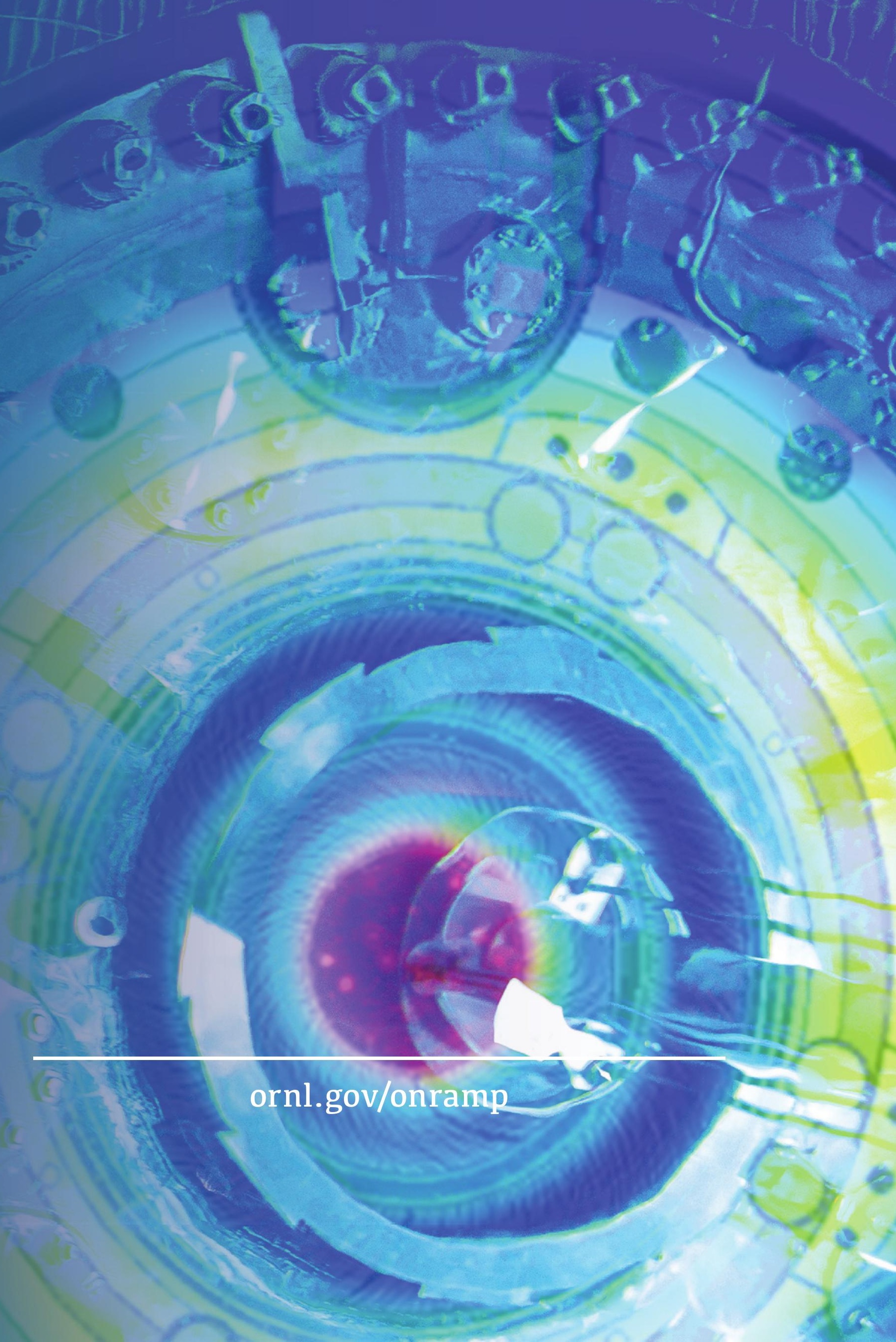

